\title{
WestVirginiaUniversity
}

THE RESEARCH REPOSITORY @ WVU

Graduate Theses, Dissertations, and Problem Reports

2015

\section{Biomechanical Evaluation of Surgical Loupes}

Marsha Chapman Holcomb

Follow this and additional works at: https://researchrepository.wvu.edu/etd

\section{Recommended Citation}

Holcomb, Marsha Chapman, "Biomechanical Evaluation of Surgical Loupes" (2015). Graduate Theses, Dissertations, and Problem Reports. 5812.

https://researchrepository.wvu.edu/etd/5812

This Thesis is protected by copyright and/or related rights. It has been brought to you by the The Research Repository @ WVU with permission from the rights-holder(s). You are free to use this Thesis in any way that is permitted by the copyright and related rights legislation that applies to your use. For other uses you must obtain permission from the rights-holder(s) directly, unless additional rights are indicated by a Creative Commons license in the record and/ or on the work itself. This Thesis has been accepted for inclusion in WVU Graduate Theses, Dissertations, and Problem Reports collection by an authorized administrator of The Research Repository @ WVU. For more information, please contact researchrepository@mail.wvu.edu. 


\title{
Biomechanical Evaluation of Surgical Loupes
}

\author{
Marsha (Chapman) Holcomb \\ Thesis submitted to the Benjamin M. Statler College of \\ Engineering and Mineral Resources at \\ West Virginia University \\ in partial fulfillment of the requirements for the degree of \\ Master of Science in \\ Industrial Engineering
}

\author{
Ashish D. Nimbarte, Ph.D., Chair \\ Majid Jaridi, Ph.D. \\ Xiaopeng Ning, Ph.D. \\ Jennifer A. Sivak-Callcott, M.D.
}

\section{Department of Industrial and Management Systems Engineering \\ Morgantown, West Virginia}

August 2015

Keywords: Neck pain, Surgical Loupes, Electromyography, Head-neck Posture

Copyright 2015 Marsha Holcomb 


\section{Abstract \\ Biomechanical Evaluation of Surgical Loupes}

\section{Marsha (Chapman) Holcomb}

Cervical musculoskeletal disorders (MSDs) are a known occupational hazard in micro surgeons who use loupes (telescopes mounted on glasses) to operate, with over $80 \%$ having neck pain related to performing surgery. Despite this known occupational risk, the cause, prevention, and treatment of cervical MSDs have been largely ignored in this population. The objective of this study was to quantify the effect of loupe use on cervical spine load and characterize the impact of loupe mount angle. The loupes were systematically altered during surgical tasks simulated by twelve healthy individuals (6 male and 6 female) in a laboratory setting. Four loupe conditions; without loupes, and with the loupe mounted at 10 degrees, 20 degrees, and 30 degrees, were tested in this study. The cervical spine loading was evaluated using three-dimensional head and neck postures (rotational as well as translational), electrical activity of the neck muscles and perceived discomfort ratings. Loupe condition had no effect on the rotational head and neck postures, neck muscle activity and discomfort ratings. Head flexion of about 30 degrees was observed during the surgical tasks; bending and rotation ranged between 4 to 7 degrees. Activation of about 3\% to 7\% of Maximum Voluntary Contraction (MVC) was observed for the neck muscles. A significant effect of loupe condition on the translational motion in the anterior-posterior and inferior-superior directions was observed, suggesting that the use of loupe may forces a more erect or straightened neck posture. Some gender differences in the posture, muscle activity pattern and perceived discomfort ratings were also observed. 


\section{Acknowledgements}

I would like to express my sincerest gratitude to my advisor, Dr. Ashish D Nimbarte for providing me the opportunity to further my education and for continuing to push me to complete my studies. Your guidance, throughout my studies has been truly appreciated and have allowed me to reach this point.

I would also like to thank the members of my committee, Dr. Majid Jaridi, Dr. Xiaopeng Ning, and Dr. Jennifer Sivak, for their advice and support.

I also wish to thank my colleagues in the Ergonomics laboratory for their assistance, advice, and friendship, for which I will always be grateful.

Finally, I wish to thank my family, friends and colleagues for their constant support and encouragement throughout those many years. 


\section{Table of Contents}

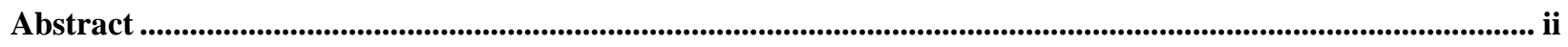

Acknowledgements ............................................................................................................................................................... iii

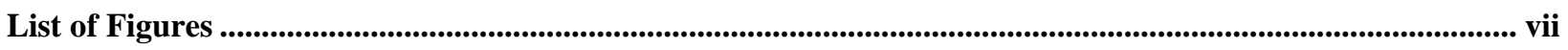

List of Acronyms............................................................................................................................................................... viii

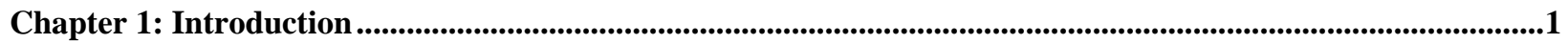

Chapter 2: Background and Literature Review .............................................................................................................4

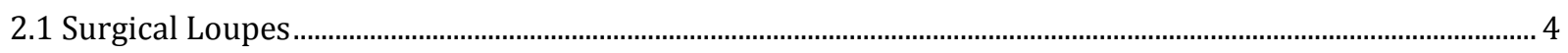

2.2 Work-related MSDs among Surgeons …………….......................................................................................................... 7

2.3 MSDs among Loupe Users....................................................................................................................................10

2.4 Physical Risk Factors for Work-related MSDs ................................................................................................11

Chapter 3: Study Rationale .......................................................................................................................................15

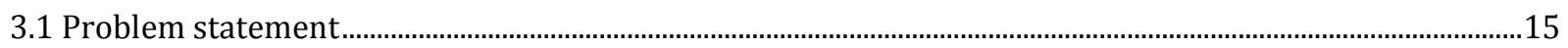

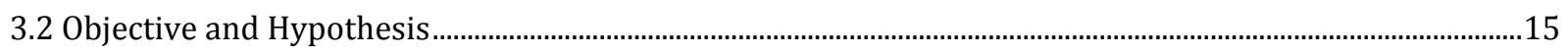

Chapter 4: Methodology ...........................................................................................................................................................................18

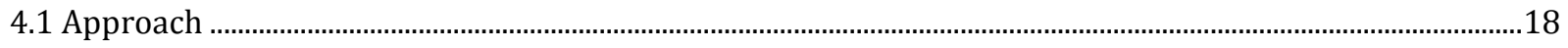

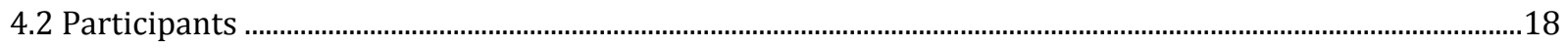

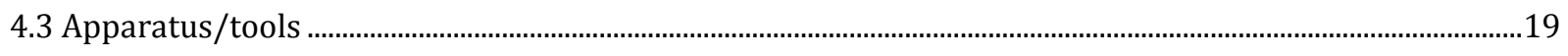

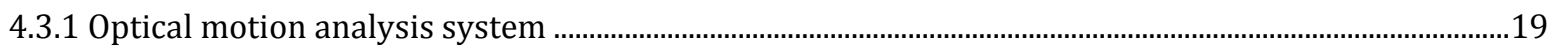

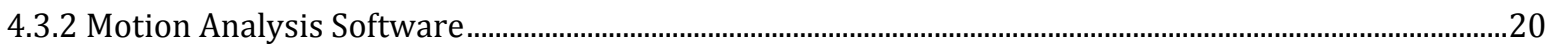

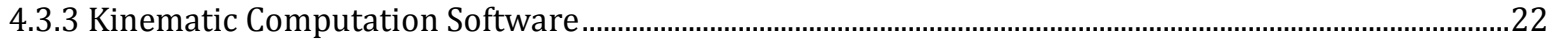

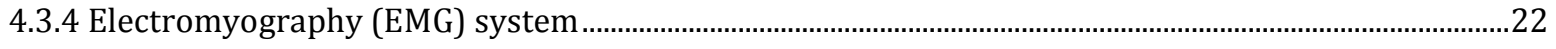

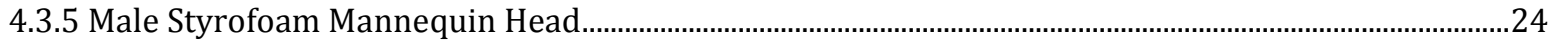

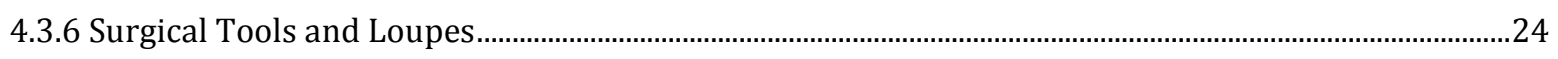

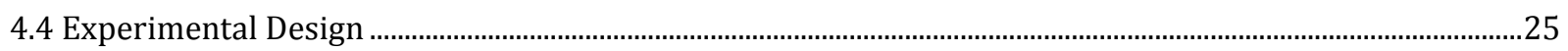

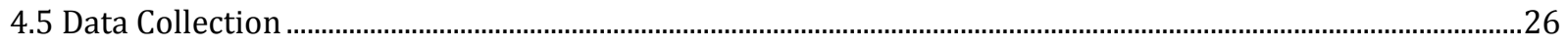

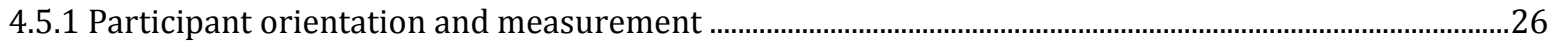

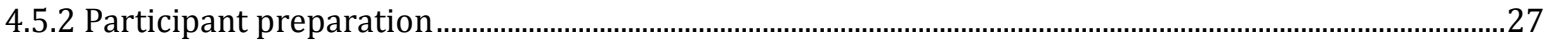

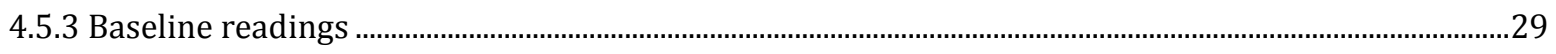

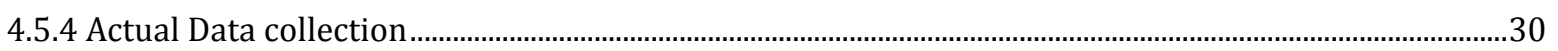

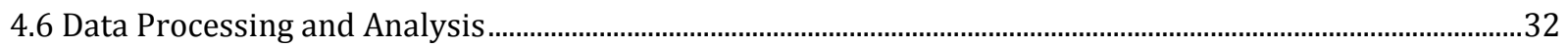

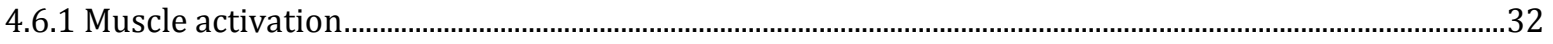

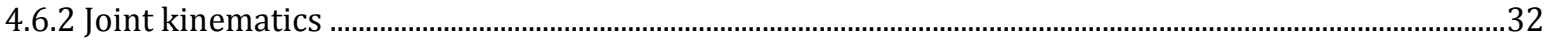

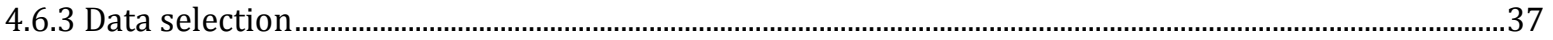




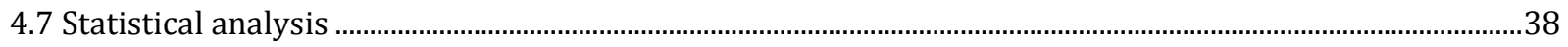

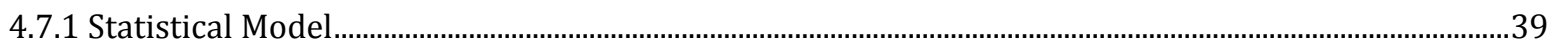

4.7.2 Power Analysis and Sample Size Determination .............................................................................4

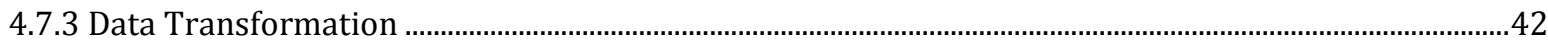

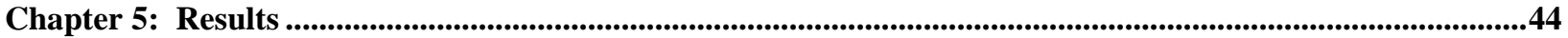

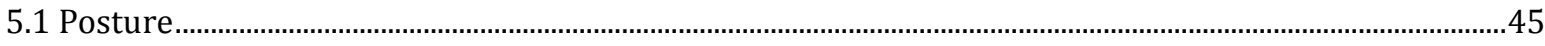

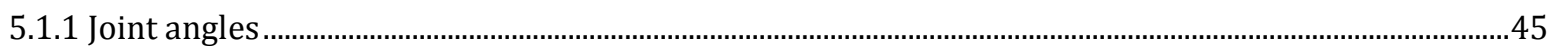

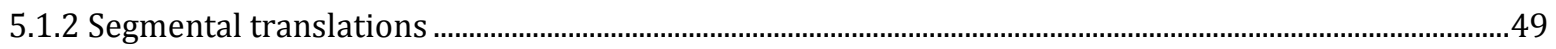

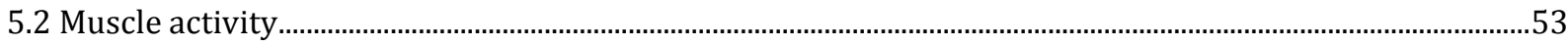

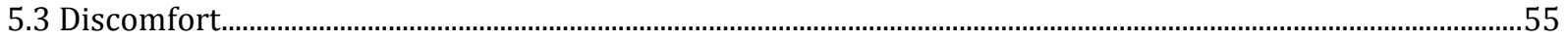

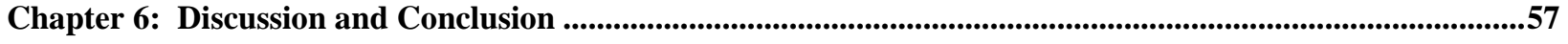

References

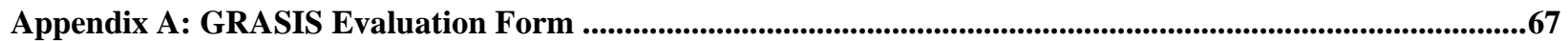

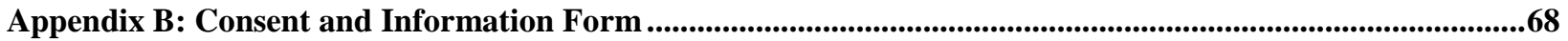

Appendix C: Participant anthropometric and characteristic data .....................................................................73

Appendix D: Discomfort Level Survey .............................................................................................................74

Appendix E: Normality and Data Transformation ..............................................................................................75

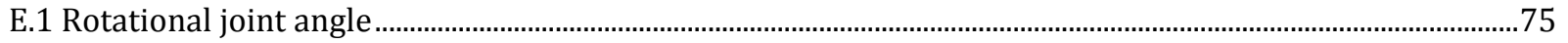

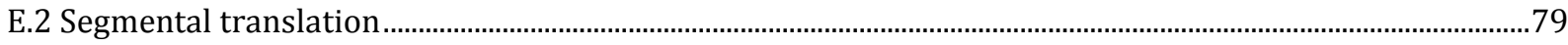

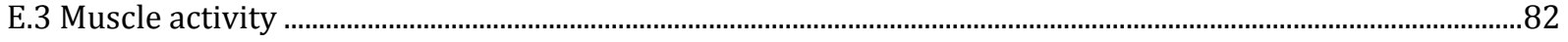

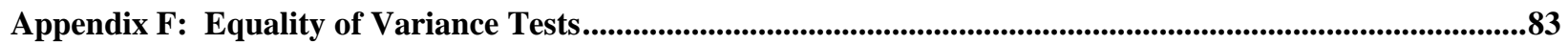

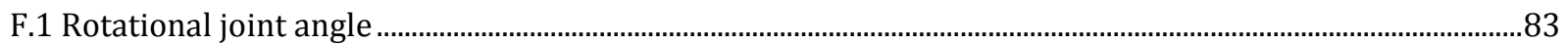

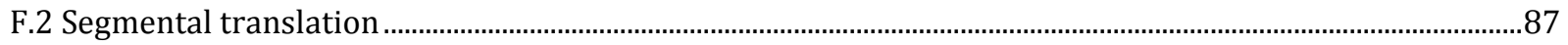

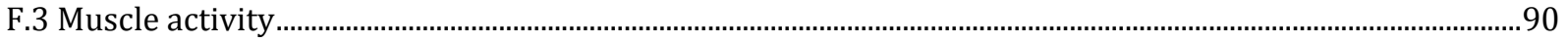

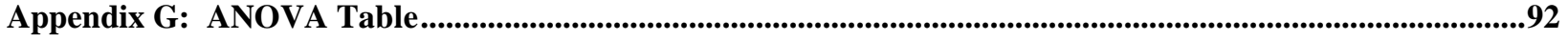

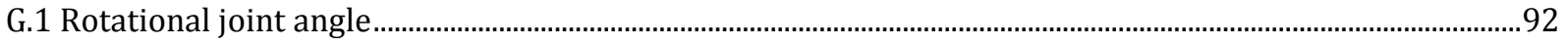

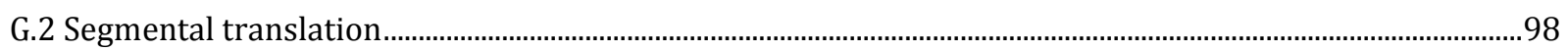

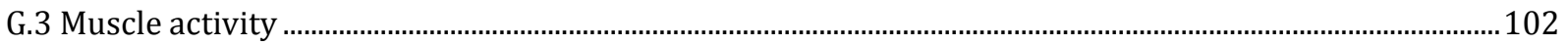




\section{List of Tables}

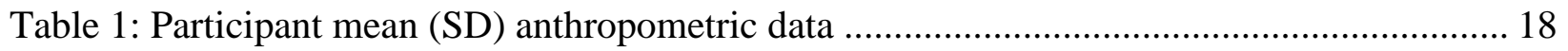

Table 2: Power values for different dependent variables....................................................... 42

Table 3: Johnson transform families and corresponding functions ..................................... 43

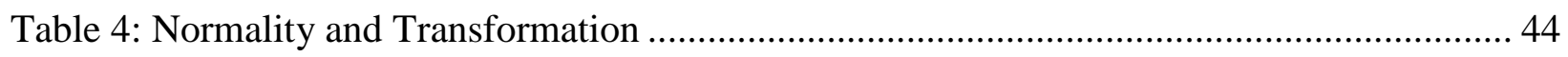

Table 6: Results of statistical analysis for postural translations. ........................................... 50

Table 7: Results of statistical analysis for muscle activity data........................................... 52

Table 8: Results of statistical analysis for the discomfort rating data.. ................................. 55 


\section{List of Figures}

Figure 1: (a) Vicon MX camera with infrared strobe lights; (b) 14mm (0.55in) Retro-

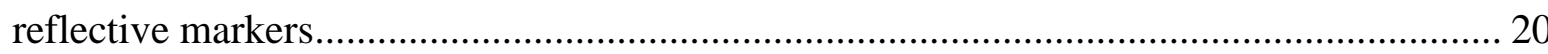

Figure 2. Real-time 3D Perspective view in Nexus 1.5.1 Software. This view can be panned, zoomed, and rotated in any direction.

Figure 3: Bagnoli system components: (a) main amplifier unit; (b) input modules; (c) surface electrodes; (e) parallel bar, active surface electrodes ....................................... 23

Figure 4: Styrofoam mannequin heads used in the surgical tasks .......................................... 24

Figure 5: Surgical loupes used in this study: (a) 10 degree loupe angle; (b) 20 degree loupe

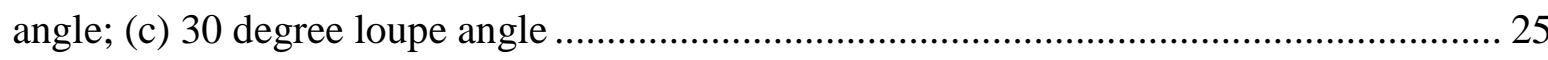

Figure 6: EMG electrode locations for (a) sternocleidomastoid; (b) upper trapezius muscles .... 28

Figure 7: Marker set used to collect the head-neck kinematic data ....................................... 29

Figure 8: Experimental setup used to collect data during a simulated suturing task .................. 31

Figure 9: Suturing task performed by the participants during data collection.......................... 31

Figure 10: Schematic representation of the kinematic model used to study head-neck kinematics 34

Figure 11: Head-neck angle definitions used in the previous marker based studies (Szeto and Sham 2008a, Yip et al. 2008, Straker et al. 2009). ............................................... 36

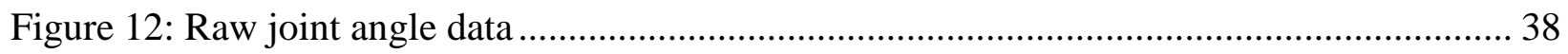

Figure 13: Effect of loupe condition on the head and neck bending angles. Please note that the transformed data is used to plot this figure. Actual data is presented in Table 5. ......... 47

Figure 14: Gender differences for the neck and head-neck flexion angles............................ 48

Figure 15: Effect of loupe condition on the head-trunk and head-neck translations in the $\mathrm{AP}$ and IS directions. Please note that the transformed data was used to plot this figure. Actual data is presented in Table 5. ............................................................... 51

Figure 16: Gender differences for the muscle activity................................................. 54

Figure 17: Gender differences for the perceived discomfort. ............................................. 56 


\section{List of Acronyms}

\begin{tabular}{|c|c|}
\hline ANOVA & Analysis of Variance \\
\hline $\mathrm{AP}$ & Anterior-Posterior \\
\hline $\mathrm{cm}$ & Centimeter \\
\hline EMG & Electromyography \\
\hline IS & Inferior-Superior \\
\hline $\mathrm{Kg}$ & Kilogram \\
\hline LSCM & Left sternocleidomastoid \\
\hline LCTRP & Left upper trapezius \\
\hline $\mathrm{m}$ & Meter \\
\hline ML & Medial-Lateral \\
\hline MSBL & Mean Square of Blocks \\
\hline MSD & Musculoskeletal Disorders \\
\hline MSE & Mean Square Error \\
\hline MVC & Maximum Voluntary Contraction \\
\hline $\mathrm{N}$ & Newtons \\
\hline PER & Perceived Exertion Rating(s) \\
\hline $\mathrm{SD}$ & Standard Deviation \\
\hline RSCM & Right sternocleidomastoid \\
\hline RCTRP & Right upper trapezius \\
\hline $3 \mathrm{D}$ & Three dimensional \\
\hline
\end{tabular}




\section{Chapter 1: Introduction}

Work-related musculoskeletal disorders (MSDs) of the neck or cervical spine significantly impact the health and economics in many industrialized countries. The Task Force of Bone and Joint Decade on Neck Pain reported an annual prevalence of 30-50\% in the general population (Hogg-Johnson et al. 2008). Among the working population, between $11 \%$ and $14.1 \%$ of workers were found to suffer from debilitating neck pain symptoms i.e., they are limited in their activities because of neck pain (Côté et al. 2008a). The MSDs of neck pain result in longer sick leaves, constitute a substantial level of human suffering, and witness reoccurrence in nearly $50-80 \%$ of people within 5 years after the first occurrence (Côté et al. 2008b). While exact costs associated with neck MSDs are not known, recent U.S. statistics report a median of 11 days away from work to recuperate from neck disorders compared to 5 days for all other body parts combined (BLS 2012). The direct annual cost of work-related MSDs in the United States is estimated to be between $\$ 45$ and $\$ 54$ billion (Bernaards et al. 2011).

Contemporary studies demonstrated that surgeons are substantially affected by workrelated neck MSDs. In a survey study performed at the Hong Kong public hospital, annual prevalence of neck pain among the surgeons was found to be $82.9 \%$, which is about eight times greater than that for the general working population (Szeto et al. 2009). Nearly $80 \%(\mathrm{n}=284)$ of European surgeons reported discomfort in the neck, shoulder, and back muscles due to operating (Wauben et al. 2006). A number of studies have identified that laparoscopic surgeries are associated with relatively higher incidence rates of neck, hand, and other MSDs (Park et al. 2010, Sari et al. 2010, Stomberg et al. 2010). 
Very recently, Sivak-Callcott et al., (2011) conducted a survey study among U.S. oculoplastic surgeons. Nearly $72.5 \%$ of ophthalmic plastic surgeons $(n=139)$ experienced pain during operating, with $58 \%$ localizing pain to the neck and $26 \%$ reported bulging or herniated cervical disc(s). More concerning, nearly $10 \%$ of the surgeons that participated in this study had to cease operating as a result of neck pain. This population, ophthalmic plastic surgeons, uses surgical loupes and headlamp to magnify and illuminate their field of view. In another study of 325 ear-nose-throat surgeons, an occupationally similar group, 53\% attributed back or neck pain directly to surgery (Babar-Craig et al., 2006).

Over 90,000 U.S. micro surgeons, which includes neurosurgery, otolaryngology, plastic, and vascular surgeons, use loupes in their practice (National Center for Health Care Statistics 2009a). Surgical loupes consist of magnifying lenses mounted on glasses. The magnification provides enhanced vision, allowing appreciation of subtle tissue differences and optimal instrument placement (Baker and Meals 1997). Previous studies have supported the usefulness of loupes in surgical tasks (Ross et al. 2003, Kono et al. 2010).

There are many aspects to performing microsurgery that impact cervical spine load and injury, including patient positioning, operating room workstation design, surgeon body habitus, or predisposing injury. However, the one variable that is held in common by all of these micro surgeons is the use of loupes to magnify their operative field of view. Survey and observational studies have established that loupe and headlamp use contribute to work-related neck MSDs (Babar-Craig et al. 2003, Hobbs 2004, Dhimitri et al. 2005b). Despite this knowledge there were no published objective studies defining the biomechanical etiology of cervical MSDs in micro 
surgeons. Therefore, this study was conducted to quantify the effect of loupe use on cervical spine loading and to characterize the impact of loupe (telescope) mount angle. 


\section{Chapter 2: Background and Literature Review}

This chapter is divided into three sections. In the first section basic information regarding different types of loupes is presented. A review of studies on the work-related MSDs among surgeons is presented in the second section. The third section focuses on the physical risk factors associated with work-related MSDs.

\subsection{Surgical Loupes}

Among most micro surgeons, the use of loupes is considered a standard of care. Surgical loupes consist of telescopic lenses mounted on glasses that enhance vision allowing the user to discern finer details compared to regular vision. The simplest type of loupe is comprised of a single pair of positive meniscus lenses. These are basic magnification lenses. A good example of a simple loupe would be an average pair of reading glasses. The simple loupe has a low cost, making it easy for anyone to purchase. The drawback of this type of loupe is that the lenses are limited by color fringing at magnifications greater than 1.5. These types of lenses are not available for purchase from major loupe distributers but are commonly available in supermarkets and stores when purchased as reading glasses.

The most common type of lens used in a loupe is a compound lens. The biggest difference between a compound loupe and a simple loupe is that it contains 2 lenses for magnification instead of just one. Compound loupes are called Galilean loupes because they use both a convex and a concave lens. Because there are two lenses in the system, a greater magnification can be achieved. This allows the user to see further and with more detail than with 
a simple loupe. As with the simple loupe, the compound loupe has its own set of drawbacks. For magnifications greater than 2.5 , the image quality becomes blurry or distorted. Also because it is a Galilean system, the periphery of the field of vision becomes blurred causing a "halo" effect. These are probably the most common loupes on the market and are produced by most loupe manufacturers.

Wide-angle compound loupes can also be found at most loupe manufactures. These loupes are better than the compound loupes because of a wider viewing angle. Since these loupes are built in the same manner as regular compound lenses, they only have a marginally higher cost, but weigh much less than higher optical quality loupes.

The best optical quality loupe utilizes prismatic lenses, thus called a prismatic loupe. This loupe is equivalent to a low power telescope consisting of several convex lenses. Users can see up to five times further, with better detail, than with a compound loupe. The field of view is also wider because the "halo" effect of the compound lens is removed. The biggest drawback of this loupe is that they are heavier than either the compound or simple loupes. Prismatic loupes are also "wide angle" and refer to the fact that compound loupes, of the same magnifications, have a narrower field of view. Most manufactures make these loupe types and are widely used.

The factors that characterize different types of loupes include the working range, field of view, depth of field, and working angle.

The working range, or working distance, is the distance between the eye and the working field. This range will differ based on surgeon's specialty. If a surgeon is generally standing or at a distance away from the patient, say arm's length, then a longer range would be optimal. 
However an oculoplastic surgeon or dental hygienist may want a shorter range because of the close proximity to the working surface being required.

Depth of field is defined as the distance in which the far and near distance are both in focus. This depth typically decreases as magnification increases. This allows the surgeon to move his/her head to see different views, without losing clarity.

The field of view is the size of the area being viewed, from one side to the other. This measurement is obtained easily by looking at a ruler through the lenses. As with depth of field, field of view is inversely proportional to magnification.

The angular position of the lens system in the regards to the wearer's face is called the working angle. If this angle is not optimal, fatigue will likely become a problem along with the load on the cervical spine. Many loupes offer adjustable working angles to compensate for the anthropometrical differences between individuals.

Loupes are worn either mounted on the lens of glasses themselves, called through the lens (TTL), or separately from the glasses on either a headband or mounting frames. Typically lenses worn on mounting frames will be able to be flipped up and moved out of the way when not in use.

Through the lens (TTL) loupes are probably the most customizable loupes available. It allows surgeons to incorporate standard lenses used for vision with the necessary loupes. TTL loupes require the lens in the glasses be the same prescription as the surgeon wears for daily activities. 
Headband type loupe mountings are very flexible. The loupes mounted on these types of apparatus' are typically heavier and often accompanied by a light. This means the surgeon does not need to wear a separate light in order to see. Because the light and the lenses would be at the same working angle, as well as having a heavier load, there is an expected difference in loading on the cervical spine, however the difference yet unknown. The disadvantage of a headband type loupe is that it can become uncomfortable for the wearer.

Flip-up mountings for loupes are similar to the TTL loupes but instead of remaining permanently stationary to the glass, they can be flipped up out of the way when not in use. These loupes have the advantage in that the working angle is adjustable and are not bulky like headband style loupes. A variable working angle means that for different types of surgeries, or different users, the angle can be adjusted, as well as the loupes being out of the way when not in use. The disadvantage of these flip up loupes is that they can become unaligned, unlike TTL loupes, which never become unaligned.

\subsection{Work-related MSDs among Surgeons}

Surgeons work in a high precision and psychologically stressful environment. Their work-related exposures include but are not limited to the use of instruments that can potentially affect vision, such as loupes, and other high precision surgical instruments, such as sutures, scalpels, forceps, etc. Therefore the MSDs and/or physical risk factors for the MSDs among surgeons may be different than standard industrial workers.

A study of general surgeons in Hong Kong (Szeto et al. 2009) evaluated the association between psychological and physical factors and the symptoms of musculoskeletal disorders. In 
order to find this association, 500 questionnaires were sent to general surgeons with a $27 \%$ response rate $(n=135)$. Of the 135 that responded, 87 were specialists, 27 were higher trainees, and 21 were basic trainees. Ages ranged from 23 to 40 with an average of 10 working years and an average of 54 hours worked per week. Results of this survey showed over $80 \%$ of respondents reported at least one body area displaying musculoskeletal symptoms in the past year. $82.9 \%$ of those respondents stated that their main symptom area was in the neck region; $68.1 \%$ had lower back symptoms, $57.8 \%$ had shoulder symptoms, and 52.6\% had upper back symptoms. The results indicate that the highest amount of discomfort for the neck was within 8-30 days of receiving the survey and have been experiencing discomfort for 4-5 years. Most respondents did not seek medical treatment for their pain. The pain experienced was mostly attributed to awkward posture maintained over prolonged work periods.

Another survey focused on the American College of Mohs Surgeons (ACMS) (Liang et al. 2012). The survey was sent out to 825 surgeons. The survey combined 42 questions pertaining to demographics, work-style habits, MSD symptoms, work-style attitudes, and ergonomic practices. The survey response was $43 \%(n=354)$ with an average age of 44.5 years, $71 \%$ male, and 9 years of field experience. Results have $90 \%$ of respondents reporting some type of musculoskeletal symptom or injury. The most common were the neck, lower back, shoulders and upper back. Almost half (45.7\%) reported having these musculoskeletal symptoms onset during their fellowship or within their first 5 years in practice. This study did not determine if the MSDs reported were directly work related or not, however, work was reported to exacerbate the pain in $63 \%$ of the respondents. 
More recent studies on the MSDs in surgeons have focused on the subspecialties that perform laparoscopic procedures. Wauben et al. (2006) surveyed 284 surgeons who routinely perform laparoscopic and/or thorasoscopic procedures within the digestive, thoracic, urologic, gynecologic, and pediatric disciplines. Nearly $80 \%$ of the surgeons reported that they routinely experience discomfort in the neck, shoulders, and back. No specific cause for the physical discomfort was reported in this study. Park et al., (2010) surveyed 317 laparoscopic surgeons using a comprehensive 23-question survey. About $86 \%$ reported physical symptoms or discomfort in the neck, hand, lower extremity, eye and back. The high rate of neck discomfort was correlated with training and high case volume. Sari et al., (2010) performed a survey study among surgeons in a university hospital $(n=92$, response rate $=60 \%)$. Nearly $73 \%$ reported physical complaints during or after laparoscopic procedures, mainly in the area of the neck, lower back, shoulders, and thumbs. Some of the causal factors identified by the surgeons were poor table height adjustment, bad monitor positioning, and suboptimal design of instrument handles.

In a different study by Stomberg et al., (2010) gynecologists and general surgeons performing laparoscopic surgery were surveyed. Among the survey respondents $(n=558$, response rate $=68 \%$ ), nearly $70 \%$ of the surgeons reported one or more symptoms in the lower back, neck, and shoulder regions. Pain was the most common symptom followed by fatigue and stiffness. Longer work duration, age, and gender showed significant association with the symptoms of pain and/or MSDs. Female surgeons had significantly more disorders than males. A correlation between awkward posture, static workload and chronic neck pain was also reported in this study. 


\subsection{MSDs among Loupe Users}

Use of loupes is considered the standard of care (Ilie et al. 2011) among optometrists, dental professionals, and many surgical subspecialties. Looking through surgical loupes restricts the surgeons' field and depth of view, forcing them to adopt awkward head-neck postures in order to see clearly. A few studies have been done on the specific populations that routinely use loupes to study musculoskeletal disorders common among these groups.

One such study was done on a population of dental hygienists in Australia (Hayes et al. 2012). A five page adapted version of the Nordic survey was used in this study. A total of 624 surveys were returned, approximately $42 \%$ of the targeted population. Results indicate that loupe users in this field had a 55\% chance of developing neck pain, a $46 \%$ chance of developing shoulder or wrist pain, and a 58\% chance of developing upper back pain.

In a study performed by Dhimitri et al., (2005) a twice-greater occurrence of neck pain was reported among the ophthalmic surgeons compared to general ophthalmologists. Ophthalmic plastic surgeons use loupes for the majority of operative procedures compared to the ophthalmologists. In another study among ear-nose-throat surgeons $(n=325)$, an occupationally similar group, $72 \%$ reported symptoms of back or neck pain; of those, $53 \%$ attributed the pain directly to the act of performing surgery (Babar-Craig, et al., 2003).

In a more recent study by Sivak-Callcott et al., (2011), U.S. ophthalmic plastic surgeons were surveyed $(n=139)$. About $81 \%$ of the respondents routinely used loupes and $72.5 \%$ had experienced pain associated with operating; $58 \%$ of who localized the pain to the neck. Twenty six percent $(26 \%)$ reported a bulging or herniated cervical disc(s) and $7.6 \%$ had undergone 
surgery for this condition. Most surgeons in this study identified loupe and headlamp use as a special concern for the neck pain or injury.

\subsection{Physical Risk Factors for Work-related MSDs}

The studies that evaluate physical or ergonomic risk factors of work-related neck MSDs among surgeons, especially the subspecialties that use loupes, are sparse. Most of the ergonomics studies on neck MSDs with similar types of exposure (sub-maximum loading, static and/or prolonged posture) focus on the occupational groups such as Video Display Terminal (VDT) or computer users, sewing machine operators, etc. For example, among computer users, the findings of previous studies suggest that inappropriate monitor position may increase the risk of neck MSD (Saito et al. 1997, Kietrys et al. 1998, Turville et al. 1998, Sommerich et al. 2001, Sillanpaa et al. 2003, Szeto and Sham 2008b). Among sewing machinists, the table inclination and needle view were found to play a critical role in the upper body posture and the risk of upper extremity MSDs (Li et al., 1995).

In one observational study performed by Shaik et al., (2011), the prevalence and risk factors for the musculoskeletal disorders among on-job dental surgeons were evaluated. Thirty dental surgeons working in a university hospital in Mangalore, India participated in the study. The MSD prevalence was studied using a close-ended questionnaire that would pinpoint the individuals' perception of pain and stiffness experienced within the prior six months. The physical risk factors were studied through observation of the working environment using a walkthrough observational survey. Results of the survey revealed that the $83.3 \%$ of the participants "sometimes" have pain in the back and 70\% "sometimes" have pain in the neck. Nearly 66.7\% 
had moderate pain in the back and $23.3 \%$ felt the pain was severe. Neck pain results showed $33.3 \%$ felt their pain was moderate while none felt it was severe. The walk through results reveal $96.7 \%$ of the surgeons experienced frequent neck bending and $86.7 \%$ of the surgeons were unable to change position while operating. Interpretations of this study lead researchers to believe that many dental surgeons suffer from back and neck pain and the severity directly correlates to the number of patients seen.

As previously noted, only a couple of objective studies on work-related neck MSDs among surgeons were available. One such study was performed by Szeto et al., (2010) to evaluate postural muscle activity during open, laparoscopic, and endovascular surgeries. The surface electromyography data from the upper extremity muscles were recorded during real surgeries. Higher muscle activity was observed for open surgery compared to laparoscopic and endovascular surgeries. No difference in the muscle activity was observed between laparoscopic and endovascular surgeries. The authors attributed the high muscle demand during the open surgeries to more dynamic movement and more forceful exertions compared to laparoscopic and endovascular surgeries.

An alternative objective study, aimed at reducing MSDs by using ergonomic intervention, was completed by a group in the Industrial and Systems Engineering department at North Carolina State University (Smith et al. 2002). In this study, three different viewing options (standard view (direct), monitor, and prism loupe) were tested while performing simulated dental procedures. Two groups of subjects were tested: the first being 12 novice subjects, with no experience in performing professional dental procedures and the second group consisted of five dental hygienists. The novice group performed a targeting task while the professional group 
performed a scaling task on a mouth model. Among the novice group, it was found that the monitor or prism loupe reduced the muscle activity and discomfort level. Head tilt and neck flexion were significantly different for the direct view as compared to the monitor and prism loupe conditions. Among the professional group, higher muscle activity was observed for the direct view than the two alternate views. It was concluded that the direct view method, if adopted for a complete 8-hour time frame, creates stress in the neck/shoulder region and can lead to development of a musculoskeletal disorder in the neck region.

Very recently, Nimbarte et al.,(2013c) performed a field study to measure the head-neck postures commonly used by ophthalmic plastic surgeons while they operated on patients. For nearly $85 \%$ of the operating time, the surgeons adopted asymmetrical postures characterized by either bending or rotation angles higher than $15^{\circ}$, coupled with flexion higher than $15^{\circ}$. Additionally, the surgeons assumed rather extreme non-neutral and asymmetrical postures with high levels of flexion $\left(>45^{\circ}\right)$, rotation $\left(>45^{\circ}\right)$, and bending $\left(>30^{\circ}\right)$ for about $26 \%$ of the operating time. Previous studies on computer users have reported a positive relationship between neck flexion and symptoms of neck pain. Among computer users, the working postures were mostly symmetrical with deviation primarily in the flexion/extension plane. However the postures adopted by the surgeons in this study were more complex and with deviations from neutral in all three planes. Such postures with increased deviation from neutral generate higher moments at the cervical joints compared to the near neutral postures. Higher moments require greater force generation by the neck muscles and thus increase the loading of the cervical spine. As a whole, the results of this study suggest that the asymmetry and the duration of the postures used by 
surgeons who operate with loupes may place substantial stresses on the cervical spine due to increased biomechanical loading. 


\section{Chapter 3: Study Rationale}

\subsection{Problem statement}

Cervical musculoskeletal disorders (MSDs) are a known occupational hazard in micro surgeons who use loupes (telescopic lenses mounted on glasses) to operate, with over $80 \%$ having neck pain related to performing surgery (Dhimitri et al. 2005a, BabarCraig et al. 2006, Esser et al. 2007, Koneczny 2009, Szeto et al. 2009, Sivak-Callcott et al. 2011). More than 90,000 U.S. surgeons suffer this risk. These physicians conducted 190 million patient office visits (nearly 20\% of encounters) in 2009 (National Center for Health Care Statistics 2009b).

Despite this known occupational risk, the cause, prevention, and treatment of cervical MSDs have largely been ignored in this population. There are many aspects to performing microsurgery that could impact cervical spine load and injury, including patient positioning, operating room workstation design, surgeon body habitus, or predisposition to injury. However, loupes are the common denominator among micro surgeons across many subspecialties and more than half of surgeons believe loupes contribute to cervical spine MSDs. There have not yet been any published objective studies that define the biomechanical etiology of cervical MSD caused by the use of loupes in micro surgeons.

\subsection{Objective and Hypothesis}

The objective in this study was to quantify the effect of loupe use on cervical spine loading and characterize the impact of loupe mount angle. Based on a recent field study by 
Nimbarte et al., (2013c), the central hypothesis for this study was that looking through surgical loupes restricts the surgeons' field and depth of view forcing them to adopt awkward head-neck postures in order to see clearly. This field study provided very useful information, but loupes cannot be altered while a surgeon is operating, so the exact role of the loupe in the awkward head-neck postures was unknown. In this study, loupes were systematically altered during surgical tasks simulated by novice users in a laboratory setting. The rationale for the research was that a laboratory-based study would allow accurate control of the loupe conditions (without loupes and loupes at different mount angles) and user preferences (experienced surgeons quickly adopt learned, conditioned postures and have certain loupe preferences), further facilitating accurate understanding of the impact of loupes on the loading of cervical spine musculature. Four loupe conditions; without loupes, and with the loupe mounted at 10 degrees, 20 degrees, and 30 degrees, were tested in this study. The effect of loupe angle on cervical spine loading was evaluated using three-dimensional (3D) head-neck postures, electrical activity of the neck muscles and perceived discomfort ratings. Additionally the gender difference was also studied. The following null hypotheses were tested in this study:

$\mathrm{H}_{01}$ : There is no effect of loupe condition on the 3D head-neck postures, the electrical activity of the neck muscles, and the perceived discomfort ratings $\mathrm{H}_{02}$ : There is no effect of gender on the 3D head-neck postures, the electrical activity of the neck muscles, and the perceived discomfort ratings 
$\mathrm{H}_{02}$ : There is no interaction effect of loupe condition and gender on the 3D headneck postures, the electrical activity of the neck muscles, and the perceived discomfort ratings

Successful completion of the proposed work has generated objective data that has allowed us to understand the impact of the loupe and its mount angle on the loading of the cervical spine. This knowledge is essential for guiding the development of future research targeting either magnification device redesign and/or alternate strategies such as environmental modifications, surgeon exercise programs, both preventative and therapeutic. 


\section{Chapter 4: Methodology}

\subsection{Approach}

A surgical task simulated in a laboratory setting was used to evaluate the effect of surgical loupes on the loading of cervical spine musculature. This task was designed by a board certified Orbital and Ophthalmic Plastic Surgeon, with over 15 years of surgical experience. Novice users, with no previous surgery-related experience, were trained by the same surgeon to become proficient in the surgical task. The effect of the loupe condition (without loupe and loupe at different mount angles) during the surgical task on the loading of the cervical spine was evaluated by measuring 3D head-neck postures, electrical activity of the neck muscles, and perceived discomfort ratings.

\subsection{Participants}

Twelve healthy individuals ( 6 male and 6 female) between the ages of 18 to 40 years were recruited to participate in this study. A summary of participant characteristics such as height, weight, and age is shown in table 1. Data for individual participants can be found in Appendix C.

Table 1: Participant mean (SD) anthropometric data

\begin{tabular}{|l|l|l|l|l|}
\hline $\begin{array}{l}\text { Gender } \\
(\mathrm{M} / \mathrm{F})\end{array}$ & Height $(\mathrm{cm})$ & Weight $(\mathrm{kg})$ & Age (yrs.) & Count \\
\hline M & $171.7(6.9)$ & $67.9(7.6)$ & $22.8(5.5)$ & 6 \\
\hline F & $163.5(4.0)$ & $65.1(21.2)$ & $23.0(5.0)$ & 6 \\
\hline All & $167.6(6.8$ & $66.5(15.3)$ & $22.9(5.0)$ & 12 \\
\hline
\end{tabular}


The primary inclusion and exclusion criterion required that participants were (1) free from any type of musculoskeletal disorder; and (2) sufficiently coordinated to perform the task. After a training session, the surgeon evaluated whether a participant was sufficiently coordinated to perform the tasks using the GRASIS evaluation form (Appendix A) (Cremers et al. 2005). This validated form is used in physician training to evaluate surgical competency. Participants who meet the inclusion criteria were then required to read and sign a consent form approved by the local Institutional Review Board (Appendix B).

\subsection{Apparatus/tools}

\subsubsection{Optical motion analysis system}

Three dimensional (3D) head-neck postures were recorded using an optical motion-capture system (Vicon Motion Systems, LA, USA). This system consists of eight optical cameras (Figure 1(a)) with infrared strobes that emit pulses of infrared light at high frequencies. The infrared light reflects off of small, round retro-reflective markers (Figure 1 (b)) and is captured by the cameras

in the Vicon system. When multiple cameras capture reflections from the markers, the Vicon Nexus software can determine the location of the marker in three-dimensional space. The motion data will be acquired at a frequency of $100 \mathrm{~Hz}$. 


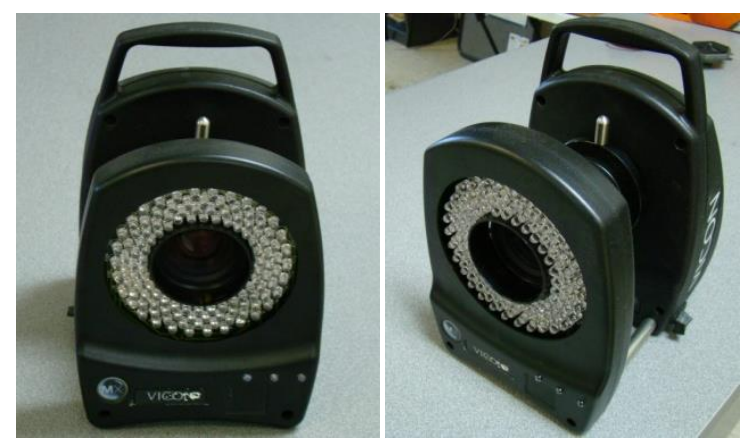

(a)

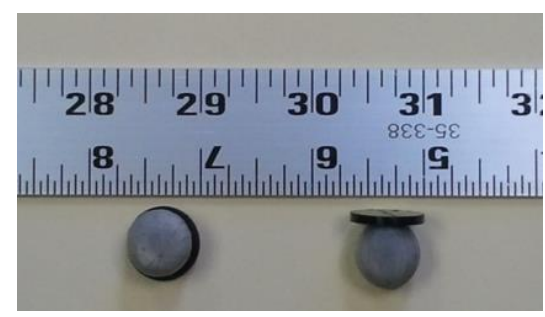

(b)

Figure 1: (a) Vicon MX camera with infrared strobe lights; (b) 14mm (0.55in) Retroreflective markers

\subsubsection{Motion Analysis Software}

The marker data was captured and processed using Vicon Nexus 1.5.1 Software (Vicon Motion Systems, Oxford, UK). A three-dimensional representation of the markers as displayed on screen through this software is shown in Figure 2. After capturing the data, the software was used to label the markers. Each marker has a unique name to represent where it is located on the body. For example, in the marker set in this research, the marker located on the Glabellas bone in the forehead area was named FHD. 


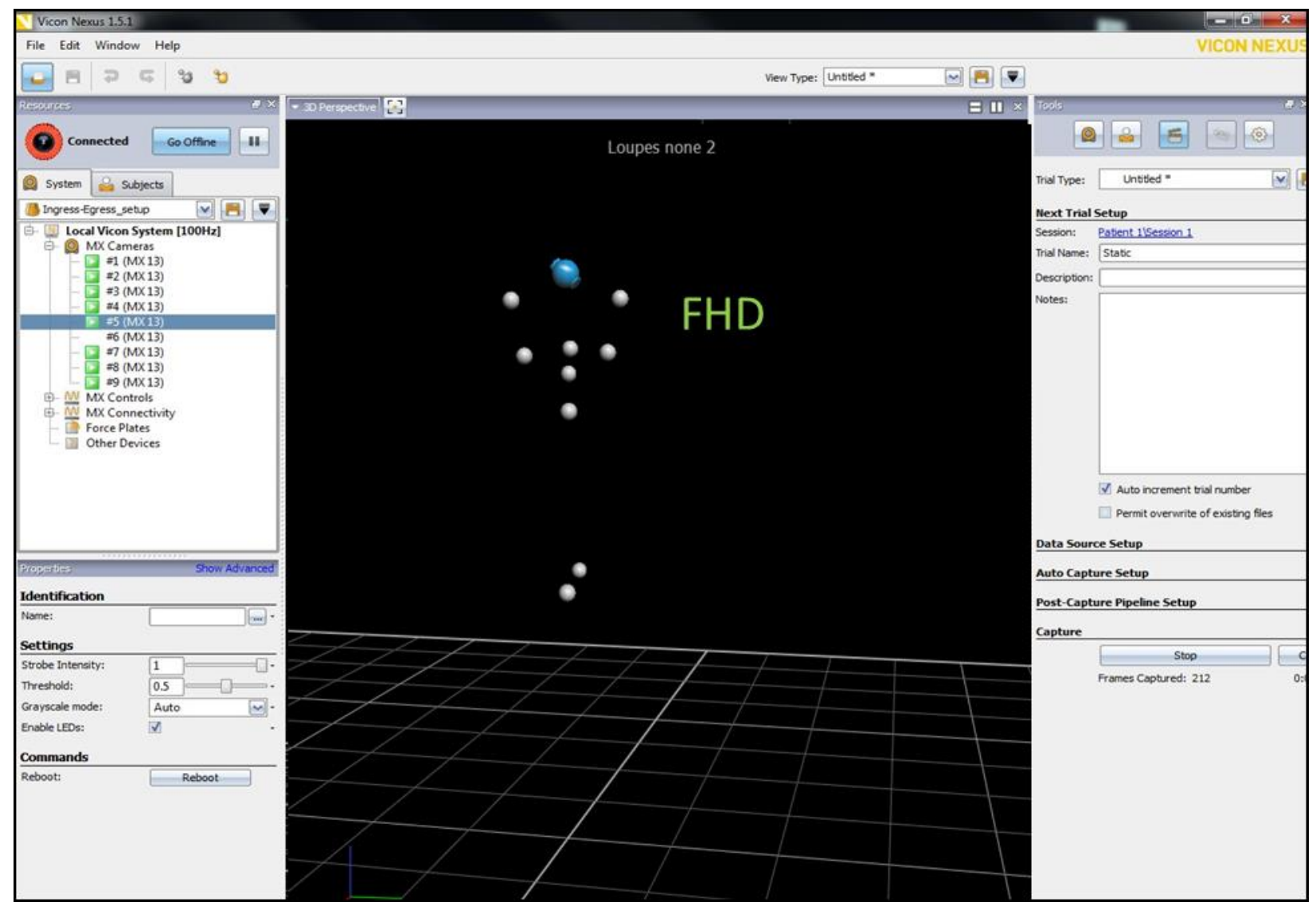

Figure 2. Real-time 3D Perspective view in Nexus 1.5.1 Software. This view can be panned, zoomed, and rotated in any direction.

After labeling the markers, the software was used for performing additional processing steps such as gap filling and filtering. Gap filling is the process of filling in any gaps in the marker data in the trial after it is labeled. The Vicon Nexus software includes three operations to assist in the gap filling: a spline-fill operation, a Woltring gap-filling routine, and a pattern-fill operation. The most basic of the three operations is the spline-fill routine. The spline-fill operation extrapolates the trajectory of the missing marker in the most logical way based on its position before and after the gap. This operation is best for shorter gaps with smooth movements. The Woltring routine uses a cubic spline algorithm to automatically fill gaps up to a user- 
specified length. The accuracy of the Woltring routine decreases as the length of the gap increases. The recommended frame limit in Nexus is five frames. The pattern-fill operation fills the gap in the original marker's data by analyzing movement pattern of a different, user-specified marker. To use this operation successfully another marker with a similar movement pattern to be labeled should be visible in every frame of the gap. The pattern-fill operation is better suited for the longer gaps

\subsubsection{Kinematic Computation Software}

Visual3D 4.89 (C-Motion Inc., Germantown, MD, USA) software was used for analysis and modeling of three-dimensional marker data. This software uses a static-posture trial to create a kinematic model. This model can then be applied to dynamic capture data to estimate joint kinematics. The software can determine frame-by-frame joint angles based on outputs from the model.

\subsubsection{Electromyography (EMG) system}

Electrical activity of the neck muscles was recorded using a Bagnoli -16 desktop EMG system (Delsys Inc., Boston, USA). The system consists of a main amplifier unit, an input module, EMG electrodes, and other peripheral cables (Figure 3). The input modules host the surface and reference EMG electrodes, power the electrodes and communicate the EMG signal to the main amplifier. The main amplifier unit receives and conditions the signals. It has a band 
pass filter of 20 to $450 \mathrm{~Hz}$, and a mechanism to check for excessive amounts of line interference. The outputs from main amplifier unit were synchronized with an analog to digital (A/D) acquisition system interfaced with the Vicon system and nexus software.

The surface electrodes are parallel bar, active surface electrodes (DE-2.3 EMG Sensors, Delsys Inc., Boston, USA). The sensor contacts are made from $99.9 \%$ pure silver bars, measuring $10 \mathrm{~mm}$ in length, $1 \mathrm{~mm}$ in diameter and spaced $10 \mathrm{~mm}$ apart (Figure $3(\mathrm{~d})$ ). The CMRR for the electrodes is $92 \mathrm{~dB}$ and input impedance greater than $10^{15} \Omega$. The frequency of EMG data acquisition will be set at $1000 \mathrm{~Hz}$.
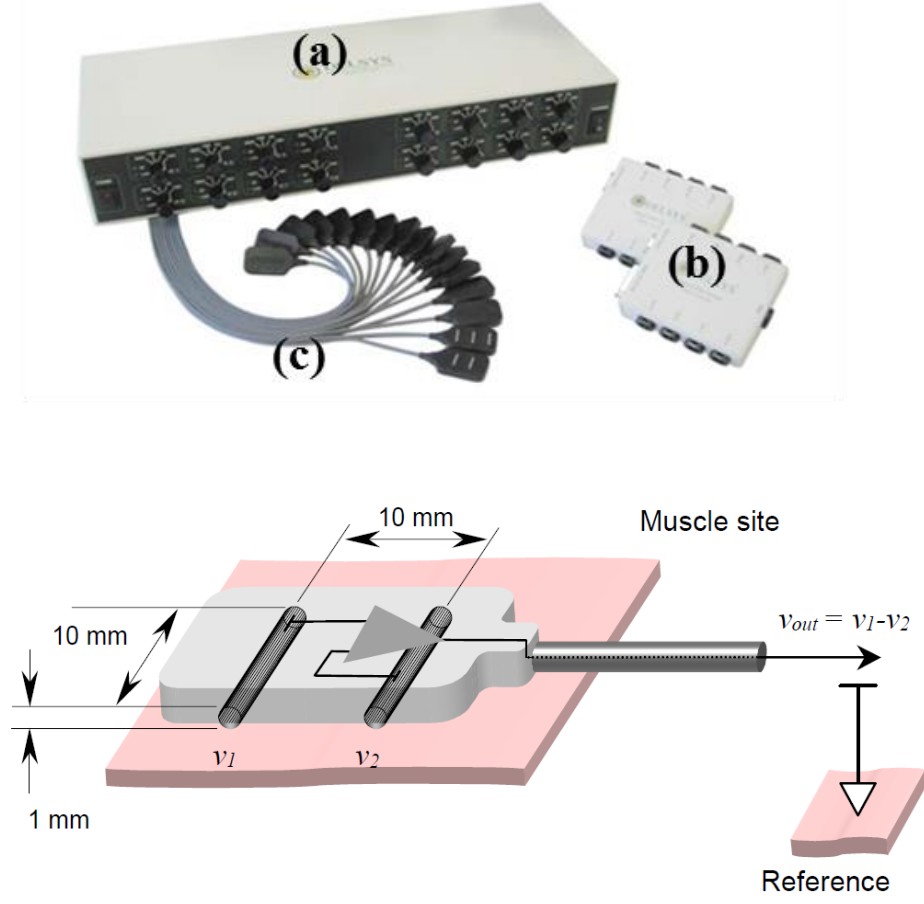

(d)

Figure 3: Bagnoli system components: (a) main amplifier unit; (b) input modules; (c) surface electrodes; (e) parallel bar, active surface electrodes 


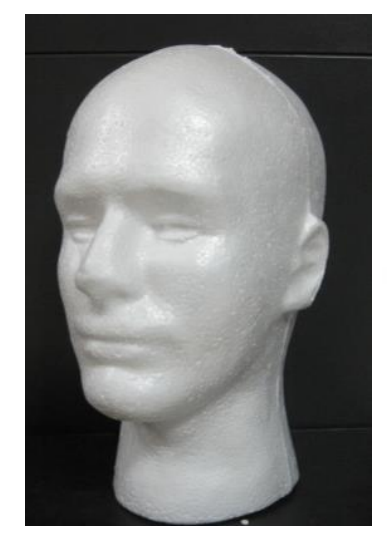

Figure 4: Styrofoam mannequin heads used in the surgical tasks

\subsubsection{Male Styrofoam Mannequin Head}

The surgical tasks were performed using male Styrofoam mannequin heads. These heads have the facial dimensions of an average adult male (Figure 4).

\subsubsection{Surgical Tools and Loupes}

To perform the surgical tasks the following tools were used: (1) needle holder (used to hold the small suture needle to keep a firm grasp on the needle and avoid errors); (2) Ethicon 5-0 Prolene (Polypropylene) Suture; (3) Surgical loupes with 2.5x magnification (Galilean), 17"/420mm working distance, 4" depth of field, 5.0" field of view, with a multi-angle adjustable hinge (Figure 5). Loupes with these specifications are the most commonly utilized. 


\subsection{Experimental Design}

A two-factor replicated block design was used in this research. Factor1, loupe condition, was treated at four fixed levels: (1) no loupe; (2) loupe mounted at 10 degrees; (3) 20 degrees; and (4) 30 degrees (Figure 5). Twenty to 30 degree loupe angles represent commonly used configurations. The additional angle of 10 degrees was tested in this study to further evaluate mount angle effect. Factor 2, gender, was treated at two levels: (1) Male and (2) Female. Three replicates were collected for each experimental condition. In total, 12 experimental trials (4 loupe conditions $\times 3$ replications) were collected from individual participants and the trial order was randomized.

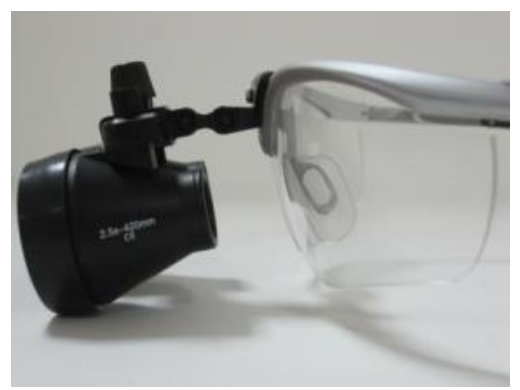

(a)
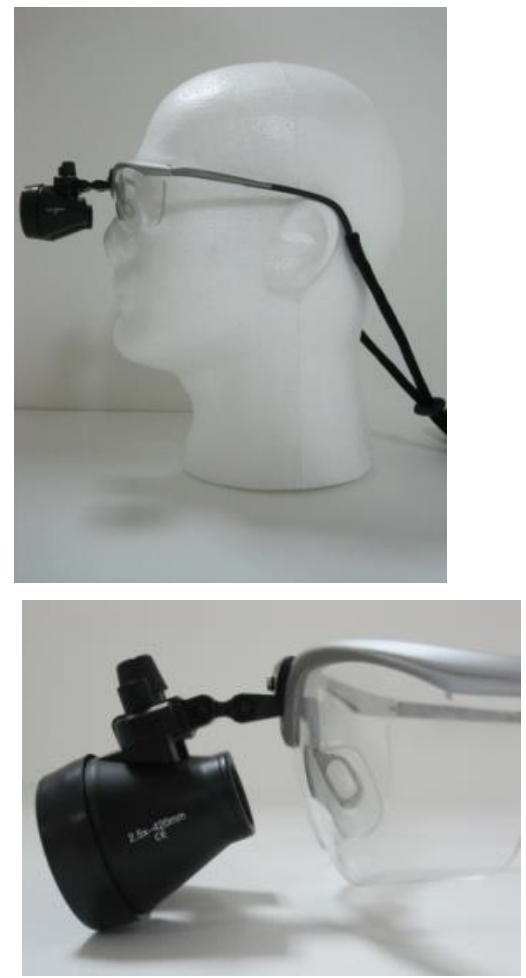

(b)

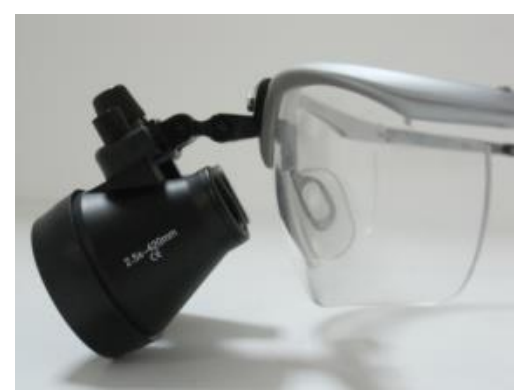

(c)

Figure 5: Surgical loupes used in this study: (a) 10 degree loupe angle; (b) 20 degree loupe angle; (c) 30 degree loupe angle 


\subsection{Data Collection}

Data collection for individual participants consisted of two sessions conducted on separate days. The first session consisted of training and practice periods. Each participant was trained on how to perform a superficial suturing task by a board certified Orbital and Ophthalmic Plastic Surgeon, with over 15 years of surgical experience. Each participant practiced the surgical tasks at least 3 times after initial training without loupes. The performance of the participants was assessed by the surgeon using the GRASIS form, to make sure that participants acquired sufficient coordination to perform the surgical tasks (Cremers et al. 2005).

The actual data collection procedure for each participant consisted of the following steps:

\subsubsection{Participant orientation and measurement}

Upon arrival at the laboratory, participants were provided with a tour of the experimental set-up. Equipment, data collection procedures, and specifics of the experimental tasks were explained to them, they were asked to sign a form approved by the local Instructional Review Board consenting to participation in the study. Subsequently, participants were then asked to change into a skin tight shirt (for females only, males remained bare chested) and shorts, and the following anthropometric measurements were recorded: height, weight, distance between sternal notch and the mastoid process, distance between the acromion and $\mathrm{C} 7$, and C6-C7 distance (Appendix C). Some of these measurements were required for kinematic analysis, while others are used for determining the exact location of the EMG electrodes. 


\subsubsection{Participant preparation}

Participants were then instrumented with the surface electrodes for EMG data collection. The skin over the anatomical landmarks was shaved (if needed) and cleaned with $70 \%$ alcohol prior to the placement of the EMG electrodes. EMG data from two major neck muscles, (1) sternocleidomastoid and (2) upper trapezius, were collected. EMG from the sternocleidomastoid muscle was recorded by placing an electrode along a line drawn from the sternal notch to the mastoid process, at 1/3rd the length of the line from the mastoid process (Figure 6(a)). Electrodes were located midway between the innervation zone (the middle of the muscle (Falla et al. 2002) and the insertion of the muscle at the mastoid process. EMG from the upper trapezius muscle was recorded by placing an electrode between the occiput and $\mathrm{C}$, at the level of C4 (Johnson and Pandyan 2005). The level of C4 was determined by marking a horizontal line at 2.5 times the distance between the C6-C7 vertebrae above the C7 (Figure 6(b)). The electrode at this location will be placed slightly inclined (approximately 35 degrees) to the vertical line between the $\mathrm{C} 7$ and $\mathrm{C} 4$. The EMG data was collected bilaterally. 


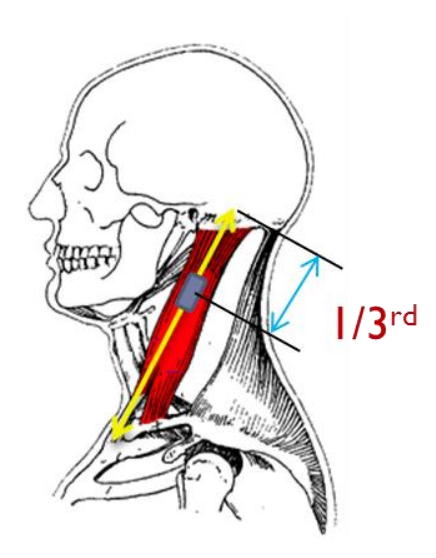

(a)

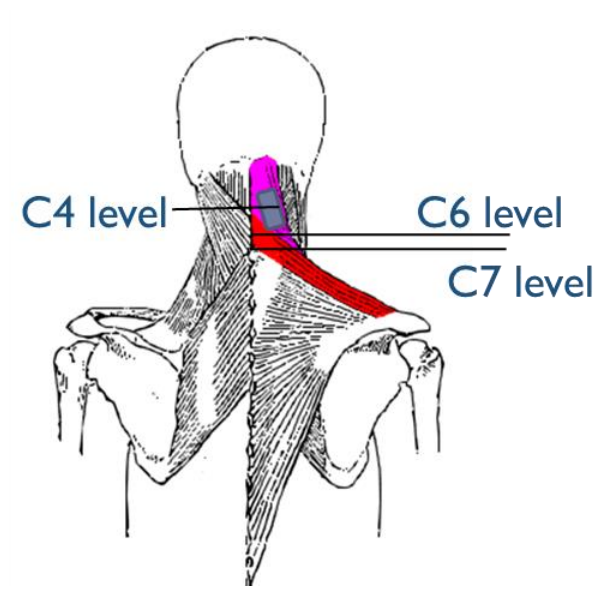

(b)

Figure 6: EMG electrode locations for (a) sternocleidomastoid; (b) upper trapezius muscles Once fitted with EMG electrodes a set of 10 reflective markers (14 mm diameter) were placed on the participants at the following landmarks (Figure 7):

1. Three head markers

- Glabellas bone in the forehead area

- Proximal aspect of temporomandibular (TMJ) joint (left and right)

2. Three neck markers

- Spinous process of C4 Vertebra

- Most lateral points (left and right) on C4 Vertebra

3. Four trunk markers

- Clavicle

- Sternum

- Spinous process of C7 Vertebra

- Spinous process of T10 Vertebra 

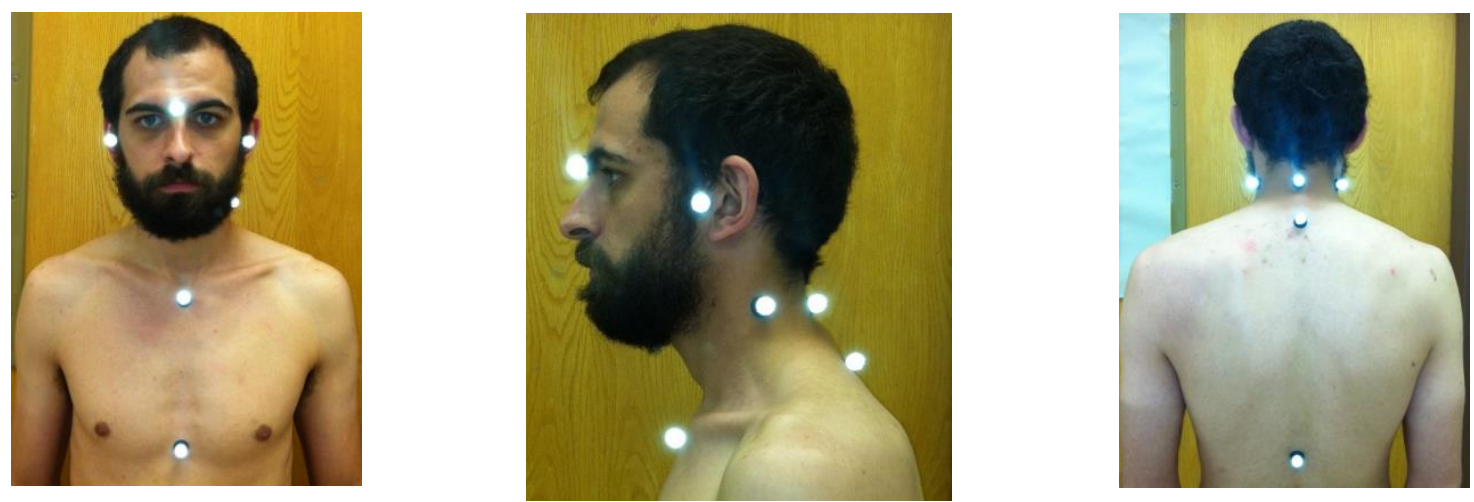

Figure 7: Marker set used to collect the head-neck kinematic data

A custom built Vicon skeletal template was created for kinematic data collection. Three rigid body segments (head, cervical spine and trunk) will be defined using 10 markers.

\subsubsection{Baseline readings}

Once participants were fitted with all the EMG sensors and the reflective markers, baseline EMG measurements were obtained using MVC reference contractions. The reference contraction involved exerting maximum forward head flexion and backward head extension force against a stationary support in a seated position (Nimbarte et al. 2010). Three trials of each exertion were conducted. The data recorded during the forward flexion exertions were used for normalizing EMG activity of anterior neck muscles. The data recorded during the backward extension exertions were used for normalizing EMG activity of posterior neck muscles.

Additionally a participant specific skeletal template was also obtained for calibrating the marker location by capturing the marker data in a standardized anatomical neutral pose. 


\subsubsection{Actual Data collection}

Prior to the actual data collection, the participant again practiced the surgical tasks at least once. The participant was then seated in an adjustable chair placed in front of an adjustable table. The Styrofoam mannequin head was placed on the table with the crown of the head situated towards the participant (Figure 8). The height of the table was adjusted such that the horizontal mannequin head came no higher than the sternum of the subject performing the task. The participant then performed the suturing task under randomized loupe conditions.

The suturing task consisted of passing a suture needle through 12 points marked around the right eye (Figure 9). Each participant began the task by carefully taking out the needle with attached suture from the pack using the needle holder. The needle was then passed clockwise through a series of dots, with the aid of a needle holder and suturing forceps. Once the suture was passed through all 12 points, participants were required to complete the suturing task by tying a knot and appropriately cutting the suture using the scissors. Once the participant had completed the task, a short 6 question subjective survey was completed to assess the participant's perspective of discomfort (Appendix D). A rest period of 3-5 minutes was provided as needed between the tasks. 


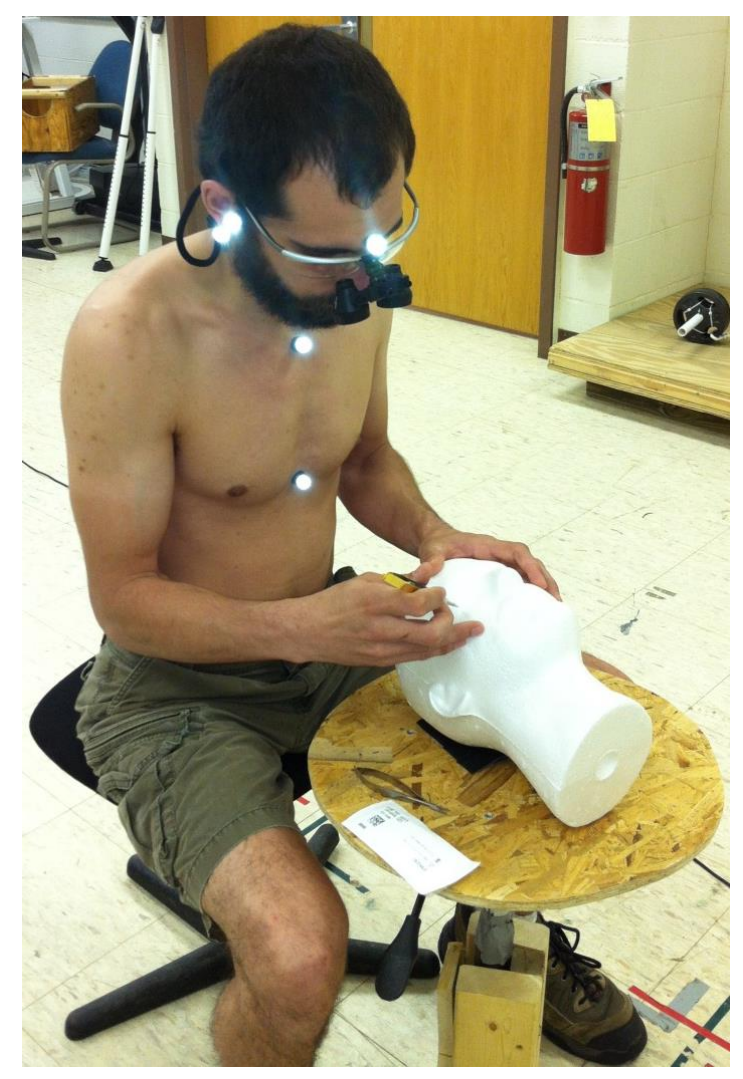

Figure 8: Experimental setup used to collect data during a simulated suturing task

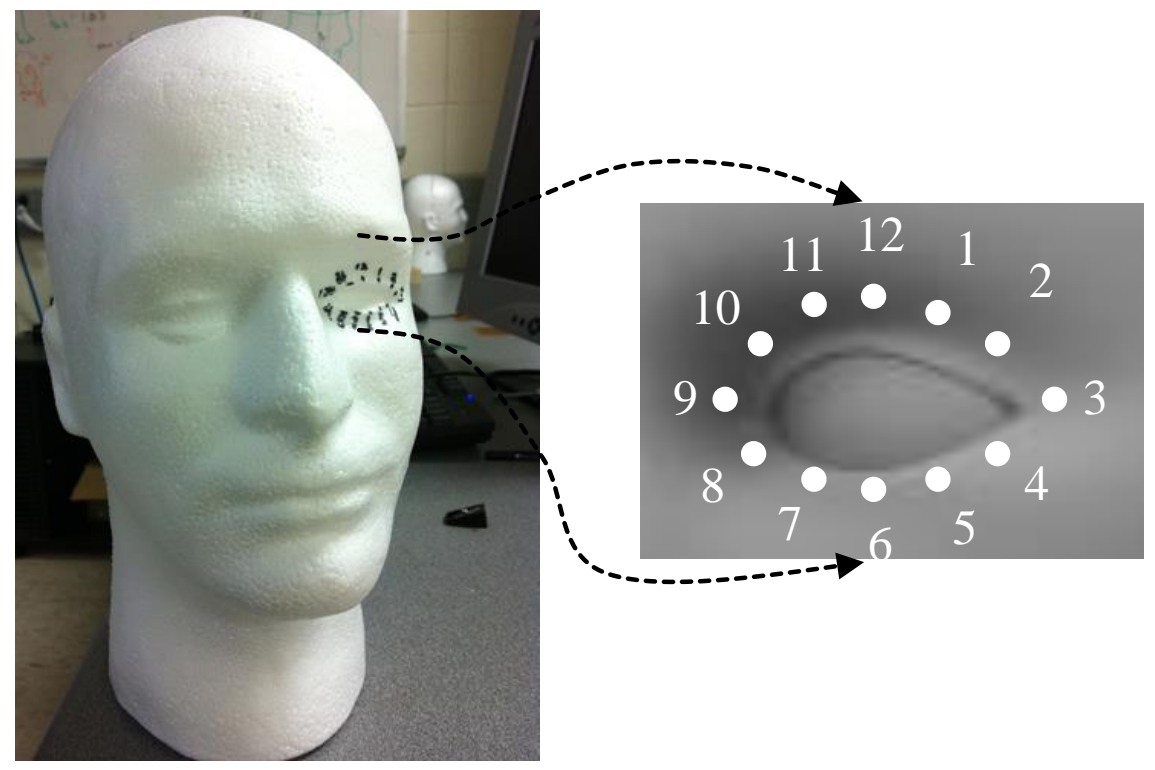

Figure 9: Suturing task performed by the participants during data collection 


\subsection{Data Processing and Analysis}

The experimental data was processed to calculate dependent variables for the statistical analysis.

\subsubsection{Muscle activation}

The raw EMG signal from each electrode location was demeaned and then full-wave rectified. The full wave rectified EMG signal was low pass filtered at $4 \mathrm{~Hz}$, using a fourth-order dual pass Butterworth digital filter, to form a linear envelope (Burnett et al. 2007). The resulting data was averaged to determine the mean absolute values (MAV) (Acierno et al. 1995). The MAV data was then normalized with respect to the average activation during MVC reference contractions recoded during the baseline measurement to obtain the normalized MAV (N-MAV).

\subsubsection{Joint kinematics}

A kinematic model was developed in Visual3D to determine Euler rotations between the head and neck, head and trunk, and neck and trunk during the experimental tasks. Visual3D allows the primary and secondary axis for each segment coordinate frame to be defined as $+/-\mathrm{X}$, $\mathrm{Y}$, or Z, to control the orientation of the segment coordinate frame. For the model used in this research, the coordinate frames were defined with the X-axis directed to the participant's right, the $\mathrm{Y}$-axis directed anteriorly, and the Z-axis directed superiorly (Figure 10). 
In Visual3D, segments are defined using proximal and distal joints or ends. The joint or end locations can be defined using a set of markers (lateral and medial) located at the end or by using joint center (or landmark) with radius. In this study a combination of markers and landmarks were used to define the head, neck, and trunk segments:

\subsubsection{Head segment}

Three virtual landmarks were created to help define the head segment. The first, marking the center of the head, was defined as the midpoint of the two Tragus markers. Another virtual landmark was projected forward $10 \mathrm{~cm}$ from the head center landmark along the global Xaxis. A final virtual landmark was projected downward from the Glabella marker onto a plane created by the two Tragus markers and the landmark projected forward of the head center landmark. The medial and lateral proximal endpoints of the primary axis of the coordinate frame for the head were defined as the right Tragus marker and left Tragus marker, respectively. The distal endpoint was defined as the virtual landmark that was projected from the Glabella marker with a radius of half the distance between the Tragus markers.

\subsubsection{Neck segment}

Three virtual landmarks were created to help define the neck segment. The first (neck center landmark) was created at the midpoint of the left and right neck markers (most lateral points on $\mathrm{C} 4$ vertebra). Another landmark was projected backward $10 \mathrm{~cm}$ from the neck center marker along the global $\mathrm{X}$-axis. A final virtual landmark was projected from the $\mathrm{C} 4$ marker onto a plane defined by the left and right neck markers and the landmark projected backward of the neck center landmark. The right and left neck markers defined the medial and lateral proximal 
endpoints of the primary axis of the coordinate frame for the neck. The distal endpoint of the primary axis was defined by the virtual landmark that was projected from the $\mathrm{C} 4$ marker with a radius of half the distance between the right and left neck markers.

\subsubsection{Trunk segment}

Three virtual landmarks were created to define the trunk segment. The virtual landmarks were created at the midpoints of 1) sternum and clavicle markers (front virtual landmark), 2) clavicle and C7 markers, and 3) C7 and T10 markers (rear virtual landmark). The front and rear virtual landmarks defined the medial and lateral proximal endpoint of the primary axis. The distal endpoint was defined by the landmark at the midpoint of the clavicle and C7 markers, with a radius of half the distance between the front and rear virtual landmarks.
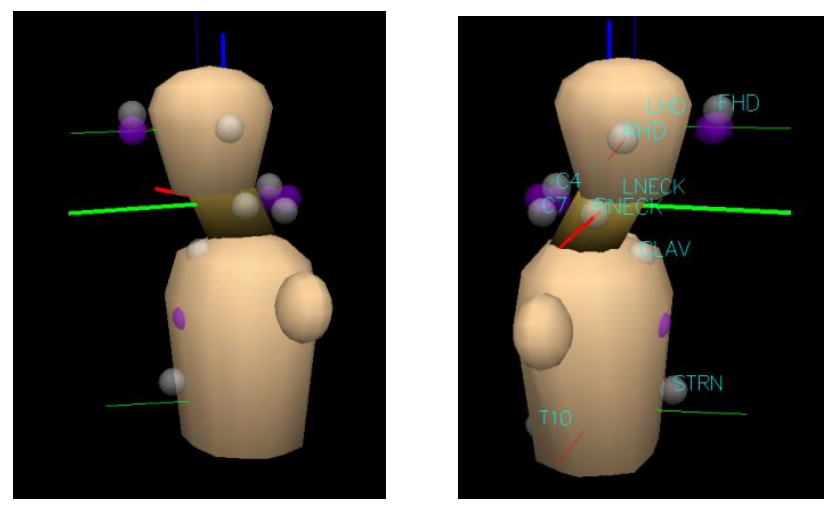

Figure 10: Schematic representation of the kinematic model used to study head-neck kinematics

The kinematic model was used to derive the following joint motions:

1) X-rotation of head segment with respect to trunk segment (head flexion)

2) Y-rotation of head segment with respect to trunk segment (head lateral bending)

3) Z-rotation of head segment with respect to trunk segment (head rotation) 
4) X-rotation of neck segment with respect to trunk segment (neck flexion)

5) Y-rotation of neck segment with respect to trunk segment (neck lateral bending)

6) Z-rotation of neck segment with respect to trunk segment (neck rotation)

7) X-rotation of head segment with respect to neck segment (head-neck flexion)

8) Y-rotation of head segment with respect to neck segment (head-neck lateral bending)

9) Z-rotation of head segment with respect to neck segment (head-neck rotation)

Additionally, landmarks created for head center, neck center and midpoint of C7 and

CLAV were used to determine three-dimensional translational motion of head with respect

to neck (head-neck) and head with respect to trunk (head-trunk) in three directions:

anterior-posterior, medial-lateral, and inferior-superior.

The proposed model estimates the three dimensional angular rotations between the three segments - head, neck and trunk. The exact axis of rotation is difficult to predict due to the presence of several vertebral bodies between these segments. For example, between head and neck segments, three vertebral bodies exist and between neck and trunk, another set of two vertebral bodies exist. Between head and trunk, total six vertebral bodies exist. These vertebral bodies can translate and rotate with respect to each other. In the previous marker-based studies, head-neck motions were primarily studied using vector angles. These vectors were defined by using markers placed at $\mathrm{C} 7$ and tragus (Figure 11) (Szeto and Sham 2008a, Yip et al. 2008, Straker et al. 2009). Such method of defining head-neck posture is over simplified and ignores the relative motions between the cervical vertebrae. Furthermore, in these previous studies the rotational axis was defined by using a 
marker placed at the posterior aspect of C7 vertebra. Such definition is erroneous as the actual rotation may takes place around multiple cervical joints.

The axis of rotation definitions for the head-neck motions is an complicated issue. The model proposed in the current study does not present a perfect solution but it is a step forward compared to the methods proposed in the previous studies. This model estimates the rotations about the axis that passes through the segment center of mass as compared to the posterior aspect of vertebra. Instead of treating seven cervical vertebrae as one segment the model proposed in the current study breaks the cervical spine into two segments, one above and one below the $\mathrm{C} 4$ level. A true solution may involve tracking each vertebra separately which is beyond the capacity of the optical motion capture system available for conducting the current study.

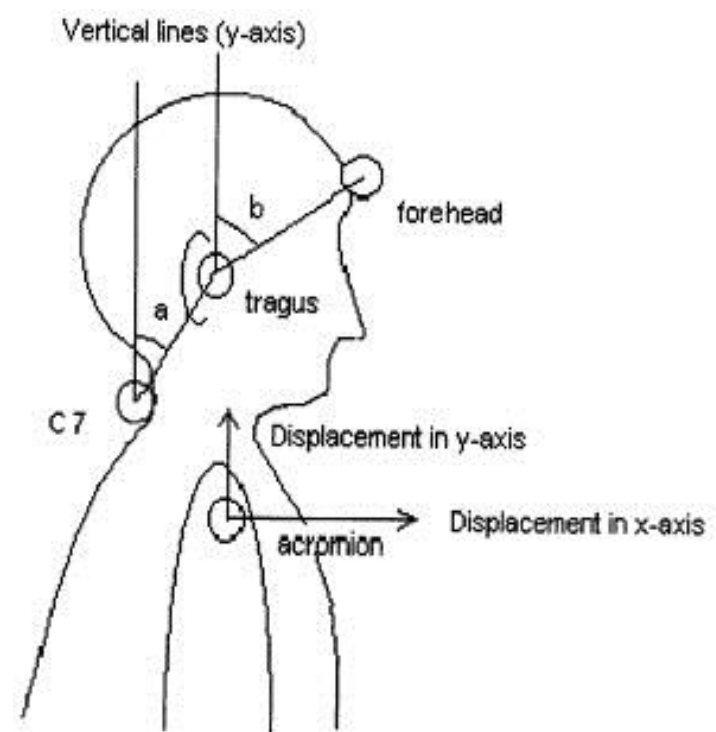

(a)

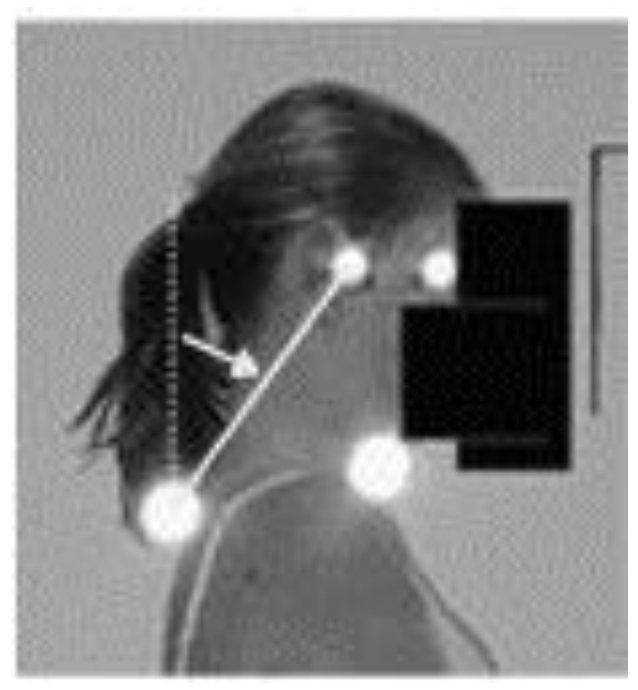

Figure 11: Head-neck angle definitions used in the previous marker based studies (Szeto and Sham 2008a, Yip et al. 2008, Straker et al. 2009). 


\subsubsection{Data selection}

In order to identify the best method to summarize and analyze the joint kinematic data, the time series data was studied for all the participants. Exemplar data for one of the participants are shown in Figure 10. The kinematic data for most of the motions, especially bending and rotation, was mainly uni-directional, i.e., the participants used bending and rotation to the right side. This was mainly due to the fixed and rightward location of the target - the participants operated on the right eye of the styrofoam head (Figure 8). Therefore, the absolute bending and rotation angles were used in the further analysis. Similarly, no extension motion was observed so only flexion angles were analyzed.

Some fluctuations in the joint motions were observed during the starting and ending phases (30 seconds) of the experimental tasks. During the rest of the task, the joint motions remained relatively stable. Therefore, the data for the first and last 30 seconds were ignored and for rest of the data, mean joint angles were estimated for the further analysis. 

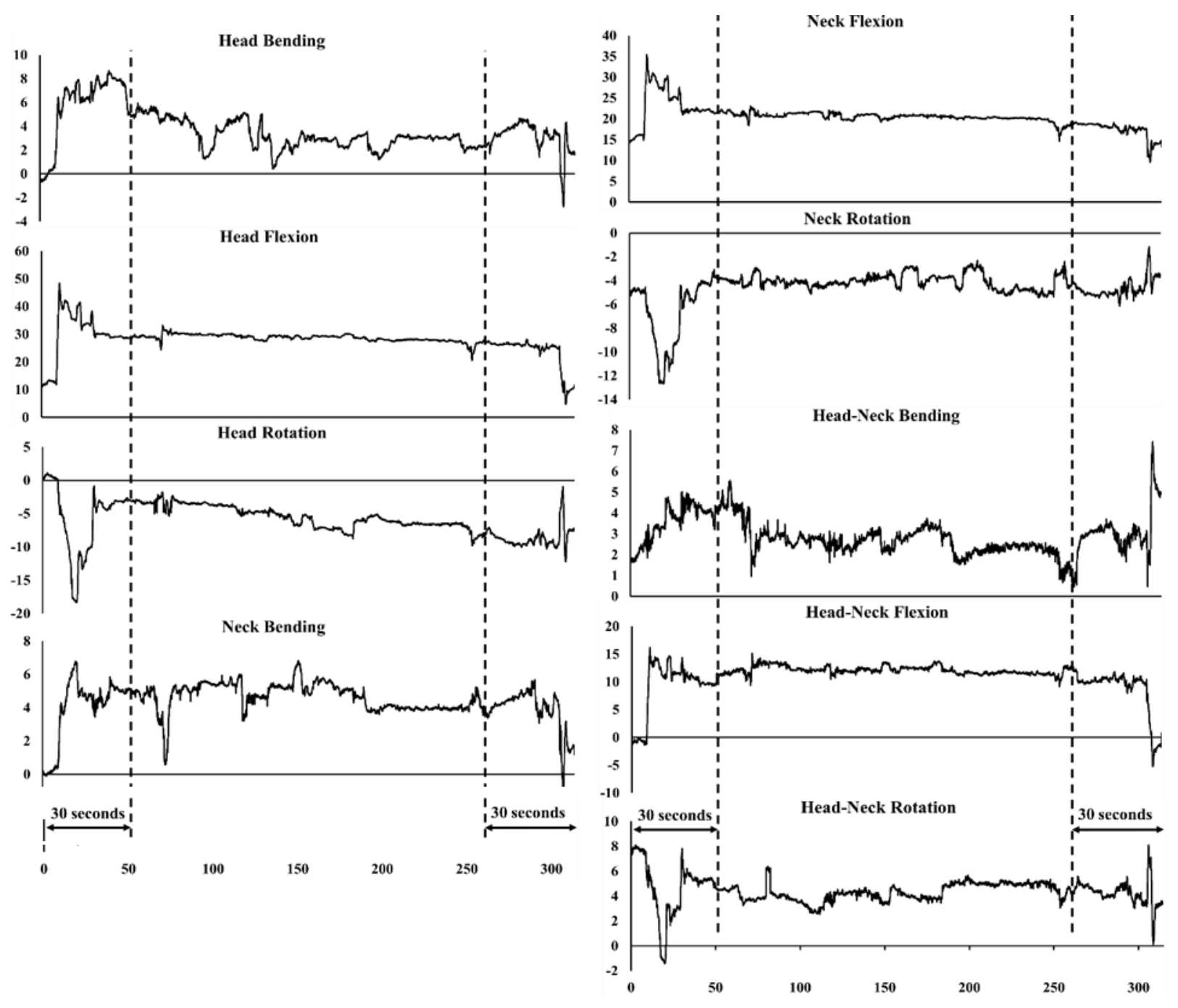

Figure 12: Raw joint angle data

\subsection{Statistical analysis}

Individual participants completed 12 randomized experimental trials (4 loupe conditions $\times 3$ replications) during the experiment. 


\subsubsection{Statistical Model}

In this study the effect of the four loupe conditions: (i) no loupe; (ii) 10 degree loupe angle; (iii) 20 degree loupe angle; (iv) 30 degree loupe angle and with gender: (i) male; (ii) female on the dependent variables related to the neck muscle activity, head-neck postures and discomfort ratings were evaluated using the following statistical model:

$$
y R_{i j k l}=\mu+\alpha_{i}+\beta_{j}+\gamma_{l}+(\alpha \beta)_{i j}+\epsilon_{i j l}\left\{\begin{array}{l}
i=1, \ldots, a \\
j=1, \ldots, b \\
l=1, \ldots, n
\end{array}\right.
$$

Where,

yR represents the dependent variables related to the neck muscle activity, head-neck postures and discomfort ratings.

$\mu$ is the overall mean common to all treatments.

$\alpha_{\mathrm{i}}$ is the effect of loupe condition, so $\mathrm{a}=4$

$\beta_{\mathrm{j}}$ is the effect of gender, so $\mathrm{b}=2$

$\gamma_{1}$ is the effect of participants (block), $\mathrm{n}$ represents the number of participants recruited in the study.

$(\alpha \beta)_{\mathrm{ij}}$ is the interaction effect of loupe condition and gender.

$\epsilon_{\mathrm{ijl}}$ is a random error term.

In the model, the loupe condition $\left(\alpha_{\mathrm{i}}\right)$ and gender $\left(\beta_{\mathrm{j}}\right)$ are treated as fixed factors. It is assumed that each factor and the two-way interaction factors have no effect on the calculated dependent variable. That is: 


$$
\begin{gathered}
\sum_{i=1}^{a} \alpha_{i}=0, \quad \sum_{j=1}^{b} \beta_{j}=0 \\
\sum_{i=1}^{a} \sum_{j=1}^{b}(\alpha \beta)_{i j}=0
\end{gathered}
$$

Participants $\left(\gamma_{l}\right)$ are treated as a random factor and it is assumed that it is a normally and independently distributed (NID) $\left(0, \sigma_{\gamma}{ }^{2}\right)$ random variable. The random error $\epsilon_{i j l}$ is also assumed to also follow $\operatorname{NID}\left(0, \sigma^{2}\right)$.

The appropriate $\mathrm{F}$ tests were applied in testing if the means of the fixed factor effects were equal to zero:

$$
\begin{gathered}
\mathrm{H}_{0}: \alpha_{i}=0, \beta_{j}=0 \text { and } \\
(\alpha \beta)_{i j}=0 \\
\mathrm{H}_{1}: \text { at least one } \alpha_{i} \neq 0, \beta_{j} \neq 0 \\
\text { and }(\alpha \beta)_{i j} \neq 0
\end{gathered}
$$

Appropriate $\mathrm{F}$ tests were also applied in testing the variance of the random factor, $\mathrm{H}_{0:} \sigma_{\gamma}{ }^{2}=0$. The Type I error probability, $\alpha=0.05$, and Power of the test $(1-\beta)$, which equals 0.90 , were chosen for hypothesis testing and sample size determination discussed is in 4.7.2.

Significant effects were further evaluated by conducting comparison between means using Tukey's Honestly Significant Difference (HSD) all-pairwise comparison test. For fixed factors such as loupe condition and gender, if the null hypothesis was rejected, the factors' 
effects were estimated. Minitab 16 statistical analysis software (Minitab Inc., PA, USA) was used to perform the statistical analysis.

\subsubsection{Power Analysis and Sample Size Determination}

Operating characteristics curves (OC curves), a graph of $\beta$ (type II error probability) versus the true difference in means, play an important role in the choice of sample size in experimental design problems. Therefore, the OC curves were used to do a power analysis and determine the number of subjects to be recruited in this research.

The random factor subject $\left(\gamma_{1}\right)$ was treated as a block, so here determining the number of subjects was actually calculating the number of blocks. The OC curves were used with the formula:

$$
\lambda=\sqrt{1+\frac{c \sigma_{\gamma}^{2}}{\sigma^{2}}}
$$

where $\quad \sigma_{\gamma}^{2}=M S B L, \quad \sigma^{2}=M S E$

$M S B L$ and MSE were calculated based on a preliminary study (Nimbarte et al. 2013b). Mean and median head flexion, lateral bending and rotation were considered as the representative dependent variables to estimate the sample size. Table 1 shows the power for different dependent variables. Note that with six subjects, a power greater than $90 \%$ was achieved for the dependent 
variables. Therefore, a sample size of six participants per gender was deemed adequate for the current study.

Table 2: Power values for different dependent variables ('c' denotes the number of blocks (subjects))

\begin{tabular}{|c|c|c|c|c|c|c|}
\hline Dependent variable & $\mathbf{c}$ & $\boldsymbol{\lambda}$ & $\boldsymbol{v}_{\mathbf{1}}$ & $\boldsymbol{v}_{\boldsymbol{2}}$ & $\boldsymbol{\beta}$ & Power (1- $\boldsymbol{\beta})$ \\
\hline Average head flexion & 2 & 6.4 & 1 & 19 & 0.25 & 0.75 \\
\hline & 3 & 7.8 & 2 & 30 & 0.07 & 0.93 \\
\hline Average head bending & 2 & 22.6 & 1 & 19 & 0.08 & 0.92 \\
\hline Average head rotation & 2 & 2.2 & 1 & 19 & 0.60 & 0.40 \\
\hline & 3 & 2.6 & 2 & 30 & 0.45 & 0.55 \\
\hline & 4 & 3.0 & 3 & 41 & 0.30 & 0.70 \\
\hline & 5 & 3.3 & 4 & 52 & 0.12 & 0.88 \\
\hline & 6 & 3.6 & 5 & 63 & 0.03 & 0.97 \\
\hline Median head flexion & 2 & 13.8 & 1 & 19 & 0.15 & 0.85 \\
\hline & 3 & 16.9 & 2 & 30 & 0.015 & 0.985 \\
\hline Median head bending & 2 & 22.3 & 1 & 19 & 0.08 & 0.92 \\
\hline Median head rotation & 2 & 2.6 & 1 & 19 & 0.6 & 0.4 \\
\hline & 3 & 3.1 & 2 & 30 & 0.38 & 0.58 \\
\hline & 4 & 3.6 & 3 & 41 & 0.18 & 0.72 \\
\hline & 5 & 4.0 & 4 & 52 & 0.05 & 0.95 \\
\hline
\end{tabular}

\subsubsection{Data Transformation}

Data transformation was used if the data failed to follow normal distribution. As a first step, several commonly used transforms such as square root, logarithmic, power, and reciprocal transformations were utilized (Bartlett 1947, Montgomery 2012). If these transformations did not 
improve the normality then Johnson transformation was used. The Johnson transformation optimally selects a function from three "families" of distributions for a variable (Johnson 1949).

The general form of the transformation is given by:

$$
\begin{gathered}
z=\gamma+\eta * \tau(x ; \varepsilon, \lambda) \\
\eta>0, \quad-\infty<\gamma<\infty \\
\lambda>0, \quad-\infty<\varepsilon<\infty
\end{gathered}
$$

Where $\mathrm{z}$ is a standard normal variable and $\mathrm{x}$ is the variable to be fitted by a Johnson family distribution. The four parameters, $\gamma, \eta, \varepsilon$, and $\lambda$ are estimated values and $\tau$ is an arbitrary function which may take on one of the functions of the Johnson family.

The Johnson distributions are labeled as SB, SL, and SU, and refer to the variable being bounded, lognormal, and unbounded, respectively (Table 3) (Chou et al. 1998). Most appropriate transformation function from the Johnson was selected to achieve the highest normality.

Table 3: Johnson transform families and corresponding functions

\begin{tabular}{|c|c|}
\hline $\begin{array}{c}\text { Johnson } \\
\text { Family: }\end{array}$ & Transformation Function: \\
\hline SB & $\gamma+\eta * \ln \left[\frac{(x-\varepsilon)}{(\lambda+\varepsilon-x)}\right]$ \\
\hline SL & $\gamma+\eta * \ln (x-\varepsilon)$ \\
\hline SU & $\gamma+\eta * \sinh ^{-1}\left[\frac{(x-\varepsilon)}{\lambda}\right]$ \\
& where, \\
\hline & $\sinh ^{-1}(x)=\ln \left[x+\sqrt{1+x^{2}}\right]$ \\
\hline
\end{tabular}




\section{Chapter 5: Results}

Normality of the dependent variables was tested using the Anderson-Darling normality test. The variables that did not follow the normal distribution were transformed. The exact transformation function as well as parameter values for all the transformed variables are shown in Table 3. Detailed analysis related to the data transformation is shown in Appendix E. The equality of variance test showed that the assumption of the homoscedasticity condition was valid for the dependent variables. Results of equality of variance test are shown in Appendix F.

Table 4: Normality and Transformation

\begin{tabular}{|c|c|c|c|c|c|c|c|}
\hline Variable & Type & $\gamma$ & $\eta$ & $\varepsilon$ & $\lambda$ & $\begin{array}{l}\text { P-value } \\
\text { Before }\end{array}$ & $\begin{array}{l}\text { P-value } \\
\text { After }\end{array}$ \\
\hline Head Flexion & SU & -0.95473 & 1.16423 & 19.64340 & 8.32520 & $<.005$ & 0.62000 \\
\hline Head Bending & SB & 2.56707 & 1.79240 & -1.07404 & 35.53484 & $<.005$ & 0.89300 \\
\hline Head Rotation & SU & -1.98963 & 1.42855 & 1.22822 & 1.48536 & $<.005$ & 0.54300 \\
\hline Neck Flexion & SL & -4.87005 & 1.70972 & 1.74179 & & $<.005$ & 0.14700 \\
\hline Neck Bending & SB & 3.20665 & 1.79645 & -0.81297 & 34.79377 & $<.005$ & 0.91900 \\
\hline Neck Rotation & SU & -1.68318 & 0.85231 & 0.72541 & 0.45034 & $<.005$ & 0.24400 \\
\hline Head-Neck Bending & SU & -2.64358 & 1.49658 & 0.47038 & 0.66627 & $<.005$ & 0.93700 \\
\hline $\begin{array}{l}\text { Head -Neck } \\
\text { Rotation } \\
\end{array}$ & SB & 0.95996 & 0.92476 & 0.57334 & 7.01552 & $<.005$ & 0.89300 \\
\hline Head Vs Neck X & SU & -0.94347 & 1.76080 & 1.92682 & 3.82061 & $<.005$ & 0.15700 \\
\hline Head Vs Trunk X & SU & 0.85893 & 1.11521 & 0.11000 & 0.01419 & $<.005$ & 0.29500 \\
\hline Head Vs Trunk Y & SU & -0.59870 & 1.07678 & 20.26590 & 7.75047 & $<.005$ & 0.21700 \\
\hline Head Vs Trunk Z & SU & 0.65374 & 1.36469 & -0.84401 & 4.55126 & $<.005$ & 0.54100 \\
\hline Neck Vs Trunk X & NA & & & & & & \\
\hline Neck Vs Trunk Y & SU & -3.06419 & 1.33816 & 2.31652 & 2.19012 & $<.005$ & 0.27800 \\
\hline Neck Vs Trunk Z & SU & 0.97402 & 1.96690 & 0.55147 & 1.99871 & $<.005$ & 0.09300 \\
\hline Right SCM & SU & 0.77250 & 1.18943 & 5.11885 & 1.02459 & $<.005$ & 0.14900 \\
\hline Right Upper Trap & SU & -0.09680 & 1.64681 & 6.22492 & 5.71864 & 0.01500 & 0.02700 \\
\hline
\end{tabular}




\subsection{Posture}

\subsubsection{Joint angles}

The analysis of kinematic data revealed that the primary motion was in the flexion extension plane. Some motion was also observed in the bending and rotation planes. Mean head flexion angles ranged between 28 and 31 degrees. Mean head bending and rotation angles ranged between 4 and 7 degrees.

The effect of loupe condition on the head and neck bending was statistically significant. In general it was observed that without the use of loupes the head and neck bending angles were slightly higher than the three loupe conditions (Table 5 \& Figure 11). However the difference was found to be very minimal (2 to 3 degrees). For the other rotational motions or joint angles the effect of loupe was statistically insignificant. 
Table 5: Results of statistical analysis for joint angle. The mean and standard deviation (SD) of all angles are expressed in degrees. Asterisk (*) denotes statistical significance. For the means that are statistically significant, the results of post-hoc analysis are shown by letters. Means that don't share a letter are significantly different.

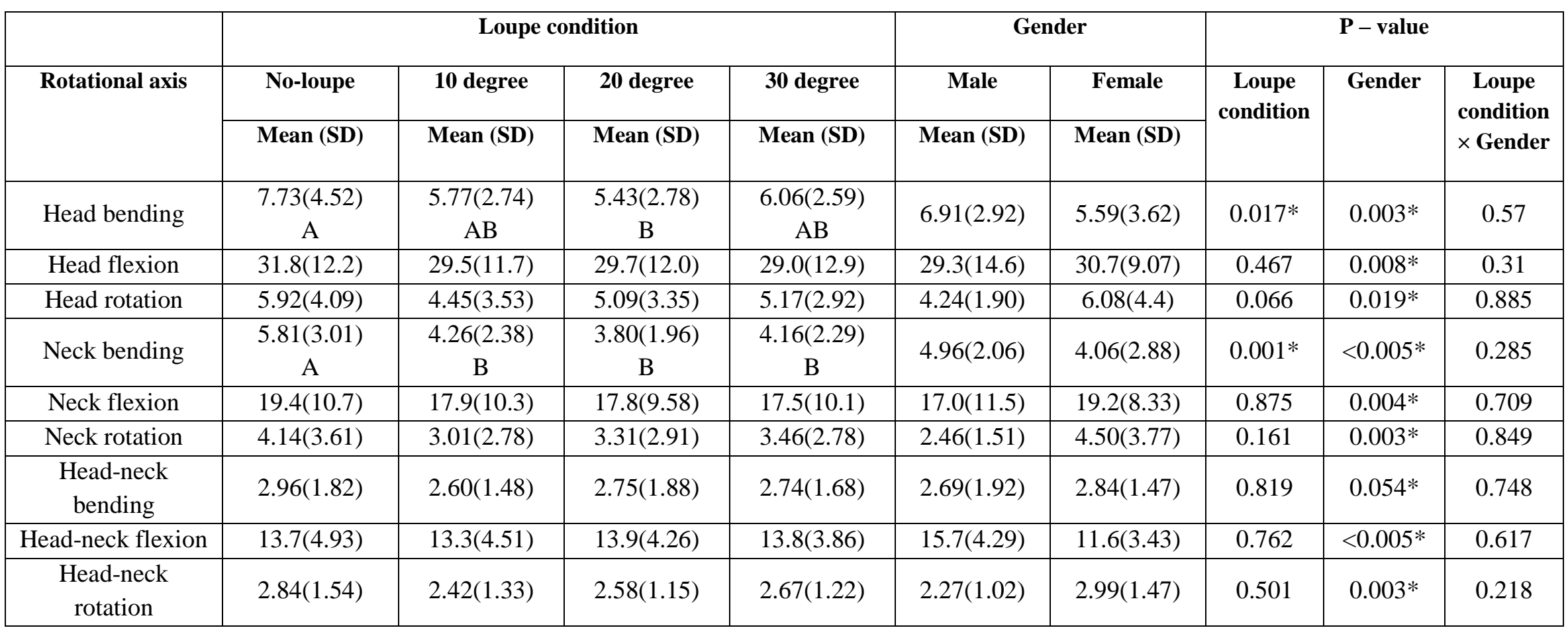


Interval Plot of Head bending transformed, Neck bending transformed

95\% CI for the Mean

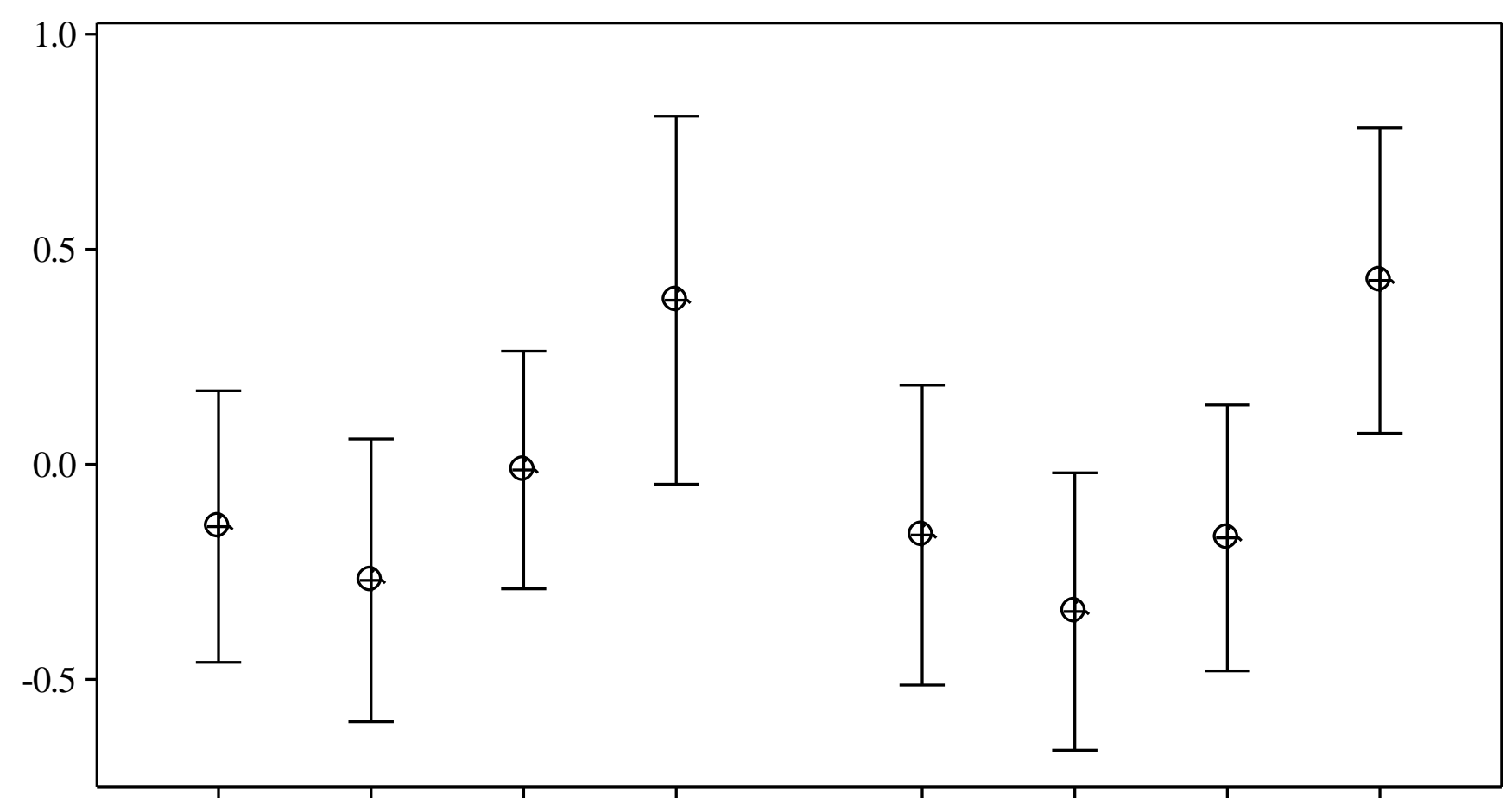

10 degree 20 degree 30 degree No loupe Head bending transformed

10 degree 20 degree 30 degree No loupe Neck bending transformed

Figure 13: Effect of loupe condition on the head and neck bending angles. Please note that the transformed data is used to plot this figure. Actual data is presented in Table 5. 
Interval Plot of Neck flexion transformed $95 \%$ Cl for the Mean

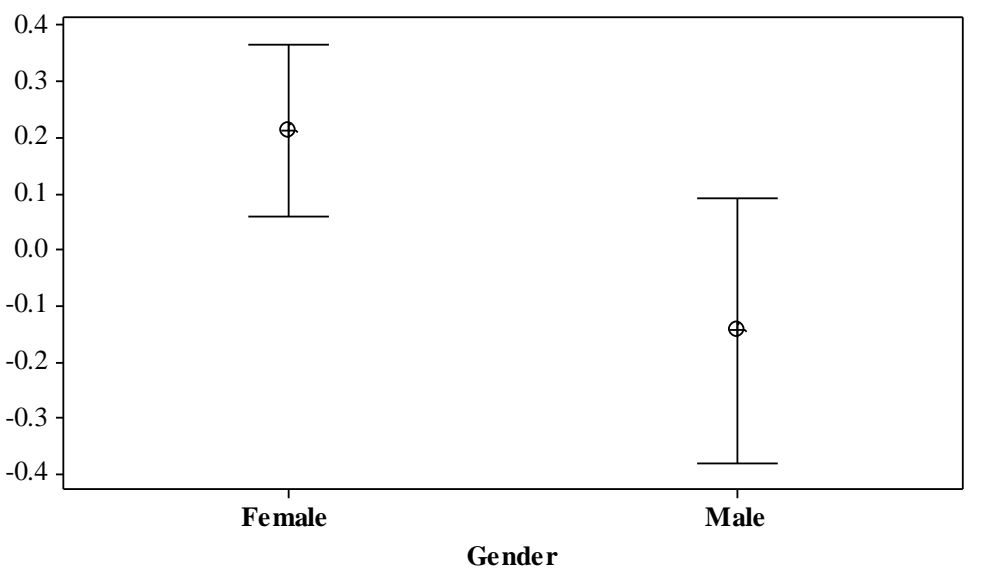

Interval Plot of Neck flexion 95\% CI for the Mean

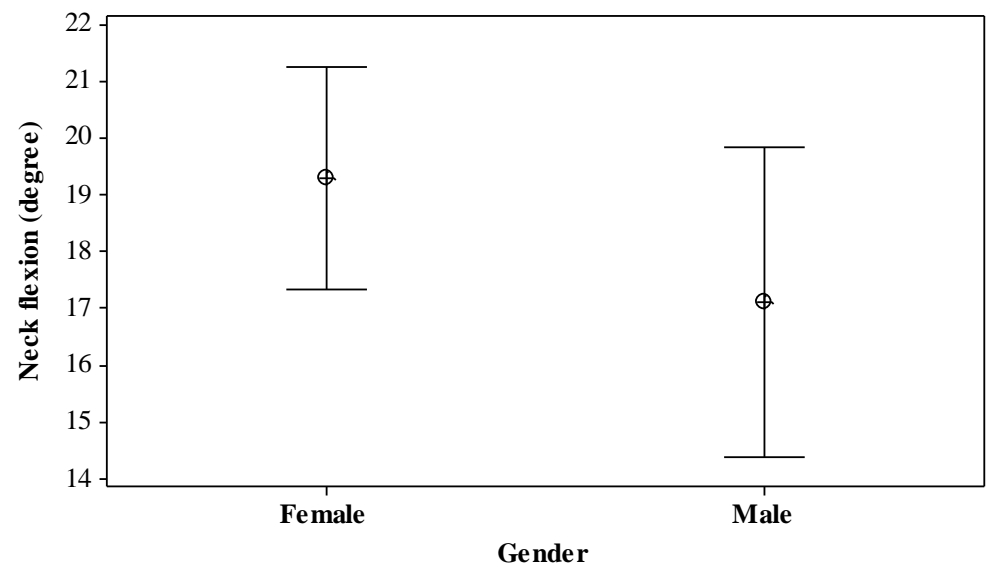

Interval Plot of Head-neck flexion 95\% Cl for the Mean

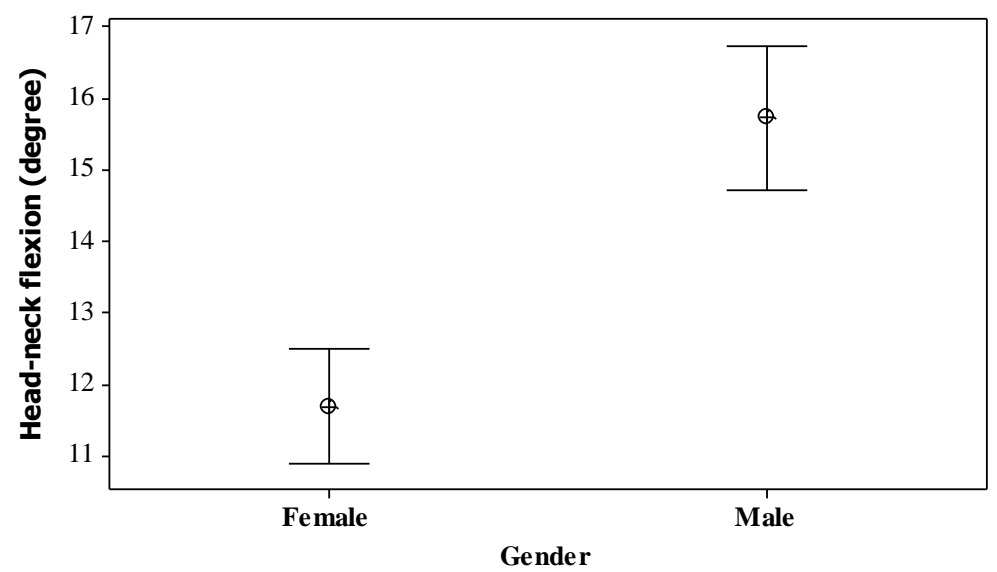

Figure 14: Gender differences for the neck and head-neck flexion angles. 
The effect of gender was statistically significant for most of the joint angles. Male participants exhibited higher head, neck and head-neck bending than females (Table 5). Female participants exhibited higher head, neck and head-neck rotations than males (Table \& Figure 11). These differences were in the range of 1 to 2 degrees. Higher neck flexion was observed for the females than males and higher head-neck flexion was observed for the males than females (Table 5 \& Figure 12). The flexion angle differences were in the range of 2 to 5 degrees.

\subsubsection{Segmental translations}

Translation of head with respect to trunk in the anterior-posterior direction was significantly affected by the loupe condition (Table 6). Higher translation in the anteriorposterior direction was observed for no-loupe condition compared to the three loupe conditions. Statistically no difference was found between the three loupe conditions (Table 6).

Translation of head with respect to trunk in the inferior-superior direction was also significantly affected by the loupe condition (Table 6). Lower translation in the inferior-superior direction was observed for no-loupe condition compared to the three loupe conditions. Statistically no difference was found between the three loupe conditions (Table 6).

Translation of head with respect to neck in the anterior-posterior direction showed trends similar to the translation of head with respect to trunk. Significantly higher translation was observed for no-loupe condition compared to the three loupe conditions and no difference was found between the three loupe conditions (Table 6).

Translation of head with respect to neck in the inferior-superior direction showed trends similar to the translation of head with respect to trunk. Significantly lower translation was 
Table 5: Results of statistical analysis for postural translations. The mean and standard deviation (SD) of all translations are expressed in meters. Asterisk (*) denotes statistical significance. For the means that are statistically significant, the results of post-hoc analysis are shown by letters. Means that don't share a letter are significantly different.

\begin{tabular}{|c|c|c|c|c|c|c|c|c|c|c|}
\hline \multirow[b]{3}{*}{ Translations } & \multirow[b]{3}{*}{ Directions } & \multicolumn{4}{|c|}{ Loupe condition } & \multicolumn{2}{|c|}{ Gender } & \multicolumn{3}{|c|}{$P$ - value } \\
\hline & & No-loupe & 10 degree & 20 degree & 30 degree & Male & Female & \multirow{2}{*}{$\begin{array}{c}\text { Loupe } \\
\text { condition }\end{array}$} & \multirow[t]{2}{*}{ Gender } & \multirow{2}{*}{$\begin{array}{c}\text { Loupe } \\
\text { condition } \\
\times \text { Gender }\end{array}$} \\
\hline & & (Mean (SD) & Mean (SD) & Mean (SD) & Mean (SD) & Mean (SD) & Mean (SD) & & & \\
\hline \multirow[t]{3}{*}{ Head-trunk } & $\begin{array}{l}\text { Anterior- } \\
\text { posterior }\end{array}$ & $\begin{array}{c}0.099(0.03) \\
\text { A }\end{array}$ & $\begin{array}{c}0.091(0.03) \\
\text { B }\end{array}$ & $\begin{array}{c}0.090(0.03) \\
\text { B }\end{array}$ & $\begin{array}{c}0.087(0.03) \\
\text { B }\end{array}$ & $0.081(0.03)$ & $0.103(0.01)$ & $0.001 *$ & $<0.005^{*}$ & 0.795 \\
\hline & $\begin{array}{c}\text { Medial- } \\
\text { lateral }\end{array}$ & $0.028(0.03)$ & $0.027(0.03)$ & $0.025(0.03)$ & $0.022(0.03)$ & $0.034(0.03)$ & $0.017(0.01)$ & 0.149 & $<0.005^{*}$ & 0.748 \\
\hline & $\begin{array}{l}\text { Inferior- } \\
\text { superior }\end{array}$ & $\begin{array}{c}0.086(0.01) \\
\text { A }\end{array}$ & $\begin{array}{c}0.096(0.06) \\
\text { B }\end{array}$ & $\begin{array}{c}0.098(0.02) \\
\text { B }\end{array}$ & $\begin{array}{c}0.101(0.01) \\
\text { B }\end{array}$ & $0.097(0.01)$ & $0.094(0.02)$ & $<0.005^{*}$ & 0.112 & 0.720 \\
\hline \multirow[t]{3}{*}{ Head-neck } & $\begin{array}{l}\text { Anterior- } \\
\text { posterior }\end{array}$ & $\begin{array}{c}0.070(0.02) \\
\text { A }\end{array}$ & $\begin{array}{c}0.064(0.02) \\
\text { B }\end{array}$ & $\begin{array}{c}0.064(0.02) \\
B\end{array}$ & $\begin{array}{c}0.062(0.02) \\
\text { B }\end{array}$ & $0.052(0.02)$ & $0.078(0.01)$ & $<0.005^{*}$ & $<0.005^{*}$ & 0.573 \\
\hline & $\begin{array}{c}\text { Medial- } \\
\text { lateral }\end{array}$ & $0.019(0.02)$ & $0.017(0.02)$ & $0.016(0.02)$ & $0.014(0.02)$ & $0.022(0.02)$ & $0.012(0.01)$ & 0.133 & $<0.005^{*}$ & 0.843 \\
\hline & $\begin{array}{l}\text { Inferior- } \\
\text { superior }\end{array}$ & $\begin{array}{c}0.047(0.02) \\
\text { B }\end{array}$ & $\begin{array}{c}0.054(0.02) \\
\mathrm{AB}\end{array}$ & $\begin{array}{c}0.055(0.02) \\
\mathrm{AB}\end{array}$ & $\begin{array}{c}0.057(0.02) \\
\mathrm{A}\end{array}$ & $0.061(0.02)$ & $0.045(0.02)$ & $0.046^{*}$ & $<0.005^{*}$ & 0.936 \\
\hline
\end{tabular}


Interval Plot of Head-trunk AP transformed, Head-trunk IS transformed $95 \%$ CI for the Mean

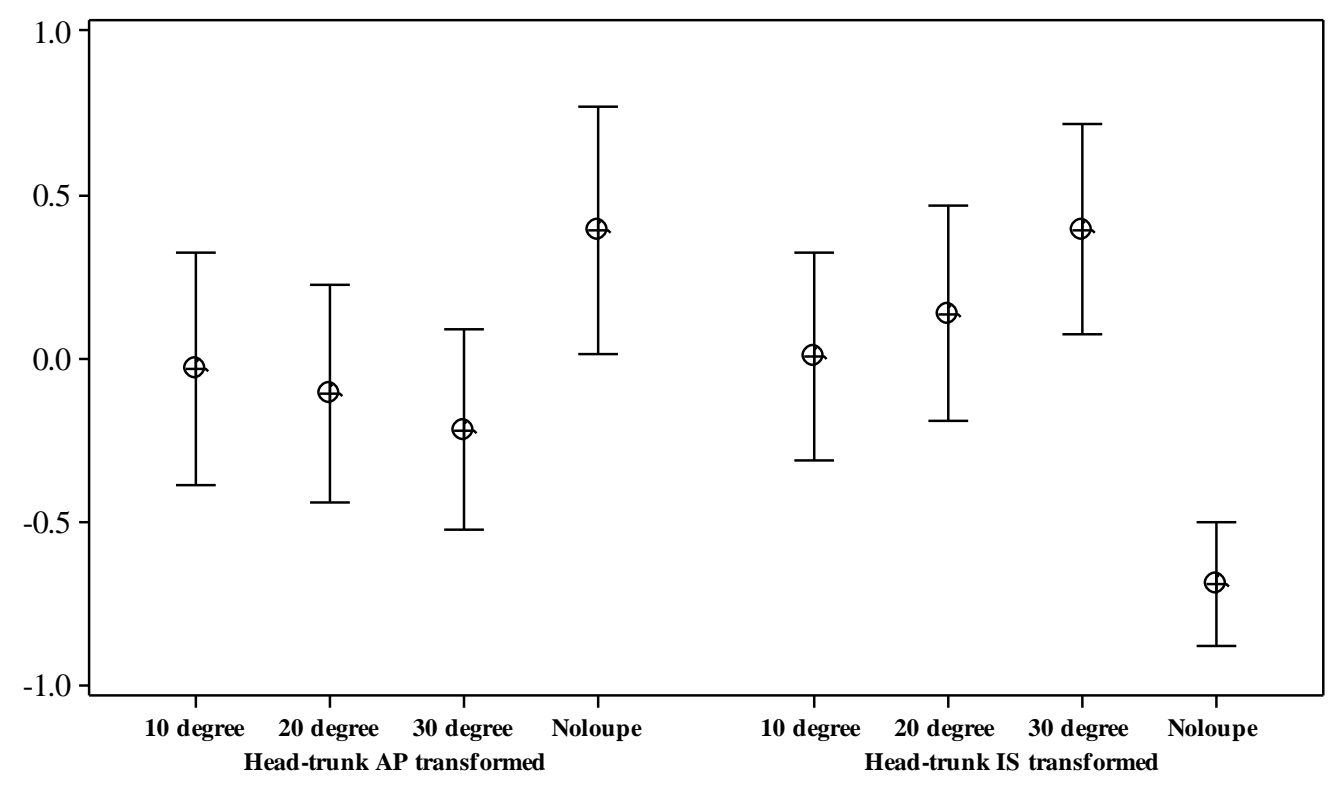

Interval Plot of Head-neck AP transformed, Head-neck IS transformed $95 \% \mathrm{CI}$ for the Mean

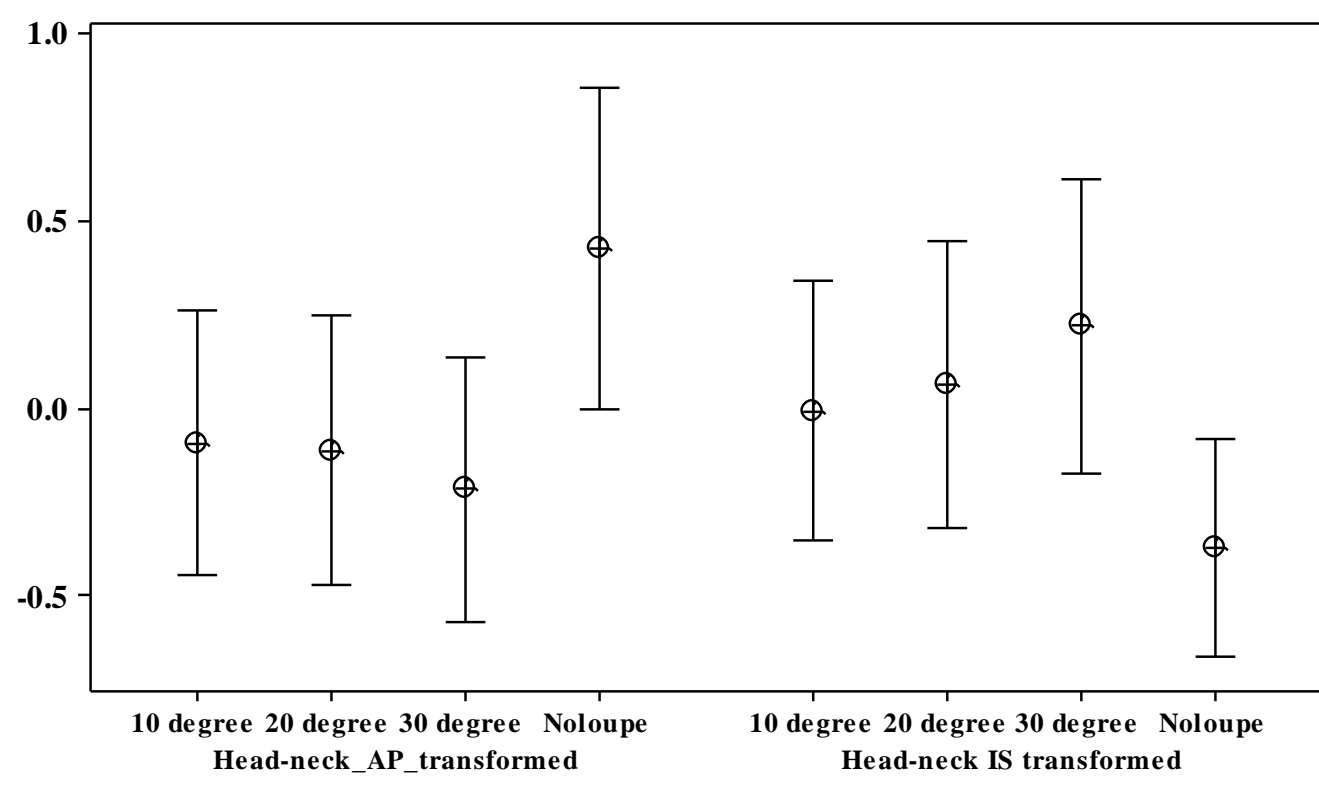

Figure 15: Effect of loupe condition on the head-trunk and head-neck translations in the AP and IS directions. Please note that the transformed data was used to plot this figure. Actual data is presented in Table 5. 
Table 6: Results of statistical analysis for muscle activity data. The mean and standard deviation (SD) of muscle activity are expressed in normalized mean absolute values. Asterisk (*) denotes statistical significance.

\begin{tabular}{|c|c|c|c|c|c|c|c|c|c|}
\hline \multirow[b]{3}{*}{ Muscles } & \multicolumn{4}{|c|}{ Loupe condition } & \multicolumn{2}{|c|}{ Gender } & \multicolumn{3}{|c|}{$P$ - value } \\
\hline & No-loupe & 10 degree & 20 degree & 30 degree & Male & Female & Loupe & Gender & Loupe \\
\hline & Mean (SD) & Mean (SD) & Mean (SD) & (Mean (SD)) & Mean (SD) & Mean (SD) & & & $\times$ Gender \\
\hline $\begin{array}{c}\text { Right } \\
\text { sternocleidomastoid }\end{array}$ & $3.86(1.27)$ & $4.28(1.51)$ & $4.11(1.47)$ & $4.04(1.58)$ & $3.93(1.09)$ & $4.22(1.74)$ & 0.405 & $0.01 *$ & 0.997 \\
\hline $\begin{array}{l}\text { Right upper } \\
\text { trapezius }\end{array}$ & $6.94(3.82)$ & $7.13(3.72)$ & $7.04(3.83)$ & $6.39(3.59)$ & $7.88(3.26)$ & $5.86(3.87)$ & 0.367 & $<0.005^{*}$ & 0.965 \\
\hline $\begin{array}{c}\text { Left } \\
\text { sternocleidomastoid }\end{array}$ & $3.76(1.90)$ & $4.07(2)$ & $4.02(1.68)$ & $4.08(1.81)$ & $3.38(2.07)$ & $4.59(1.32)$ & 0.592 & $<0.005^{*}$ & 0.411 \\
\hline $\begin{array}{l}\text { Left upper } \\
\text { Trapezius }\end{array}$ & 7.01(3.98) & $7.39(4.44)$ & $6.82(3.58)$ & $6.81(3.65)$ & $7.24(3.89)$ & $6.77(3.90)$ & 0.857 & 0.38 & 0.746 \\
\hline
\end{tabular}


observed for no-loupe condition compared to the 30 degree loupe conditions and no difference was found between the three loupe conditions (Table 6).

The three dimensional translations were also found to be different between males and females. Females showed significantly higher translations in the anterior-posterior directions for head with respect to trunk as well as for head with respect to neck. Translations in medial-lateral and inferior-superior directions were higher for males than females for head with respect to trunk as well as for head with respect to neck.

\subsection{Muscle activity}

Loupe condition had no effect on the activity of neck muscles (Table 7). Gender difference was observed for muscle activity. Females showed significantly higher muscle activation for right and left sternocleidomastoid muscles than males. Males showed higher activation for right upper trapezius muscles than females. 
Interval Plot of RSCM transformed, RSCM, RCTRP transforme, RCTRP, LSCM 95\% CI for the Mean

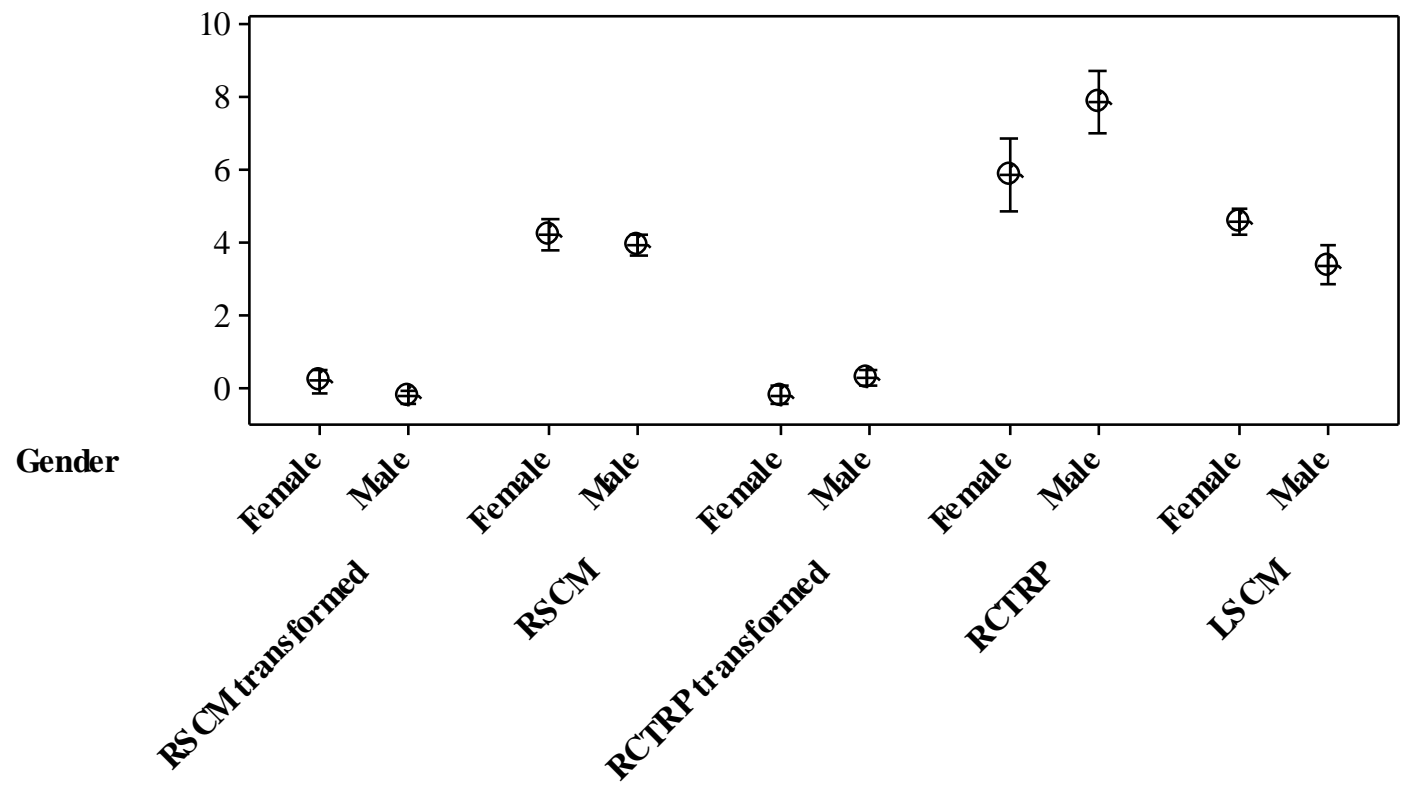

Figure 16: Gender differences for the muscle activity. 


\subsection{Discomfort}

Loupe condition had no effect on the perceived discomfort in the right shoulder, left shoulder, base of the neck and top of the neck. Vision discomfort was significantly affected by the loupe condition. Mean discomfort for the 30 degree loupe condition was significantly higher than the rest of the conditions (Table 8).

Statistically significant gender difference was observed for the discomfort ratings. Males reported significantly higher discomfort than females for all the body regions (Table 8 and Figure 15).

Table 8: Results of statistical analysis for the discomfort rating data. Asterisk (*) denotes statistical significance.

\begin{tabular}{|c|c|c|c|c|c|}
\hline & No loupe & 10 degree & 20 degree & 30 degree & $\mathrm{P}$-value \\
\hline & & & & & \\
\hline Right shoulder & $1.94(0.98)$ & $1.94(0.95)$ & $1.77(0.83)$ & $1.83(0.81)$ & 0.739 \\
\hline Left shoulder & $1.55(0.96)$ & $1.38(0.64)$ & $1.30(0.52)$ & $1.36(0.54)$ & 0.389 \\
\hline $\begin{array}{c}\text { Base of neck, } \\
\text { near shoulder }\end{array}$ & $2.30(0.92)$ & $2.25(0.96)$ & $2.02(0.81)$ & $2(0.82)$ & 0.214 \\
\hline $\begin{array}{c}\text { Top of neck, near } \\
\text { skull }\end{array}$ & $2.16(0.97)$ & $2(0.89)$ & $1.83(0.77)$ & $1.94(0.71)$ & 0.352 \\
\hline Vision & $\begin{array}{c}1.83(0.87) \\
\mathrm{A}\end{array}$ & $\begin{array}{c}2.19(0.92) \\
\mathrm{AB}\end{array}$ & $\begin{array}{c}2.05(0.82) \\
\mathrm{AB}\end{array}$ & $\begin{array}{c}2.38(1.02) \\
\mathrm{B}\end{array}$ & $0.036^{*}$ \\
\hline
\end{tabular}

\begin{tabular}{|c|c|c|c|}
\hline & Male & Female & $\mathbf{P}-$ value \\
\hline & & & \\
\hline Right shoulder & $2.20(0.73)$ & $1.54(0.91)$ & $<0.005^{*}$ \\
\hline Left shoulder & $1.51(0.62)$ & $1.29(0.74)$ & $0.040^{*}$ \\
\hline $\begin{array}{c}\text { Base of neck, } \\
\text { near shoulder }\end{array}$ & $2.54(0.80)$ & $1.75(0.78)$ & $<0.005^{*}$ \\
\hline $\begin{array}{c}\text { Top of neck, } \\
\text { near skull }\end{array}$ & $2.29(0.72)$ & $1.68(0.85)$ & $<0.005^{*}$ \\
\hline Vision & $2.37(0.91)$ & $1.86(0.87)$ & $<0.005^{*}$ \\
\hline
\end{tabular}




\section{Interval Plot for discomfort data}

$95 \%$ CI for the Mean

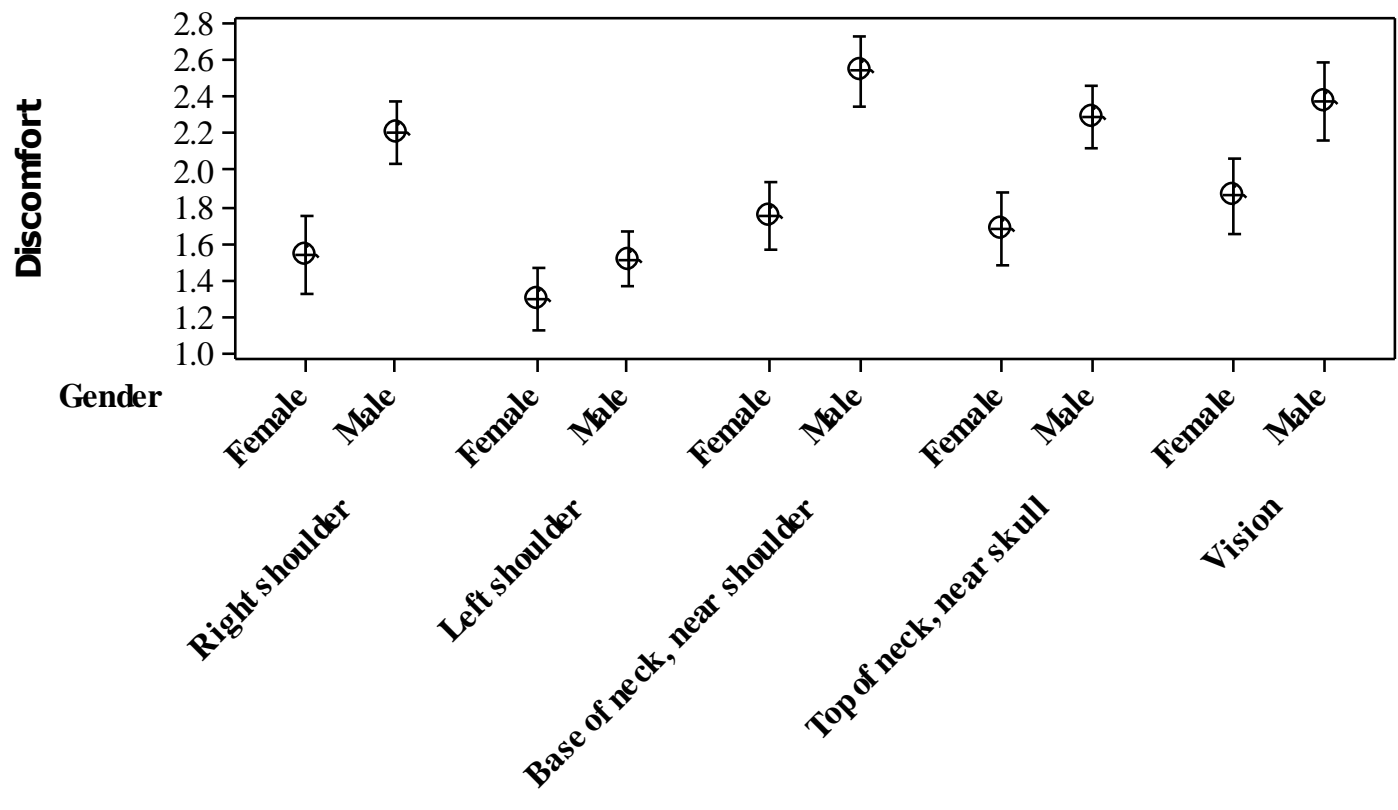

Figure 17: Gender differences for the perceived discomfort. 


\section{Chapter 6: Discussion and Conclusion}

In this study, a simple surgical procedure was emulated in a laboratory setting to help understand the effect of using surgical loupes on the behavior of head and neck region/musculature. Additionally, gender difference and its interaction with the use of loupes were studied. Loupe condition had minimal effect on the head and neck joint angles. The only variables significantly affected were head bending and neck bending. Use of the loupe reduced these bending angles by a very small amount ( $\sim 2$ to 3 degree) and therefore the effect of loupe is biomechanically insignificant. For the rest of the joint angles the loupe condition had no effect. Thus, the data failed to reject the null hypothesis pertaining to the effect of loupe condition on the joint angles.

For the surgical task tested in this study head flexion ranged between 25 and 30 degrees. Several previous studies have reported a positive relationship between head flexion and selfreported symptoms of neck pain for various working populations (Kilbom et al. 1986, Dartigues et al. 1988, Ignatius et al. 1993, Yu and Wong 1996, Szeto et al. 2002). In a prospective cohort study among 1334 workers with many different job titles Ariens et al.,(2001) quantified the relation between neck pain and work related head inclination at three categories: 0-20, 20-45, $>45^{\circ}$ from the neutral position. The authors have found that working time (>70\%) with the neck at a minimum of $20^{\circ}$ head flexion were associated with an increased risk of neck pain.

In the current study the head and neck postures were studied by defining three segments: head, neck, and trunk. To our knowledge, motions of these segments haven't previously been evaluated in similar types of studies. Although head flexion (i.e., flexion of head 
with respect to trunk) was found to be very similar for males and females, some differences in neck flexion (i.e., flexion of neck with respect to trunk) and head-neck flexion (i.e., flexion of head with respect to neck) were observed. Mean neck flexion for females was significantly higher than males; and mean head-neck flexion for males was significantly higher than females. This trend suggests that the lower cervical spine is less flexible and more rigid for males than females. Subsequently males tend to rely on the upper cervical spine to a greater extent than the lower cervical spine to accomplish head flexion.

In this research, loupe condition had a much more significant effect on translational motion than rotational motion, with effects reaching significance in the anterior-posterior and inferior-superior directions. The data rejected the null hypothesis pertaining to the effect of loupe condition on the segmental translations. The no-loupe condition was significantly different than all three with-loupe conditions, suggesting the presence of the loupe was more of a factor than which loupe angle was used. Reduced translation in the anterior-posterior direction and increased translation in the inferior-superior direction was observed when loupes were used. The corresponding change in rotational joint angles was minimal and insignificant. Anterior-posterior motion, such as moving the chin forward or backward, and inferior-superior motion, such as making the neck more or less erect, are examples of motion that can occur independently of a change in rotational angle.

Mismatch between the rotational and translational motions of the cervical spine also suggest that these motions are not perfectly correlated with each other when a marker based optical motion capture system is used. With a marker based system local coordinate frames are established for the segments. Rotations of these segments are quantified along fixed orthogonal 
axes. Such axes may not represent the true rotational axes for the vertebral joints; as the vertebral joints are represented as universal joints with small range of motion but infinite functional degrees of freedom.

Reduced translation in the anterior-posterior direction and increased translation in the inferior-superior directions as well as reduced joint angles for the loupe conditions suggest that the use of loupe may forces a more erect or straightened neck posture. Such postures may not alter the response of active tissues (muscles) but may affect the loading of passive tissues. The analysis of muscle activity data indicates no difference in the loupe condition and thus seems to support this notion. The increased loading of passive tissue may lead to creep deformation of passive tissue. A number of studies have identified that creep and the resulting deformation of passive tissues may compromise the stability of the spinal structures (Solomonow et al. 2003, Shin et al. 2009, Sánchez-Zuriaga et al. 2010). A less stable spine can be both a cause as well as a consequence of spinal pain. Future studies should evaluate the effect of loupe use on the interaction between cervical spine active and passive tissues.

The neck muscle activity data failed to reject the null hypothesis related to the loupe condition, i.e., the loupe condition had no effect on the neck muscle activity. The neck muscle activity levels found in this study are somewhat similar, if not, slightly higher than the data reported in the previous Video Display Terminal (VDT) studies. For the sternocleidomastoid muscles the mean activation of 3 to $4 \% \mathrm{MVC}$ was observed in the current study. Previous VDT studies have reported an activity of 2 to $4 \%$ MVC (Turville et al. 1998, Nimbarte et al. 2013a). For the upper trapezius muscles, the previous VDT studies have reported activation levels of 4 to 5\% MVC (Villanueva et al. 1997, Turville et al. 1998, Nimbarte et al. 2013a). In the current 
study, the activation levels of 6 to $7 \%$ MVC were observed for the upper trapezius muscles. Sustained muscle activation greater than $5 \%$ of the MVC is known to generate faster muscles fatigue and can also increase biomechanical load on passive structures (Jonsson 1982, HarmsRingdahl et al. 1986), further increasing the risk of neck musculoskeletal pain.

Some interesting trends were observed for the muscle activity patterns between males and females. Females showed higher activation for the anterior neck muscles than the males; and the males showed higher activation for the posterior neck muscles than females. This suggest that posterior neck muscles (extensors) provide the required extension moment in males but in females the extension moment is provided by both anterior and posterior neck muscles. A few previous studies have reported difference in neck muscle activations for females compared to males (Nordander et al. 2008, Johansen et al. 2013). These studies have attributed the gender difference to factors such as difference in the functional capacity, physiological cross sectional areas and fiber composition for the gender differences in the muscle activity. One previous study reported findings similar to the current study, i.e., higher activation of anterior neck muscle for females and higher activation of posterior neck muscles for males than their counterparts(Nimbarte 2014). The anterior and posterior neck muscles in addition to supporting the head motions also connect the shoulder joints with the skull. The three joints that constitute the shoulder complex include glenohumeral, acromioclavicular, and sternoclavicular joints. The anterior sternocleidomastoid muscle originates at the sternoclavicular joint, with medial and lateral heads located at the manubrium of the sternum and the superior-anterior surface of the medial third of the clavicle, respectively. The insertion for the sternocleidomastoid muscle is the lateral surface of the mastoid process. The posterior upper trapezius muscle originates at the 
external occipital protuberance and insert at lateral third of clavicle and acromion of scapula. The articulation between lateral aspect of clavicle and acromion of scapula forms the acromioclavicular joints. The sternoclavicular joint is more prominent in females than males and perhaps its stabilization may demand higher contribution by the sternocleidomastoid muscle in females than males.

Finally, the perceived discomfort ratings were significantly affected by the gender but not by the loupe condition. Males reported higher ratings of perceived discomfort than females. One possible reason for this is the nature of the task tested in this study. The suturing task performed in this study required some level of dexterity and hand eye coordination. Traditionally females are better versed with the skills required for such tasks than males. Therefore it is possible that the males found the tasks slightly more discomforting than the females.

The head postures observed in the current study when the loupes were tested required good amount of flexion with only mild bending and rotation. In a recent field study by Nimbarte et al., (2013c) much higher flexion, bending and rotation angles were reported. In this study professional surgeons operated on patients in a real operating room environment and most of the surgeries required operating on very small, irregular surfaces, often requiring working into a deep hole where visualization is difficult. Lack of realism is always an issue with lab-based simulation studies and is one of the limitations of this study. It is also possible that the tasks tested in this study were too simplistic and failed to evoke true biomechanical response. The other item of note in a lab based study is that the conclusions made with this study are only a snapshot of the muscles. While there was not a significant amount of muscle activation reported, if these same subjects were to continue this same operation over an extended period of time it 
may be found that the muscle activation and fatigue is greatly increased as posture becomes learned. For this reason it would be beneficial to use professionals to complete the research from a different perspective.

In conclusion, the results of this study indicate that the participants relied on translational motions instead of the rotational motions of the head and neck to accommodate the different loupe conditions. Different postural and muscle recruitment patterns were observed for the males compared to the females when the suturing tasks were performed with and without loupes.

Future research should be performed using more demanding surgical tasks and perhaps using trained professionals. It would also be beneficial to complete research that would test the chronic aspect of the muscle activation using trained professionals. Another possibility would be to test the muscle response against physician "training" where the training would consist of simple stretches and movements designed to help with the formation of creep in the physicians. 


\section{References}

Acierno, S.P., Baratta, R.V. \& Solomonow, M., 1995. A practical guide to electromyography for biomechanics. Louisiana State University.

Ariëns, G., Bongers, P., Douwes, M., Miedema, M., Hoogendoorn, W., Van Der Wal, G., Bouter, L. \& Van Mechelen, W., 2001. Are neck flexion, neck rotation, and sitting at work risk factors for neck pain? Results of a prospective cohort study. Occupational and Environmental Medicine, 58 (3), 200-207.

Babar-Craig, H., Banfield, G. \& Knight, J., 2003. Prevalence of back and neck pain amongst ent consultants: National survey. The Journal of Laryngology \& Otology, 117 (12), 979-982.

Babar-Craig, H., Banfield, G. \& Knight, J., 2006. Prevalence of back and neck pain amongst ent consultants: National survey. The Journal of Laryngology and Otology, 117 (12), 979-982.

Baker, J.M. \& Meals, R.A., 1997. A practical guide to surgical loupes. The Journal of Hand Surgery, 22 (6), 967-974.

Bartlett, M.S., 1947. The use of transformations. Biometrics, 3 (1), 39-52.

Bernaards, C.M., Bosmans, J.E., Hildebrandt, V.H., Van Tulder, M.W. \& Heymans, M.W., 2011. The costeffectiveness of a lifestyle physical activity intervention in addition to a work style intervention on recovery from neck and upper limb symptoms and pain reduction in computer workers. Occupational and environmental medicine, 68 (4), 265-272.

Bls, 2012. Nonfatal occupational injuries and illnesses requiring days away from work, 2011.

Burnett, A., Green, J., Netto, K. \& Rodrigues, J., 2007. Examination of emg normalisation methods for the study of the posterior and posterolateral neck muscles in healthy controls. Journal of Electromyography and Kinesiology, 17 (5), 635-641.

Chou, Y.-M., Polansky, A.M. \& Mason, R.L., 1998. Transforming non-normal data to normality in statistical process control. Journal of Quality Technology, 30 (2), 133.

Côté, P., Van Der Velde, G., David Cassidy, J., Carroll, L.J., Hogg-Johnson, S., Holm, L.W., Carragee, E.J., Haldeman, S., Nordin, M. \& Hurwitz, E.L., 2008a. The burden and determinants of neck pain in workers. European Spine Journal, 17, 60-74.

Côté, P., Van Der Velde, G., David Cassidy, J., Carroll, L.J., Hogg-Johnson, S., Holm, L.W., Carragee, E.J., Haldeman, S., Nordin, M. \& Hurwitz, E.L., 2008b. The burden and determinants of neck pain in workers:: Results of the bone and joint decade 2000-2010 task force on neck pain and its associated disorders. Spine, 33 (4S), S60-S74.

Cremers, S.L., Lora, A.N. \& Ferrufino-Ponce, Z.K., 2005. Global rating assessment of skills in intraocular surgery (grasis). Ophthalmology, 112 (10), 1655-1660.

Dartigues, J., Henry, P., Puymirat, E., Commenges, D., Peytour, P. \& Gagnon, M., 1988. Prevalence and risk factors of recurrent cervical pain syndrome in a working population. Neuroepidemiology, 7 (2), 99105.

Dhimitri, K., Mcgwin Jr, G., Mcneal, S., Lee, P., Morse, P., Patterson, M., Wertz, F. \& Marx, J., 2005a. Symptoms of musculoskeletal disorders in ophthalmologists. American journal of ophthalmology, 139 (1), 179-181.

Dhimitri, K.C., Mcgwin, G., Mcneal, S.F., Lee, P., Morse, P.A., Patterson, M., Wertz, F.D. \& Marx, J.L., 2005b. Symptoms of musculoskeletal disorders in ophthalmologists. American journal of ophthalmology, 139 (1), 179-181.

Esser, A.C., Koshy, J.G. \& Randle, H.W., 2007. Ergonomics in office based surgery: A survey guided observational study. Dermatologic Surgery, 33 (11), 1304-1314.

Falla, D., Dall'alba, P., Rainoldi, A., Merletti, R. \& Jull, G., 2002. Repeatability of surface emg variables in the sternocleidomastoid and anterior scalene muscles. European Journal of Applied Physiology, 87 (6), 542-549.

Harms-Ringdahl, K., Ekholm, J., Schüldt, K., Németh, G. \& Arborelius, U.P., 1986. Load moments and myoelectric activity when the cervical spine is held in full flexion and extension. Ergonomics, 29 (12), 1539-1552. 
Hayes, M., Taylor, J. \& Smith, D., 2012. Predictors of work-related musculoskeletal disorders among dental hygienists. International journal of dental hygiene, 10 (4), 265-269.

Hobbs, C., 2004. Prevalence of back and neck pain amongst ent consultants: National survey. The Journal of Laryngology \& Otology, 118 (05), 395-396.

Hogg-Johnson, S., Van Der Velde, G., Carroll, L.J., Holm, L.W., Cassidy, J.D., Guzman, J., Côté, P., Haldeman, S., Ammendolia, C. \& Carragee, E., 2008. The burden and determinants of neck pain in the general population. European Spine Journal, 17, 39-51.

Ignatius, Y., Yee, T.Y. \& Yan, L., 1993. Self reported musculoskeletal problems amongst typist and possible risk factors. Journal of human ergology, 22 (2), 83-93.

Ilie, V.I., Ilie, V.G. \& Lefter, M., 2011. Loupes in surgical training. ANZ Journal of Surgery, 81 (9), 580-581.

Johansen, T.I., Samani, A., Antle, D.M., Côté, J.N. \& Madeleine, P., 2013. Gender effects on the coordination of subdivisions of the trapezius muscle during a repetitive box-folding task. European journal of applied physiology, 113 (1), 175-182.

Johnson, G.R. \& Pandyan, A.D., 2005. The activity in the three regions of the trapezius under controlled loading conditions--an experimental and modelling study. Clinical Biomechanics 20 (2), 155-61.

Johnson, N.L., 1949. Systems of frequency curves generated by methods of translation. Biometrika, 149-176.

Jonsson, B., 1982. Measurement and evaluation of local muscular strain in the shoulder during constrained work. Journal of Human Ergology.

Kietrys, D., Mcclure, P. \& Fitzgerald, G., 1998. The relationship between head and neck posture and vdt screen height in keyboard operators. Physical Therapy, 78 (4), 395.

Kilbom, Å., Persson, J. \& Jonsson, B.G., 1986. Disorders of the cervicobrachial region among female workers in the electronics industry. International journal of industrial ergonomics, 1 (1), 37-47.

Koneczny, S., 2009. The operating room: Architectural conditions and potential hazards. Work: A Journal of Prevention, Assessment and Rehabilitation, 33 (2), 145-164.

Kono, K., Uka, A., Mori, M., Haga, S., Hamada, Y. \& Nagata, S., 2010. Usefulness of surgical loupes and headlights for the neurosurgical field]. No shinkei geka. Neurological surgery, 38 (4), 335.

Liang, C.A., Levine, V.J., Dusza, S.W., Hale, E.K. \& Nehal, K.S., 2012. Musculoskeletal disorders and ergonomics in dermatologic surgery: A survey of mohs surgeons in 2010. Dermatologic Surgery, 38 (2), 240-248.

Montgomery, D.C., 2012. Design and analysis of experiments, 8th ed.: John Wiley \& Sons.

National Center for Health Care Statistics, 2009a. National ambulatory medical care survey data: 2009 summary Centers for Disease Control and Prevension (CDC).

National Center for Health Care Statistics, 2009b. National ambulatory medical care survey data: 2009 summary

Nimbarte, A.D., 2014. Risk of neck musculoskeletal disorders among males and females in lifting exertions. International Journal of Industrial Ergonomics.

Nimbarte, A.D., Aghazadeh, F., Ikuma, L.H. \& Harvey, C.M., 2010. Neck disorders among construction workers: Understanding the physical loads on the cervical spine during static lifting tasks. Industrial health, 48 (2), 145-153.

Nimbarte, A.D., Alabdulmohsen, R.T., Guffey, S.E. \& Etherton, J.R., 2013a. The impact of use of dual monitor screens on $3 \mathrm{~d}$ head-neck posture and activity of neck muscles. IIE Transactions on Occupational Ergonomics and Human Factors, 1 (1), 38-49.

Nimbarte, A.D., Chapman, M., Sivak-Callcott, J., Ning, X. \& Jaridi, M., 2013b. Biomechanical evaluation of surgical loupes. Industrial Systems Engineering Research Conference. San Juan, Puerto Rico.

Nimbarte, A.D., Sivak-Callcott, J.A., Zreiqat, M. \& Chapman, M., 2013c. Neck postures and cervical spine loading among microsurgeons operating with loupes and headlamp. IIE Transactions on Occupational Ergonomics and Human Factors, 1 (4), 215-223.

Nordander, C., Ohlsson, K., Balogh, I., Hansson, G.-Å., Axmon, A., Persson, R. \& Skerfving, S., 2008. Gender differences in workers with identical repetitive industrial tasks: Exposure and musculoskeletal disorders. International archives of occupational and environmental health, 81 (8), 939-947.

Park, A., Lee, G., Seagull, F.J., Meenaghan, N. \& Dexter, D., 2010. Patients benefit while surgeons suffer: An impending epidemic. Journal of the American College of Surgeons, 210 (3), 306-313. 
Ross, D.A., Ariyan, S., Restifo, R. \& Sasaki, C.T., 2003. Use of the operating microscope and loupes for head and neck free microvascular tissue transfer: A retrospective comparison. Archives of Otolaryngology- Head and Neck Surgery, 129 (2), 189.

Saito, S., Miyao, M., Kondo, T., Sakakibara, H. \& Toyoshima, H., 1997. Ergonomic evaluation of working posture of vdt operation using personal computer with flat panel display. Industrial health, 35 (2), 264.

Sánchez-Zuriaga, D., Adams, M.A. \& Dolan, P., 2010. Is activation of the back muscles impaired by creep or muscle fatigue? Spine, 35 (5), 517-525 Available from: http://search.ebscohost.com/login.aspx?direct=true \&db=c8h\&AN=2010591991\&site=ehost-live.

Sari, V., Nieboer, T.E., Vierhout, M.E., Stegeman, D.F. \& Kluivers, K.B., 2010. The operation room as a hostile environment for surgeons: Physical complaints during and after laparoscopy. Minimally Invasive Therapy \& Allied Technologies, 19 (2), 105-109.

Shin, G., D'souza, C. \& Liu, Y.H., 2009. Creep and fatigue development in the low back in static flexion. Spine, 34 (17), 1873-1878.

Sillanpaa, J., Huikko, S., Nyberg, M., Kivi, P., Laippala, P. \& Uitti, J., 2003. Effect of work with visual display units on musculo-skeletal disorders in the office environment. Occupational Medicine, 53 (7), 443.

Sivak-Callcott, J.A., Diaz, S.R., Ducatman, A.M., Rosen, C.L., Nimbarte, A.D. \& Sedgeman, J.A., 2011. A survey study of occupational pain and injury in ophthalmic plastic surgeons. Ophthalmic Plastic \& Reconstructive Surgery, 27 (1), 28.

Smith, C.A., Sommerich, C.M., Mirka, G.A. \& George, M.C., 2002. An investigation of ergonomic interventions in dental hygiene work. Applied Ergonomics, 33 (2), 175-184.

Solomonow, M., Baratta, R.V., Banks, A., Freudenberger, C. \& Zhou, B.H., 2003. Flexion-relaxation response to static lumbar flexion in males and females. Clinical Biomechanics, 18 (4), 273-279.

Sommerich, C.M., Joines, S. \& Psihogios, J.P., 2001. Effects of computer monitor viewing angle and related factors on strain, performance, and preference outcomes. Human Factors: The Journal of the Human Factors and Ergonomics Society, 43 (1), 39.

Stomberg, M.W., Tronstad, S.-E., Hedberg, K., Bengtsson, J., Jonsson, P., Johansen, L. \& Lindvall, B., 2010. Work-related musculoskeletal disorders when performing laparoscopic surgery. Surgical Laparoscopy, Endoscopy \& Percutaneous Techniques, 20 (1), 49-53 Available from: http://search.ebscohost.com/login.aspx?direct=true \&db=cmedm\&AN=20173622\&site=ehost-live.

Straker, L.M., O'sullivan, P.B., Smith, A.J. \& Perry, M.C., 2009. Relationships between prolonged neck/shoulder pain and sitting spinal posture in male and female adolescents. Manual therapy, 14 (3), 321-329.

Szeto, G., Ho, P., Ting, A., Poon, J., Tsang, R. \& Cheng, S., 2010. A study of surgeons' postural muscle activity during open, laparoscopic, and endovascular surgery. Surgical Endoscopy, 24 (7), 17121721.

Szeto, G.P. \& Sham, K.S., 2008a. The effects of angled positions of computer display screen on muscle activities of the neck-shoulder stabilizers. International Journal of Industrial Ergonomics, 38 (1), 917.

Szeto, G.P.Y., Ho, P., Ting, A.C.W., Poon, J.T.C., Cheng, S.W.K. \& Tsang, R.C.C., 2009. Work-related musculoskeletal symptoms in surgeons. Journal of Occupational Rehabilitation, 19 (2), 175-184.

Szeto, G.P.Y. \& Sham, K.S.W., 2008b. The effects of angled positions of computer display screen on muscle activities of the neck-shoulder stabilizers. International Journal of Industrial Ergonomics, 38 (1), 917.

Szeto, G.P.Y., Straker, L. \& Raine, S., 2002. A field comparison of neck and shoulder postures in symptomatic and asymptomatic office workers. Applied Ergonomics, 33 (1), 75-84.

Turville, K., Psihogios, J., Ulmer, T. \& Mirka, G., 1998. The effects of video display terminal height on the operator: A comparison of the 15 and 40 recommendations. Applied Ergonomics, 29 (4), 239-246.

Villanueva, M., Jonai, H., Sotoyama, M., Hisanaga, N., Takeuchi, Y. \& Saito, S., 1997. Sitting posture and neck and shoulder muscle activities at different screen height settings of the visual display terminal. Industrial health, 35 (3), 330-336. 
Wauben, L.S.G.L., Van Veelen, M., Gossot, D. \& Goossens, R.H.M., 2006. Application of ergonomic guidelines during minimally invasive surgery: A questionnaire survey of 284 surgeons. Surgical Endoscopy, 20 (8), 1268-1274.

Yip, C.H.T., Chiu, T.T.W. \& Poon, A.T.K., 2008. The relationship between head posture and severity and disability of patients with neck pain. Manual therapy, 13 (2), 148-154.

Yu, I. \& Wong, T., 1996. Musculoskeletal problems among vdu workers in a hong kong bank. Occupational Medicine, 46 (4), 275-280. 


\section{Appendix A: GRASIS Evaluation Form}

Global Rating Assessment of Skills in Intraocular Surgery (GRASIS)

Global Rating Scale of Operative Performance

Resident

Surgery Date

Circle Procedure: Clear Cornea Extracap Scleral Tunnel Trabeculectomy PPV PKP Other $\square$ Beginning $\square$ Middle $\square$ End of Rotation

\begin{tabular}{|c|c|c|c|c|}
\hline \multicolumn{5}{|l|}{ Preoperative Planning/Knowledge of Patient } \\
\hline 1 & 3 & 4 & 5 & NA \\
\hline $\begin{array}{l}\text { Did not recognize or analyze potential } \\
\text { ocular/non-ocular risk factors of case }\end{array}$ & \multicolumn{2}{|l|}{$\begin{array}{l}\text { Identified risk factors and had partially } \\
\text { complete plan for them }\end{array}$} & \multicolumn{2}{|c|}{$\begin{array}{l}\text { Identified risk factors; planned ahead } \\
\text { appropriately }\end{array}$} \\
\hline \multicolumn{5}{|l|}{ Knowledge of Procedure } \\
\hline 1 & 3 & 4 & 5 & NA \\
\hline Required specific instruction at most steps. & \multicolumn{2}{|l|}{ Demonstrated some forward planning } & \multicolumn{2}{|c|}{ Familiar with all aspects of procedure } \\
\hline \multicolumn{5}{|l|}{ Microscope Use: Centration } \\
\hline 1 & 3 & 4 & 5 & NA \\
\hline $\begin{array}{l}\text { Constantly was asked to re-center and/or } \\
\text { re-focus the microscope or eye }\end{array}$ & & & \multicolumn{2}{|c|}{$\begin{array}{l}\text { Kept the eye centered, maintained good } \\
\text { view with microscope }\end{array}$} \\
\hline \multicolumn{5}{|l|}{ Instrument Handling } \\
\hline 1 & 3 & 4 & 5 & NA \\
\hline $\begin{array}{l}\text { Repeatedly makes tentative, awkward, or } \\
\text { inappropriate movements with instruments }\end{array}$ & $\begin{array}{l}\text { Competent use of instruments but } \\
\text { occasionally stiff or awkward }\end{array}$ & & \multicolumn{2}{|c|}{$\begin{array}{l}\text { Fluid moves with instruments, no } \\
\text { awkwardness }\end{array}$} \\
\hline \multicolumn{5}{|c|}{ Treatment of Ocular Structures and Other Tissues } \\
\hline 1 & 3 & 4 & 5 & NA \\
\hline $\begin{array}{l}\text { Frequently used unnecessary force or } \\
\text { caused damage by inappropriate use of } \\
\text { instruments }\end{array}$ & \multicolumn{2}{|l|}{$\begin{array}{l}\text { Careful handling of tissues but occasionally } \\
\text { caused inadvertent damage }\end{array}$} & \multicolumn{2}{|c|}{$\begin{array}{l}\text { Appropriate handling of tissues and } \\
\text { structures. Produced no damage }\end{array}$} \\
\hline \multicolumn{5}{|l|}{ Flow of Operation: Time and Motion } \\
\hline $1 \quad 2$ & 3 & 4 & 5 & NA \\
\hline $\begin{array}{l}\text { Frequently seemed unsure of surgical plan. } \\
\text { Many unnecessary movements. Entered } \\
\text { and exited eye needlessly }\end{array}$ & \multicolumn{2}{|l|}{$\begin{array}{l}\text { Knew most important steps of the operation. } \\
\text { Efficient time/motion/energy but some } \\
\text { unnecessary movements }\end{array}$} & \multicolumn{2}{|c|}{$\begin{array}{l}\text { Progressed effortlessly. Maximum } \\
\text { efficiency by conserving intraocular motion } \\
\text { and energy }\end{array}$} \\
\hline \multicolumn{5}{|l|}{ Use of Non-dominant Hand } \\
\hline 1 & 3 & 4 & 5 & NA \\
\hline $\begin{array}{l}\text { Does not use non-dominant hand or } \\
\text { performs few, inappropriate movements }\end{array}$ & \multicolumn{2}{|l|}{$\begin{array}{l}\text { Performs few movements with dexterity at } \\
\text { certain steps of procedure }\end{array}$} & \multicolumn{2}{|c|}{$\begin{array}{l}\text { Uses non-dominant hand with dexterity } \\
\text { throughout the procedure }\end{array}$} \\
\hline \multicolumn{5}{|c|}{ Knowledge of Phacoemulsification and Vitrector Equipment and Instruments } \\
\hline 1 & 3 & 4 & 5 & NA \\
\hline $\begin{array}{l}\text { Frequently asked/used wrong instrument; } \\
\text { unaware of proper equipment settings }\end{array}$ & \multicolumn{2}{|l|}{$\begin{array}{l}\text { Knew names of most instruments; used } \\
\text { appropriate settings/tools for task }\end{array}$} & \multicolumn{2}{|c|}{$\begin{array}{l}\text { Obviously familiar with instruments and } \\
\text { equipment }\end{array}$} \\
\hline \multicolumn{5}{|c|}{ Surgical Professionalism: Interaction with Assistants/Scrub Nurse/Surgical Preceptor } \\
\hline 1 & 3 & 4 & 5 & NA \\
\hline $\begin{array}{l}\text { Failed to request or use assistance when } \\
\text { needed }\end{array}$ & \multicolumn{2}{|l|}{$\begin{array}{l}\text { Appropriate use of assistance most of the } \\
\text { time }\end{array}$} & \multicolumn{2}{|c|}{$\begin{array}{l}\text { Strategically used assistant to the best } \\
\text { advantage at all times }\end{array}$} \\
\hline \multicolumn{5}{|c|}{ Handling of Unexpected Operative Events/Adverse Events } \\
\hline 1 & 3 & 4 & 5 & NA \\
\hline $\begin{array}{l}\text { Unable to recognize adverse event or } \\
\text { inappropriate over reaction due to inability } \\
\text { to request proper assistance }\end{array}$ & \multicolumn{2}{|l|}{$\begin{array}{l}\text { Professional and competent identification of } \\
\text { event; appropriate assistance }\end{array}$} & \multicolumn{2}{|c|}{ Superior independent management of event } \\
\hline \multicolumn{5}{|l|}{ Overall Performance } \\
\hline 1 & & 4 & 5 & NA \\
\hline Unable to perform operation independently & \multicolumn{2}{|l|}{$\begin{array}{l}\text { Competent, could perform operation with } \\
\text { minimal assistance }\end{array}$} & $\begin{array}{l}\text { Clearly superior, perf } \\
\text { independently with } c 0\end{array}$ & \\
\hline
\end{tabular}

from Ophthaimology 2005;112(10):1655-1880)

We have reviewed this assessment together. 


\section{Appendix B: Consent and Information Form

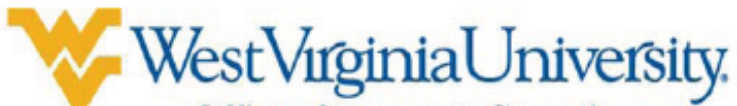 \\ Office of Research Compliance}

\section{CONSENT AND INFORMATION FORM}

Biomechanical evaluation of loupes using simulated surgeries

Principal Investigator: Nimbarte, Ashish

Department:

ENGINEERING - Ind./Mgt. Sys. Engineering

Tracking Number:

$\mathrm{H}-23641$

\section{Study Title:}

Biomechanical evaluation of loupes using simulated surgeries

Co-Investigator(s):

Sivak-Callcott, Jennifer, Chapman, Marsha,

\section{Sponsor}

NA

\section{Contact Persons}

In the event you experience any side effects or injury related to this research, you should contact Dr. Ashish Nimbarte at 304/293-9473. (After hours contact Dr. Ashish Nimbarte at 304/212-4653.)

If you have any questions, concerns, or complaints about this research, you can contact Dr. Ashish Nimbarte or Dr. Jennifer Sivak-Callcott at 304/598-6950

For information regarding your rights as a research subject, you may contact the Office of Research Compliance at 304/293-7073.

\section{Introduction}

In addition if you would like to discuss problems, concerns, have suggestions related to research, or would like to offer input about the research, contact the Office of Research Integrity and Compliance at 304293-7073.

$\begin{array}{lll}\text { Tracking \#: } & \text { H-23641 } & \text { Page } 1 \text { of } 5 \\ \text { Approved On: } & 10 / 17 / 2013 & \\ \text { Valid Through: } & 10 / 16 / 2014 & \\ \text { Last Amended: } & \text { N/A } & \end{array}$

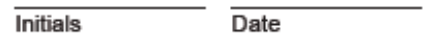


You, have been asked to participate in this research study, which has been explained to you by Dr. Ashish Nimbarte,Ph.D., or Dr. Jennifer Sivak-Callcott, MD, or Marsha Chapman, B.S. This research is being conducted to fulfill the requirements for a Master's thesis of Marsha Chapman in the field of Ergonomics in the Department of Industrial and Management Systems Engineering at West Virginia University, under the supervision of Drs. Ashish Nimbarte and Jennifer Sivak-Callcott.

\section{Purposes of the Study}

The purpose of this study is to understnad the effect of surgical loupes on the behaviour of head position and the activity of neck and shoulder muscles. You will perform tasks similar to actual surgeries in the lab setting. Your head position and muscle activity data will be recorded during these tasks. This data will be used to calculate the forces acting on the cervical spine. WVU expects to enroll approximately 30 subjects.

\section{Description of Procedures}

The data collection session for each participant will consist of two sessions: (1) Training session: Before the actual data collection session you will be required to attend a training session on how to perform surgical tasks. During this session, you will be shown the experimental set up and research objectives, apparatus, and the data collection procedure will be explained to you. If you agree to participate you will need to give informed consent. Any questions that you may have about this study will be answered. If you decide to participate then you will be asked to sign the consent form.(2) Data collection session:(i) On the day of data collection, as a first step, you will change into a set of test clothes and a set of your anthropometric measurements will be taken. This involves using a caliper to meausure lengths of body segments, like the distance between your shoulder and elbow.(ii) Twenty-two reflective markers will be attached like a band-aid on your body at fixed anatomical locations. The position of these markers is recorded by the Vicon motion analysis system using of eight optical cameras. Based on the locations of the markers, real time position of the head with respect to the shoulder is calculated.(iii) Your skin will be prepared for muscle activity data collection using electromyography

\begin{tabular}{lllll}
\hline Tracking \#: & $\mathrm{H}-23641$ & Page 2 of 5 & \\
Approved On: & $10 / 17 / 2013$ & & Date \\
Valid Through: & $10 / 16 / 2014$ & & \\
Last Amended: & N/A & &
\end{tabular}


(EMG). In EMG sensors are placed on the muscles of interest and electrical activity is recorded using a computer. There is no pain. Skin preparation involves shaving the skin over the anatomical landmarks (if needed) using disposable razor and cleaning it with $70 \%$ alcohol prior to the placement of the EMG electrodes.(iv) Prior to the initiation of testing you will stand in a $T$ -pose to be captured by Vicon motion analysis system as a calibration trial. (v) Subsequently you will perform the simulated surgeries under the different conditions of loupe designs and task demands. Duration of each task is approximately $10-15$ minutes. The total duration of data collection will be approximately 2 hours. (vi) Once all tests are completed, you will be free to change back to your clothes and leave. You will be given a copy of consent form for your record.

\section{Risks and Discomforts}

There are no known or expected risks from participating in this study. You may experience some level of discomfort in the neck and shoulder region while performing simulated surgeries using different types of surgical loupes. There is the possibility that you may cut yourself with a needle while perfomring the simulated surgical tasks.

\section{Alternatives}

You do not have to participate in this study.

There are no other alternatives. The partipant can withdraw their particpation at any time.

\section{Benefits}

You may not receive any direct benefit from this study. The knowledge gained from this study may eventually benefit others.

\section{Financial Considerations}

Subjects will recieve $\$ 10 /$ hour for participation in the study and will not incur any costs related to the study. Participation is expected to take 2 hours and the payment for participating will be given at the completion of the study. It is very important for you to understand that neither the investigator nor WVU or its associated affiliates has the funds set aside to

\begin{tabular}{llll}
\hline Tracking \#: & H-23641 & Page 3 of 5 & \\
Approved On: & $10 / 17 / 2013$ & & Initials \\
Valid Through: & 10/16/2014 & & \\
Last Amended: & N/A & & \\
\cline { 2 - 4 }
\end{tabular}


Tracking \#: $\quad \mathrm{H}-23641$

pay for the cost of lost work wages or any care or treatment that might be necessary because you get hurt or sick taking part in thisstudy. Any injuries that may result from this study would not be eligible for Workers ' Compensation as this is not a job related injury. Understand that any treatments necessary will be billed to the participant or to your personal health insurance, and you may wish to consult your insurance provider before participating in this study.

\section{Confidentiality}

Any information about you that is obtained as a result of your participation in this research will be kept as confidential as legally possible. Your research records and test results, just like hospital records, may be subpoenaed by court order or may be inspected by federal regulatory authorities without your additional consent.In any publications that result from this research, neither your namenor any information from which you might be identified will be published without your consent.

\section{Voluntary Participation}

Participation in this study is voluntary. You are free to withdraw your consent to participate in this study at any time. Refusal to participateor withdrawal will not affect your employee status at West Virginia University or, for students, your class standing or grades and willinvolve no penalty to you. In the event new information becomes available that may affect your willingness to participate in this study, this information will be given to you so that you can make an informed decision about whether or not to continue your participation. You havebeen given the opportunity to ask questions about the research, and you have received answers concerning areas you did not understand.

\begin{tabular}{lllll}
\hline Tracking \#: & $\mathrm{H}-23641$ & Page 4 of 5 & \\
Approved On: & $10 / 17 / 2013$ & & Initials & \\
Valid Through: & $10 / 16 / 2014$ & & \\
Last Amended: & N/A & &
\end{tabular}


Upon signing this form, you will receive a copy.

I willingly consent to participate in this research.

Signature of Subject or

Subjects Legal Representative

The participant has had the opportunity to have questions addressed. The participant willingly agrees to be in the study.

\begin{tabular}{lll}
\hline Tracking \#: & $\mathrm{H}-23641$ & Page 5 of 5 \\
Approved On: & $10 / 17 / 2013$ & \\
Valid Through: & $10 / 16 / 2014$ & \\
Last Amended: & N/A &
\end{tabular}

$\overline{\text { Initials }} \overline{\text { Date }}$

Last Amended: N/A 
Appendix C: Participant anthropometric and characteristic data

\begin{tabular}{|c|c|c|c|c|c|c|c|c|c|c|c|c|}
\hline & Gender & $\begin{array}{c}\text { age } \\
\text { (yrs.) }\end{array}$ & $\begin{array}{l}\text { height } \\
\text { (cm) }\end{array}$ & $\begin{array}{c}\text { weight } \\
\text { (kg) }\end{array}$ & $\begin{array}{c}\text { shoulder } \\
\text { width } \\
(\mathrm{cm})\end{array}$ & $\begin{array}{c}\text { trunk } \\
\text { length } \\
(\mathrm{cm})\end{array}$ & $\begin{array}{l}\text { head } \\
\text { circ } \\
(\mathrm{cm})\end{array}$ & $\begin{array}{l}\text { head } \\
\text { width } \\
(\mathrm{cm})\end{array}$ & $\begin{array}{c}\text { head } \\
\text { depth } \\
(\mathrm{cm})\end{array}$ & $\begin{array}{l}\text { head } \\
\text { height } \\
(\mathrm{cm})\end{array}$ & $\begin{array}{l}\mathrm{c} 7 \text { top } \\
\text { of head } \\
(\mathrm{cm})\end{array}$ & $\begin{array}{c}\text { Trans- } \\
\text { distance } \\
\text { head trunk } \\
(\mathrm{cm})\end{array}$ \\
\hline 1 & $\mathrm{~F}$ & 20 & 164 & 42 & 33 & 43 & 52 & 15 & 19 & 21 & 26 & 38.139 \\
\hline 2 & $\mathrm{~F}$ & 19 & 166 & 61 & 32 & 34 & 55 & 14 & 18 & 18 & 25 & 34.754 \\
\hline 3 & $\mathrm{~F}$ & 21 & 160 & 66 & 39 & 46 & 56 & 16 & 18 & 20 & 25 & 39.051 \\
\hline 4 & $\mathrm{~F}$ & 19 & 158 & 43 & 33 & 43 & 51 & 14 & 18 & 19 & 25 & 37.836 \\
\hline 5 & $\mathrm{~F}$ & 33 & 165 & 92 & 37 & 46 & 55 & 15 & 18 & 20 & 27 & 40.812 \\
\hline 6 & $\mathrm{~F}$ & 25 & 169 & 87 & 37 & 45 & 55 & 14 & 19 & 21 & 24 & 37.232 \\
\hline 7 & $M$ & 24 & 165 & 66 & 39 & 37 & 54 & 15 & 20 & 21 & 26 & 35.384 \\
\hline 8 & $M$ & 20 & 175 & 64 & 45 & 53 & 57 & 16 & 19 & 22 & 26 & 42.817 \\
\hline 9 & $\mathrm{M}$ & 24 & 166 & 82 & 39 & 42 & 56 & 15 & 20 & 20 & 27 & 38.747 \\
\hline 10 & $\mathrm{M}$ & 32 & 166 & 59 & 35 & 45 & 54 & 15 & 18 & 19 & 25 & 39.538 \\
\hline 11 & $M$ & 19 & 177 & 69 & 41 & 47 & 56 & 15 & 21 & 21 & 27 & 40.872 \\
\hline 12 & $\mathrm{M}$ & 19 & 181 & 68 & 39 & 49 & 56 & 14 & 19 & 20 & 23 & 38.381 \\
\hline \multirow{2}{*}{\multicolumn{2}{|c|}{$\begin{array}{r}\text { Male avg } \\
\text { St dev. }\end{array}$}} & 23.0 & 171.7 & 67.9 & 39.5 & 45.3 & 55.4 & 13.3 & 19.3 & 20.5 & 25.7 & 39.3 \\
\hline & & 5.0 & 6.9 & 7.6 & 3.3 & 5.7 & 1.2 & 4.3 & 1.0 & 1.1 & 1.4 & 2.5 \\
\hline \multirow{2}{*}{\multicolumn{2}{|c|}{$\begin{array}{l}\text { Female } \\
\text { St dev. }\end{array}$}} & 22.8 & 163.5 & 65.1 & 35.0 & 42.8 & 54.0 & 14.6 & 18.4 & 19.7 & 25.3 & 38.0 \\
\hline & & 5.5 & 4.0 & 21.2 & 2.7 & 4.3 & 2.2 & 0.8 & 0.4 & 1.4 & 1.1 & 2.0 \\
\hline \multirow{2}{*}{\multicolumn{2}{|c|}{$\begin{array}{r}\text { Combined } \\
\text { St dev. }\end{array}$}} & 22.9 & 167.6 & 66.5 & 37.3 & 44.1 & 54.7 & 13.9 & 18.8 & 20.1 & 25.5 & 38.6 \\
\hline & & 5.0 & 6.8 & 15.3 & 3.7 & 5.0 & 1.8 & 3.1 & 0.9 & 1.3 & 1.2 & 2.3 \\
\hline
\end{tabular}




\section{Appendix D: Discomfort Level Survey}

Discomfort Level Survey

\begin{tabular}{|l|l|l|}
\hline Name: & \multicolumn{2}{|l|}{} \\
\hline Date: & Loupe Angle: & Trial \#: \\
\hline
\end{tabular}

For each item identified below, circle the number to the right that best fits your judgment.

\begin{tabular}{|c|c|c|c|c|c|c|}
\hline \multirow{3}{*}{$\begin{array}{l}\text { Description/Identification of Survey Item } \\
\text { Discomfort in lower back }\end{array}$} & \multicolumn{6}{|c|}{ Scale } \\
\hline & $\begin{array}{l}\mathrm{L} \\
\mathrm{o}\end{array}$ & \multicolumn{4}{|c|}{$\begin{array}{l}\text { Discomfort } \\
\text { Level }\end{array}$} & $\begin{array}{l}\mathrm{H} \\
\mathrm{i} \\
\mathrm{g}\end{array}$ \\
\hline & 1 & 2 & 3 & 4 & 5 & 6 \\
\hline Discomfort in right shoulder & 1 & 2 & 3 & 4 & 5 & 6 \\
\hline Discomfort in left shoulder & 1 & 2 & 3 & 4 & 5 & 6 \\
\hline Discomfort at the base of neck, near shoulders & 1 & 2 & 3 & 4 & 5 & 6 \\
\hline Discomfort at top of neck, near skull & 1 & 2 & 3 & 4 & 5 & 6 \\
\hline Discomfort in vision & 1 & 2 & 3 & 4 & 5 & 6 \\
\hline
\end{tabular}




\section{Appendix E: Normality and Data Transformation}

\section{E.1 Rotational joint angle}
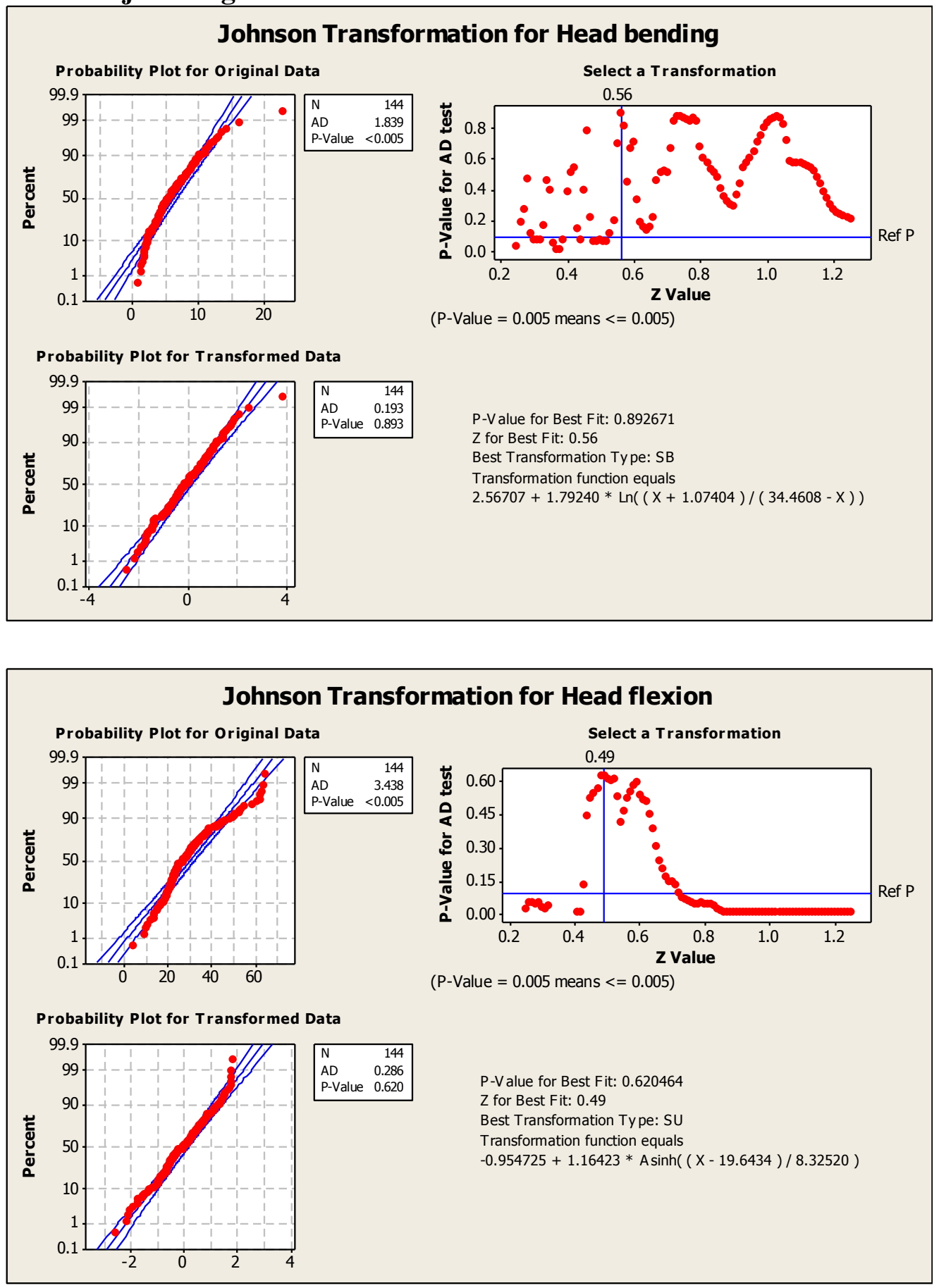

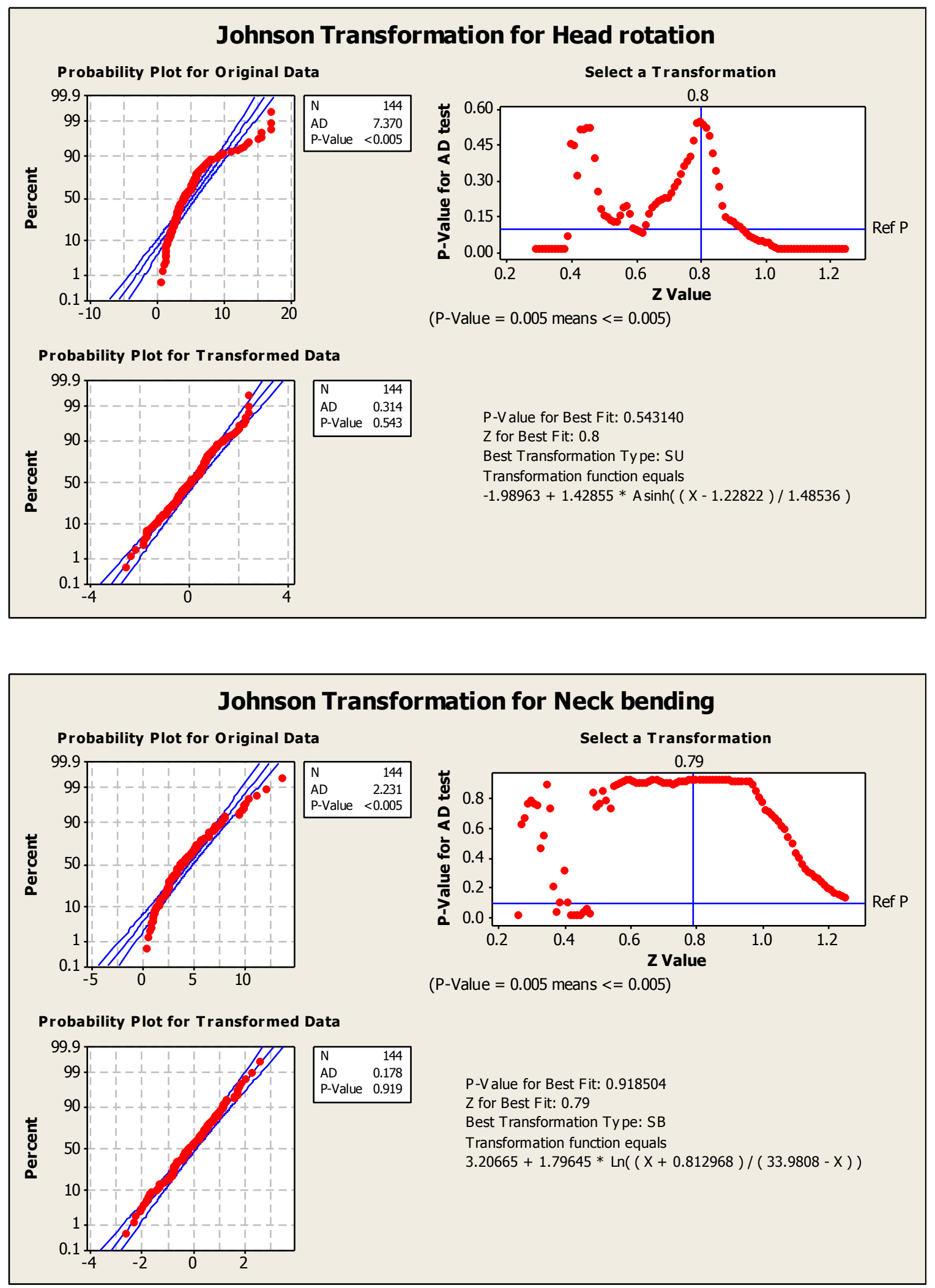

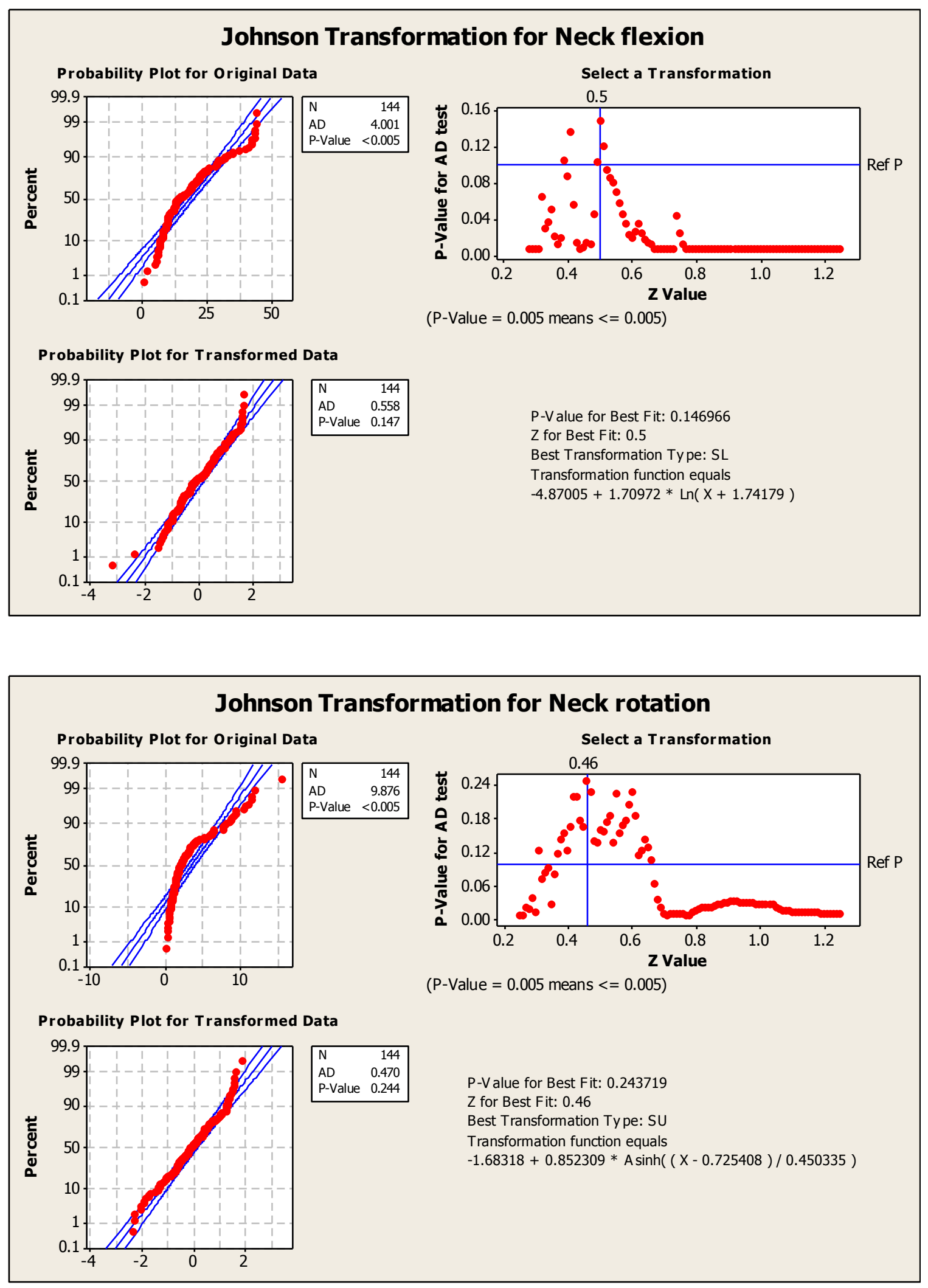


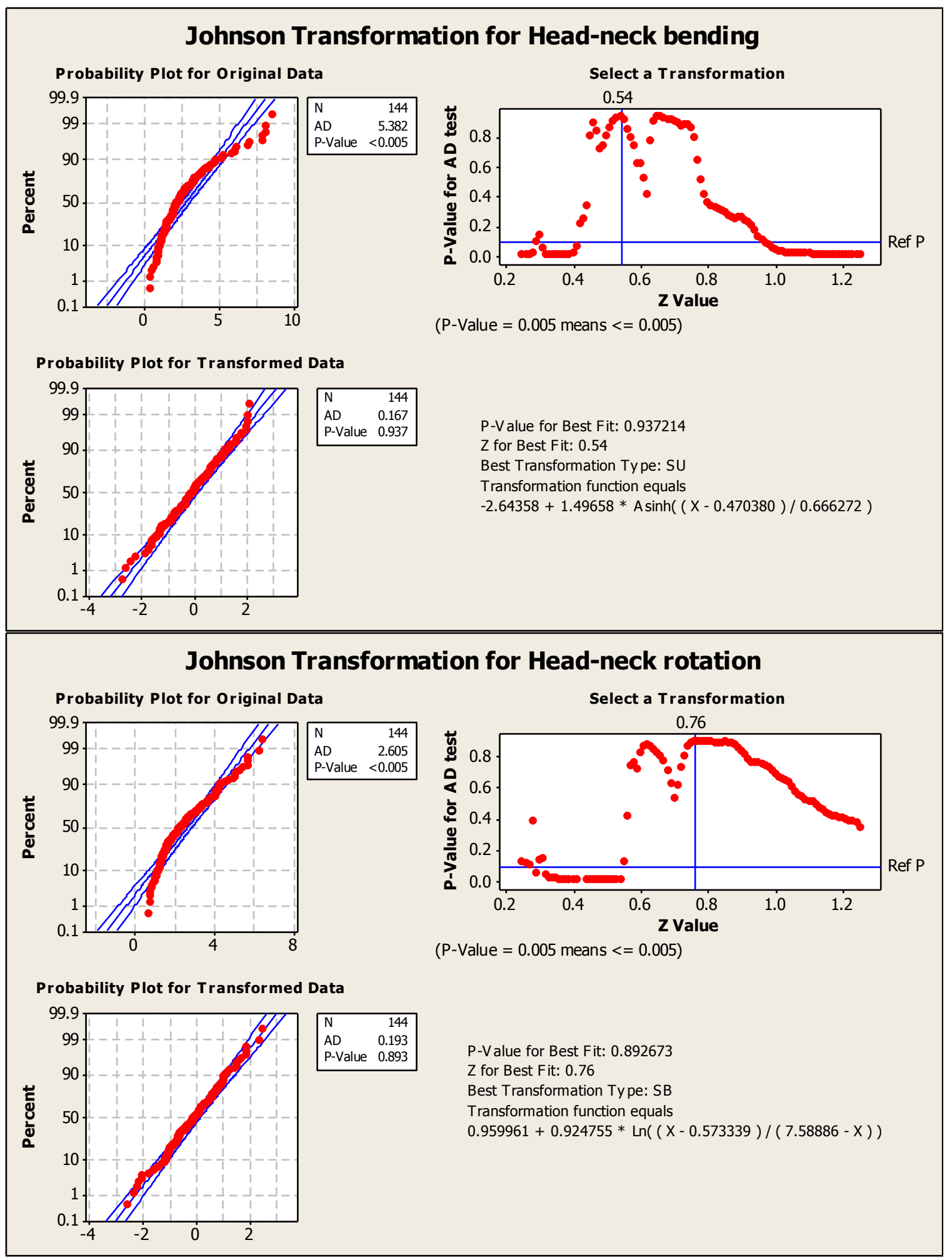




\section{E.2 Segmental translation}

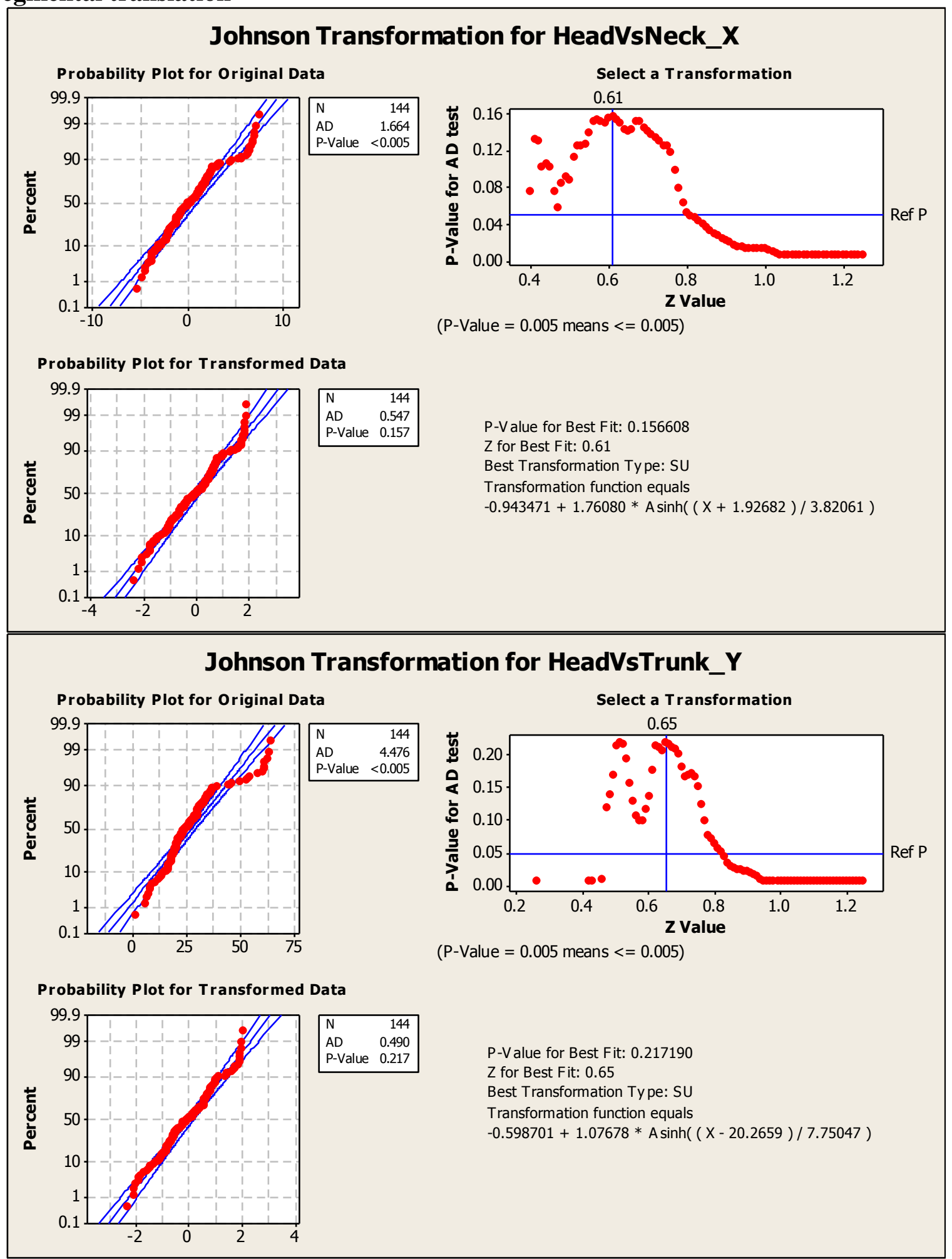




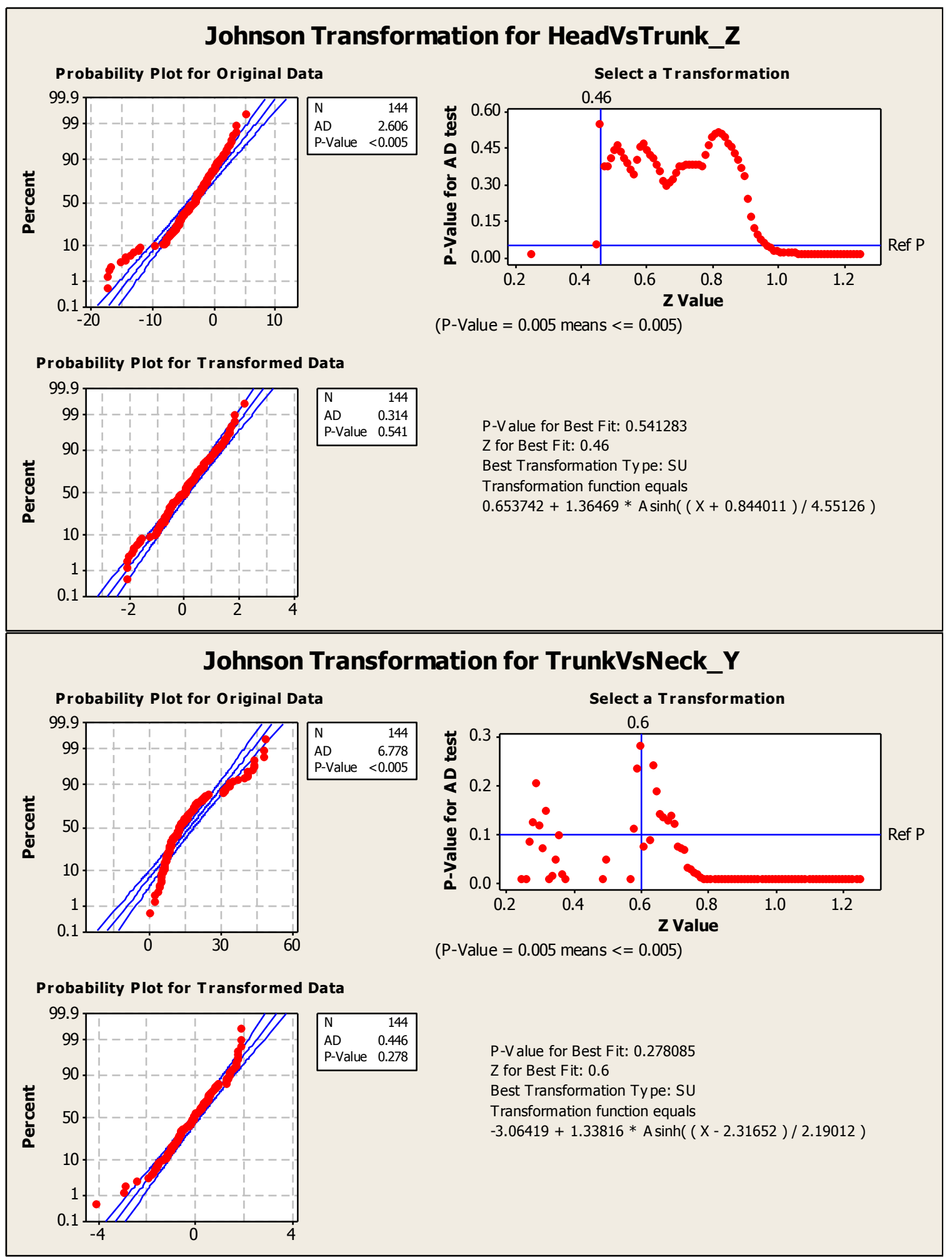




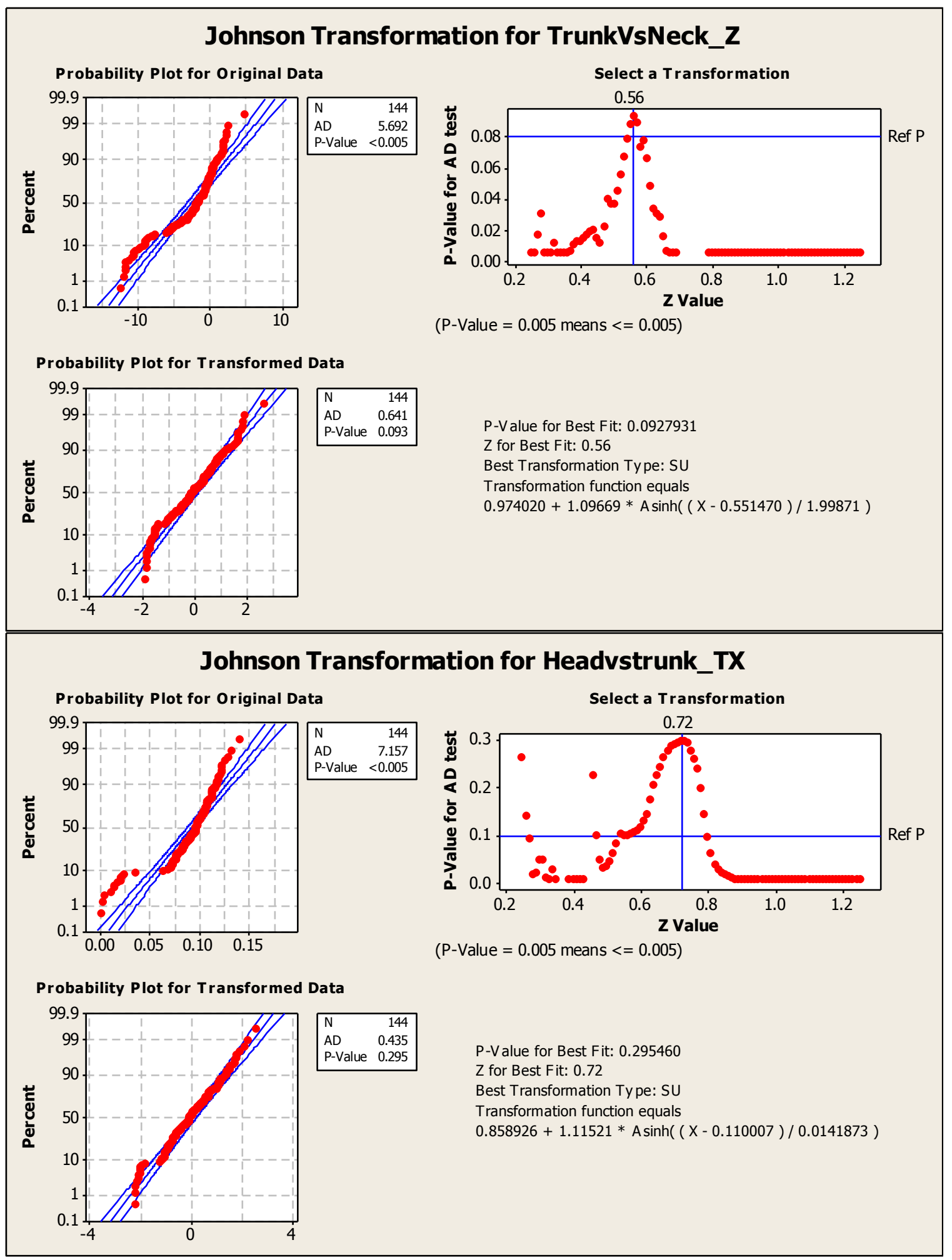




\section{E.3 Muscle activity}
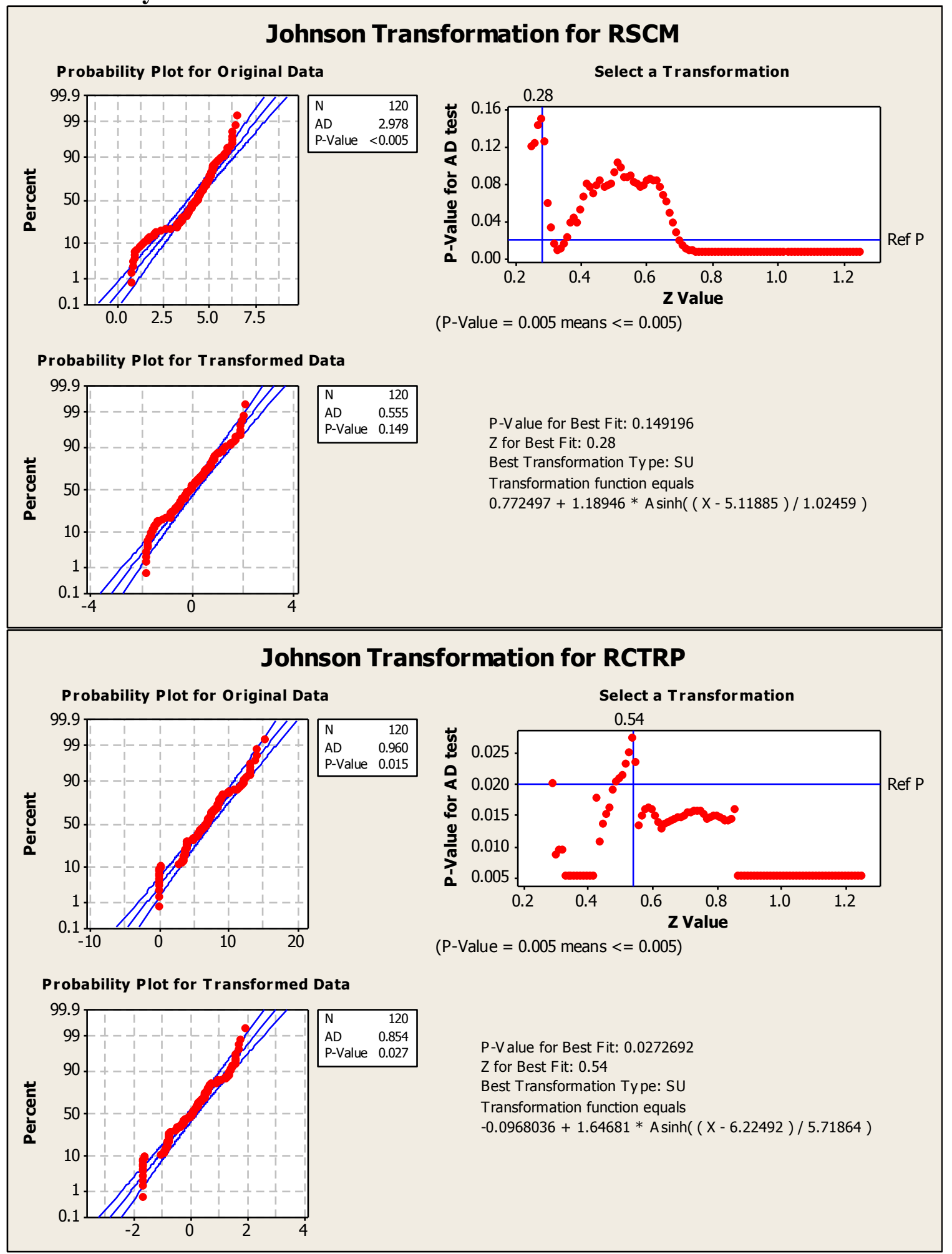


\section{Appendix F: Equality of Variance Tests}

\section{F.1 Rotational joint angle}

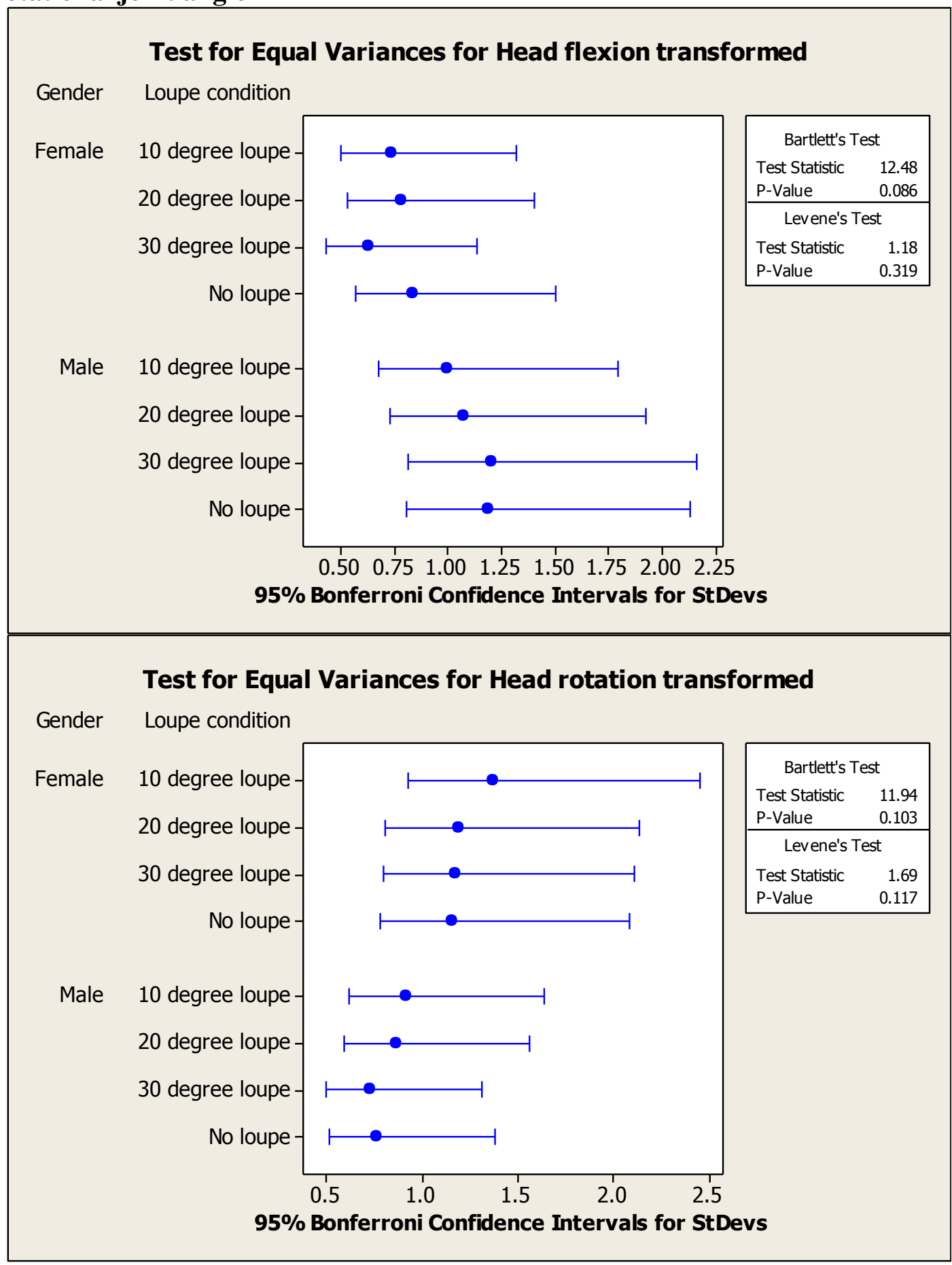




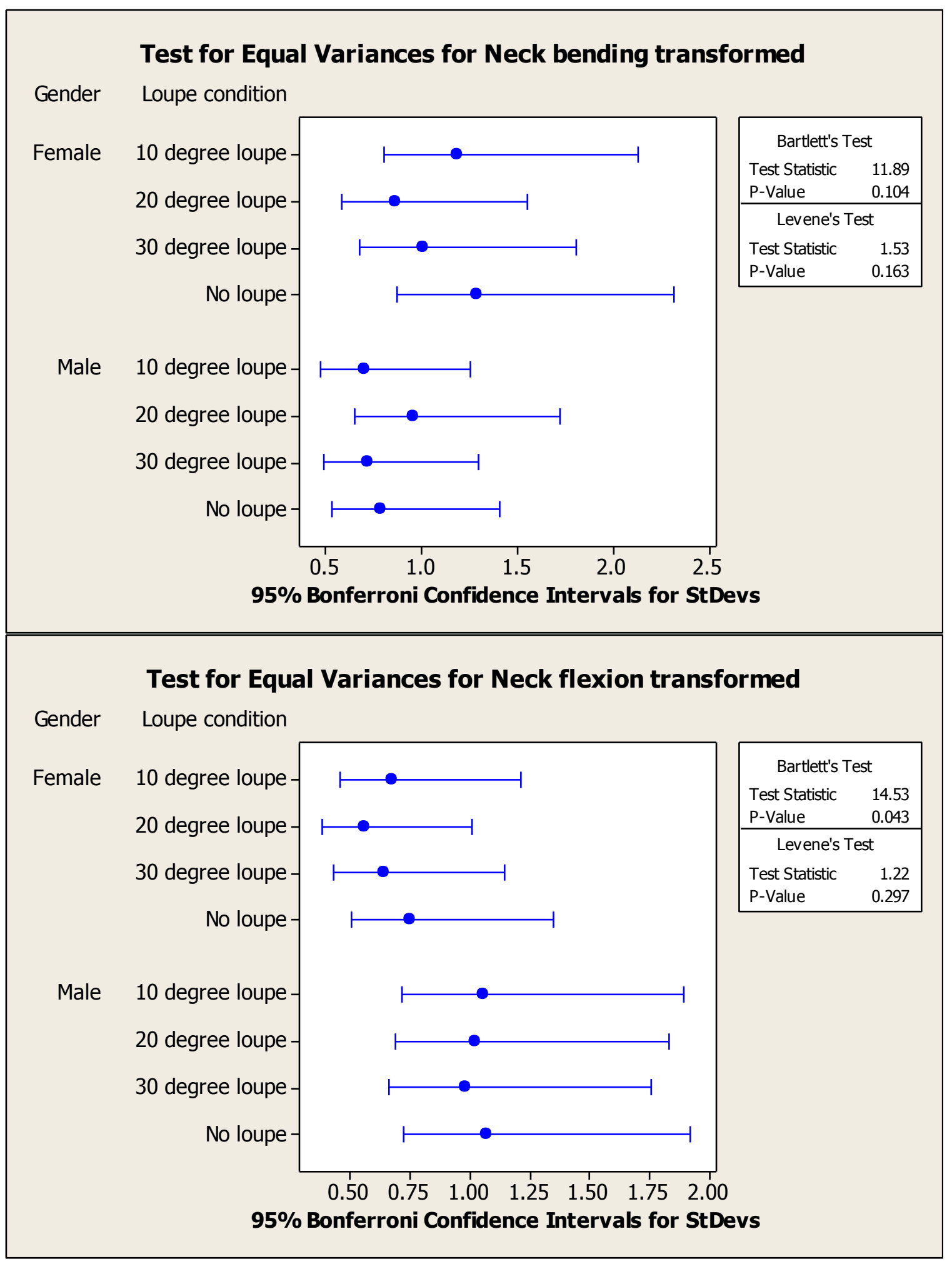




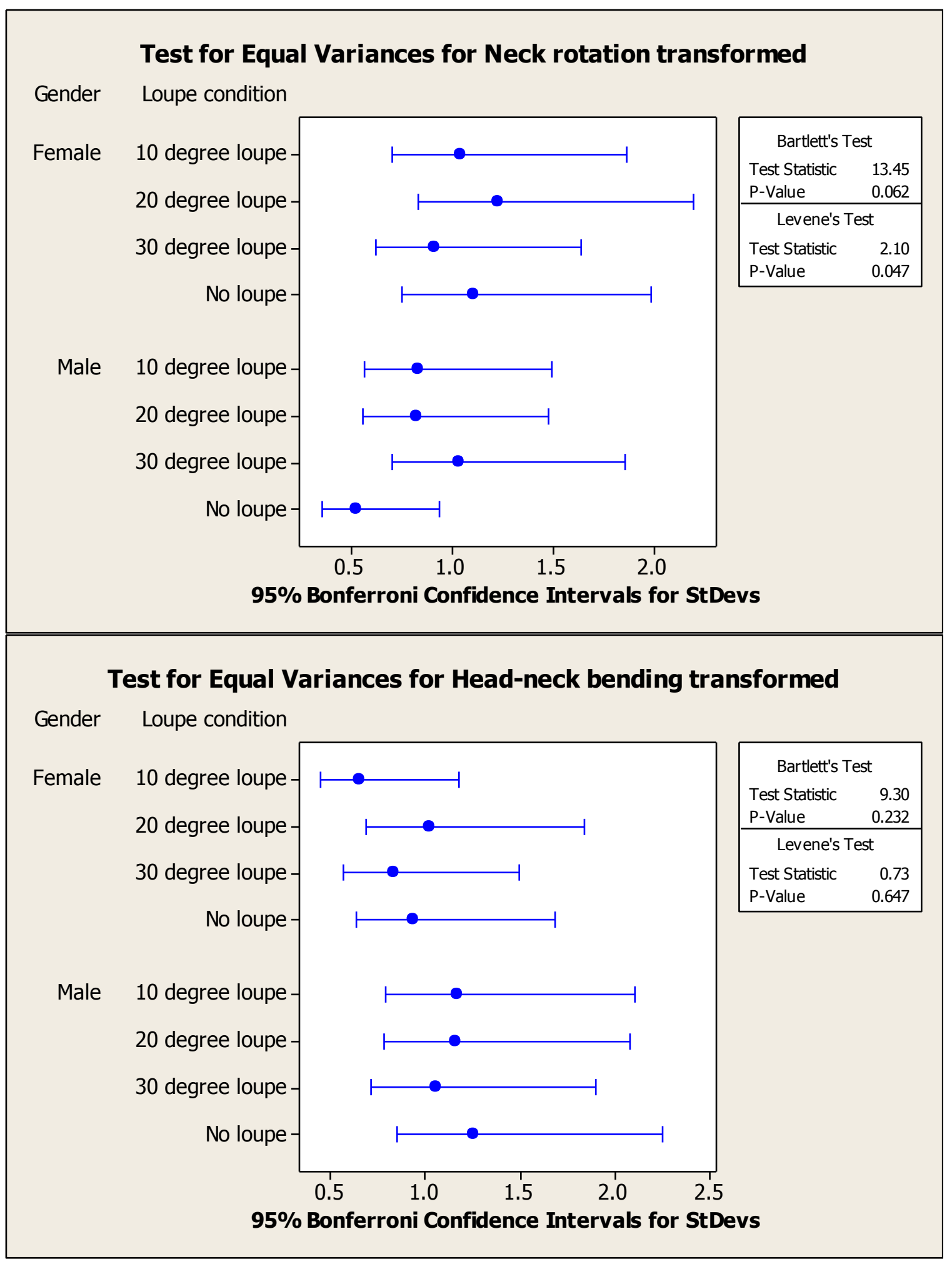




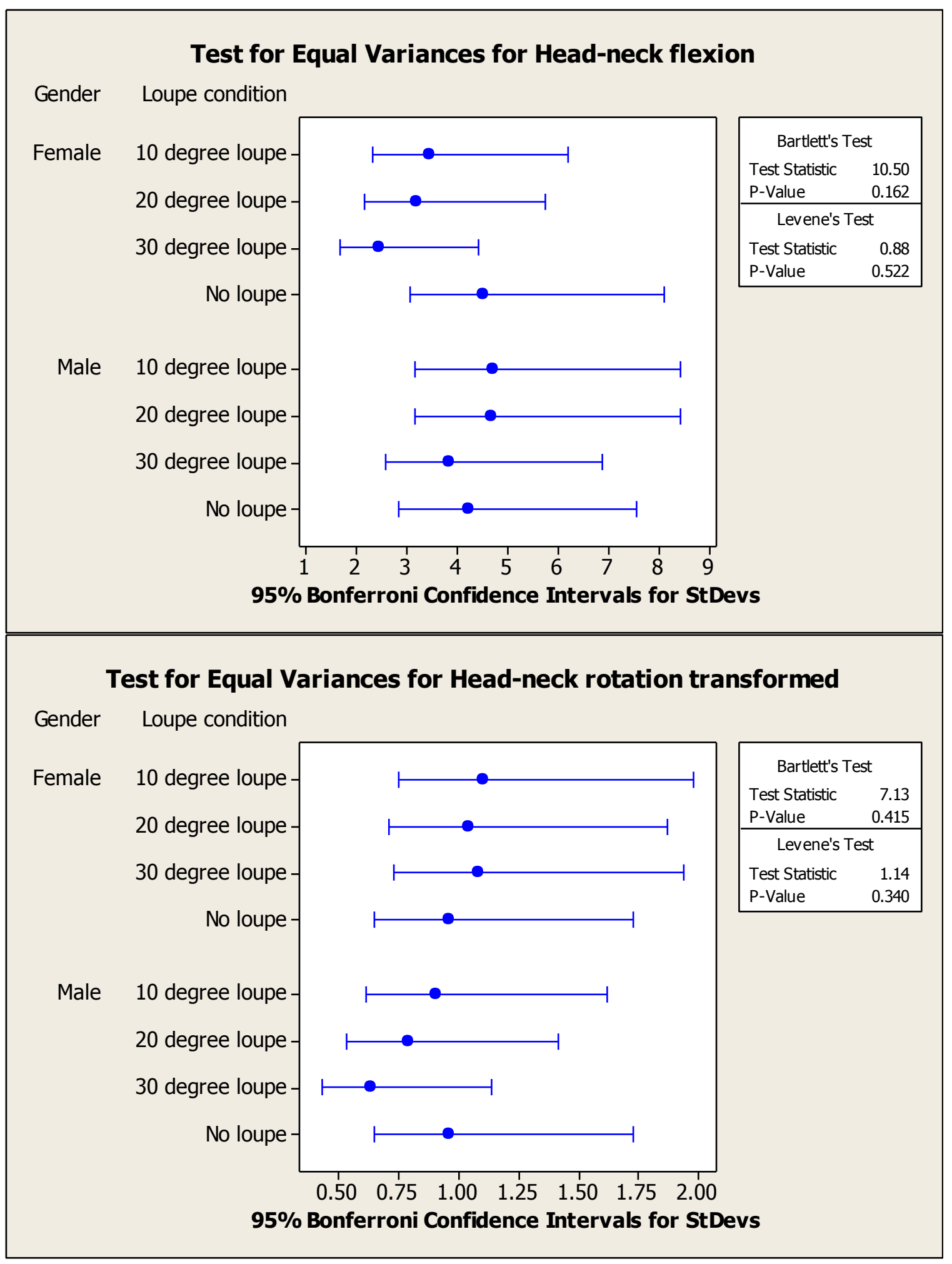


F.2 Segmental translation

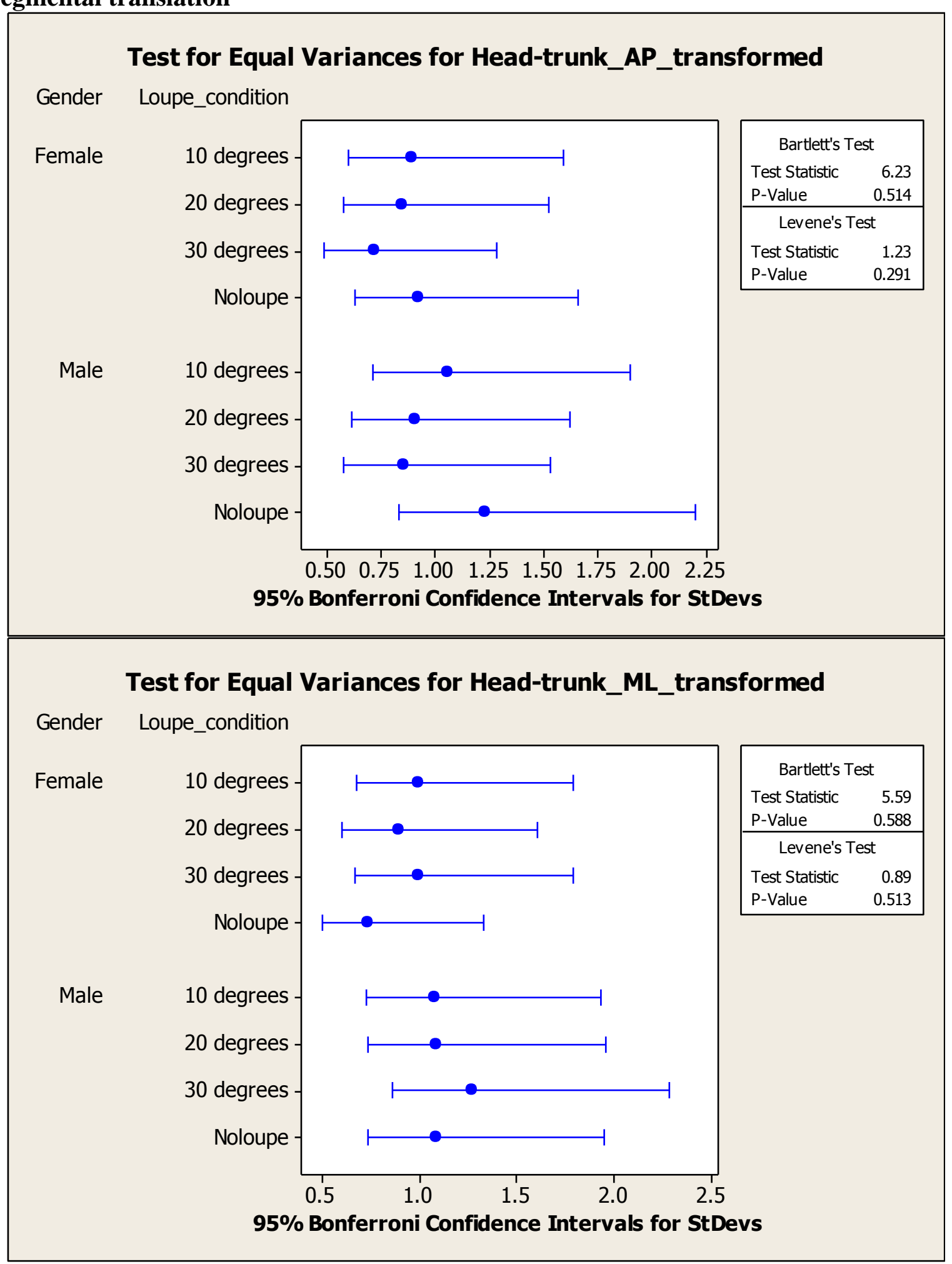




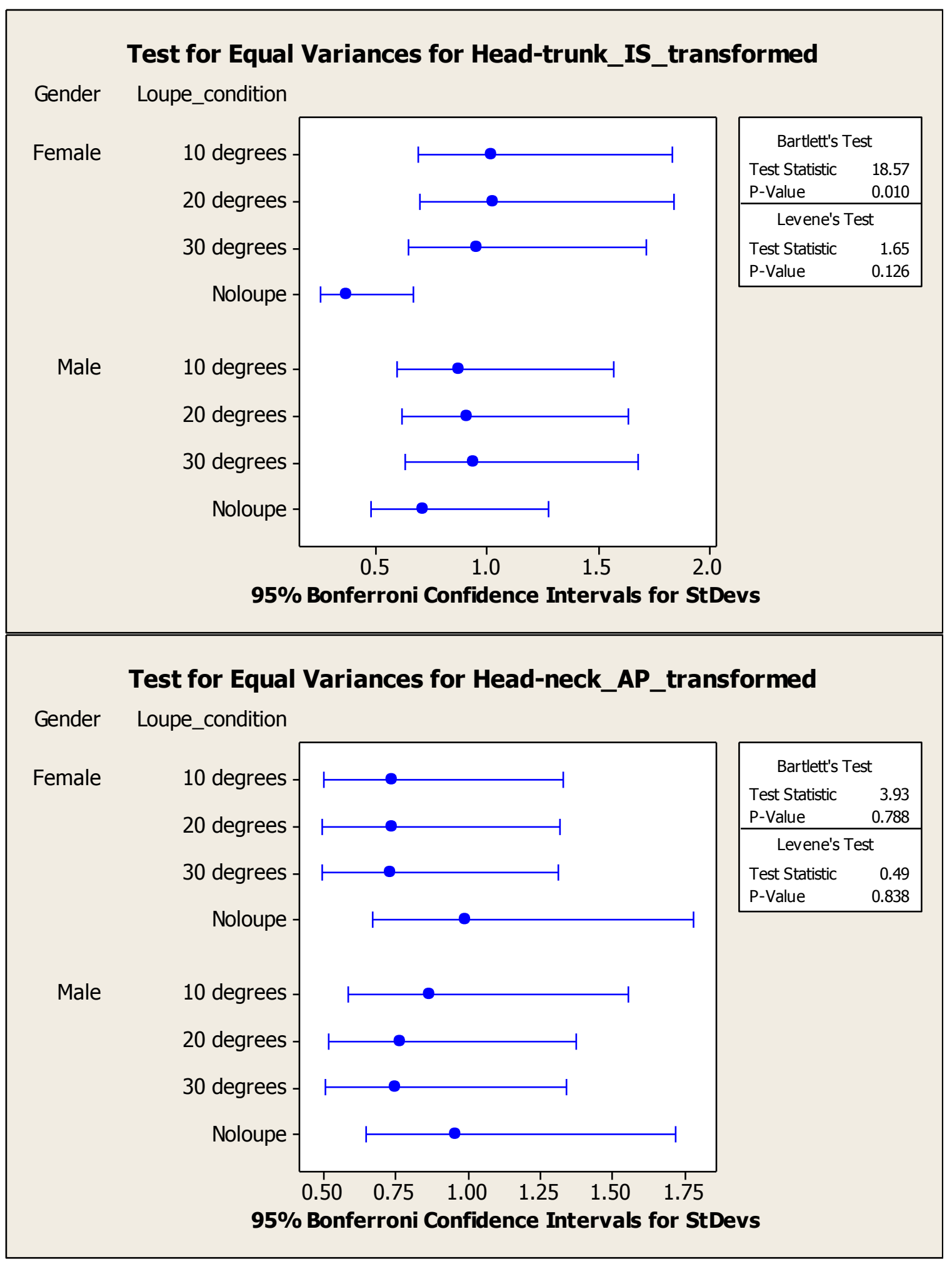




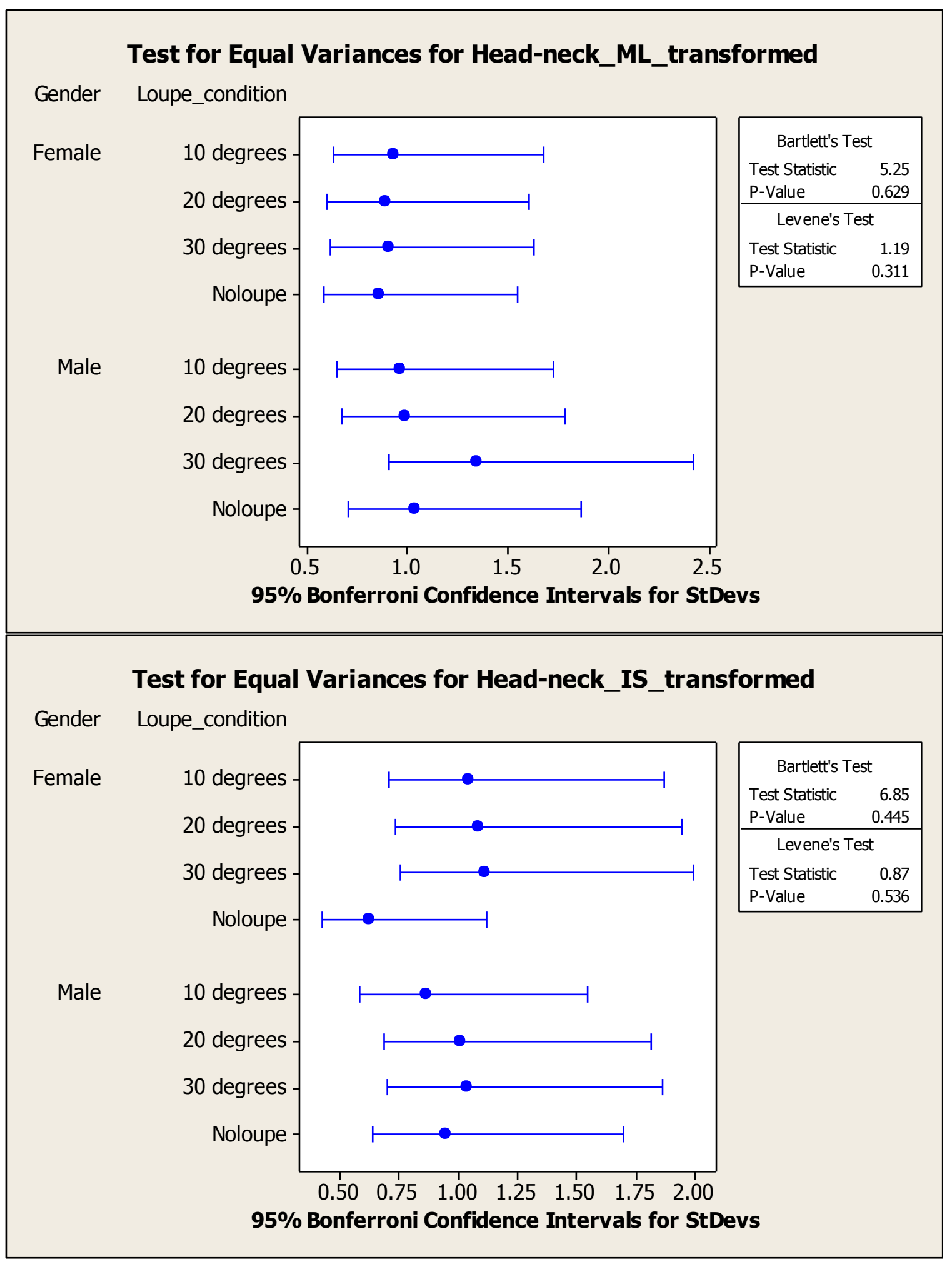


F.3 Muscle activity

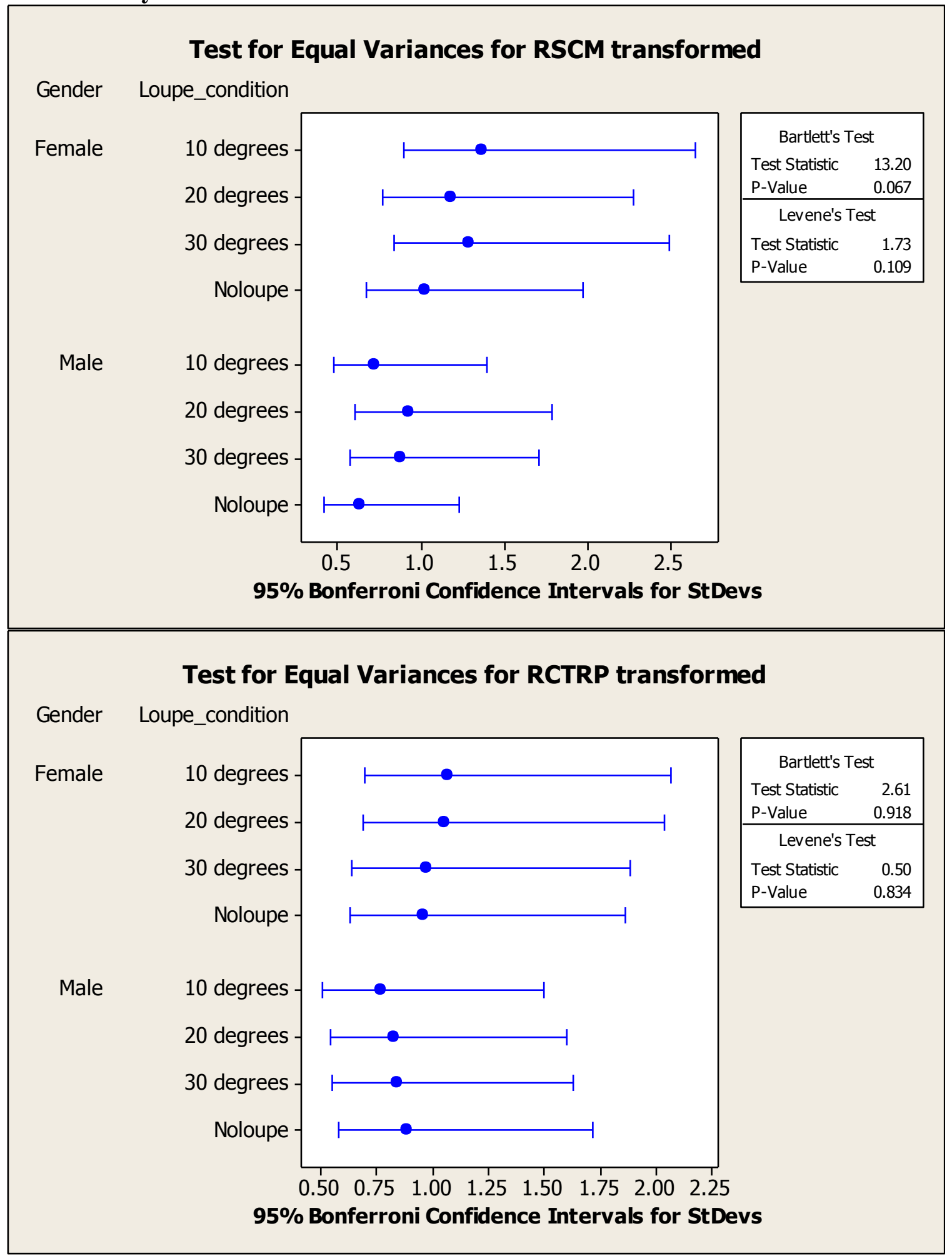


Test for Equal Variances for LSCM

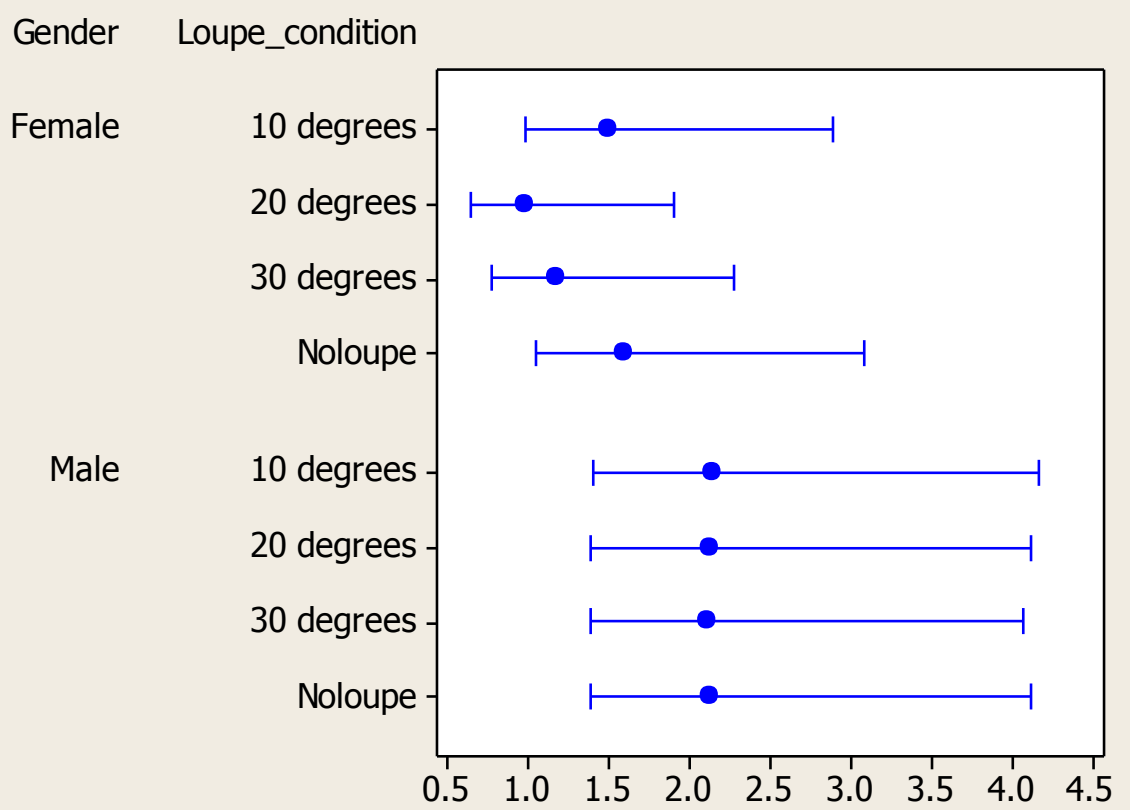

Bartlett's Test

Test Statistic $\quad 15.43$

P-Value $\quad 0.031$

Levene's Test

Test Statistic

1.77

P-Value

$\mathbf{9 5 \%}$ Bonferroni Confidence Intervals for StDevs

\section{Test for Equal Variances for LCTRP}

Gender Loupe_condition

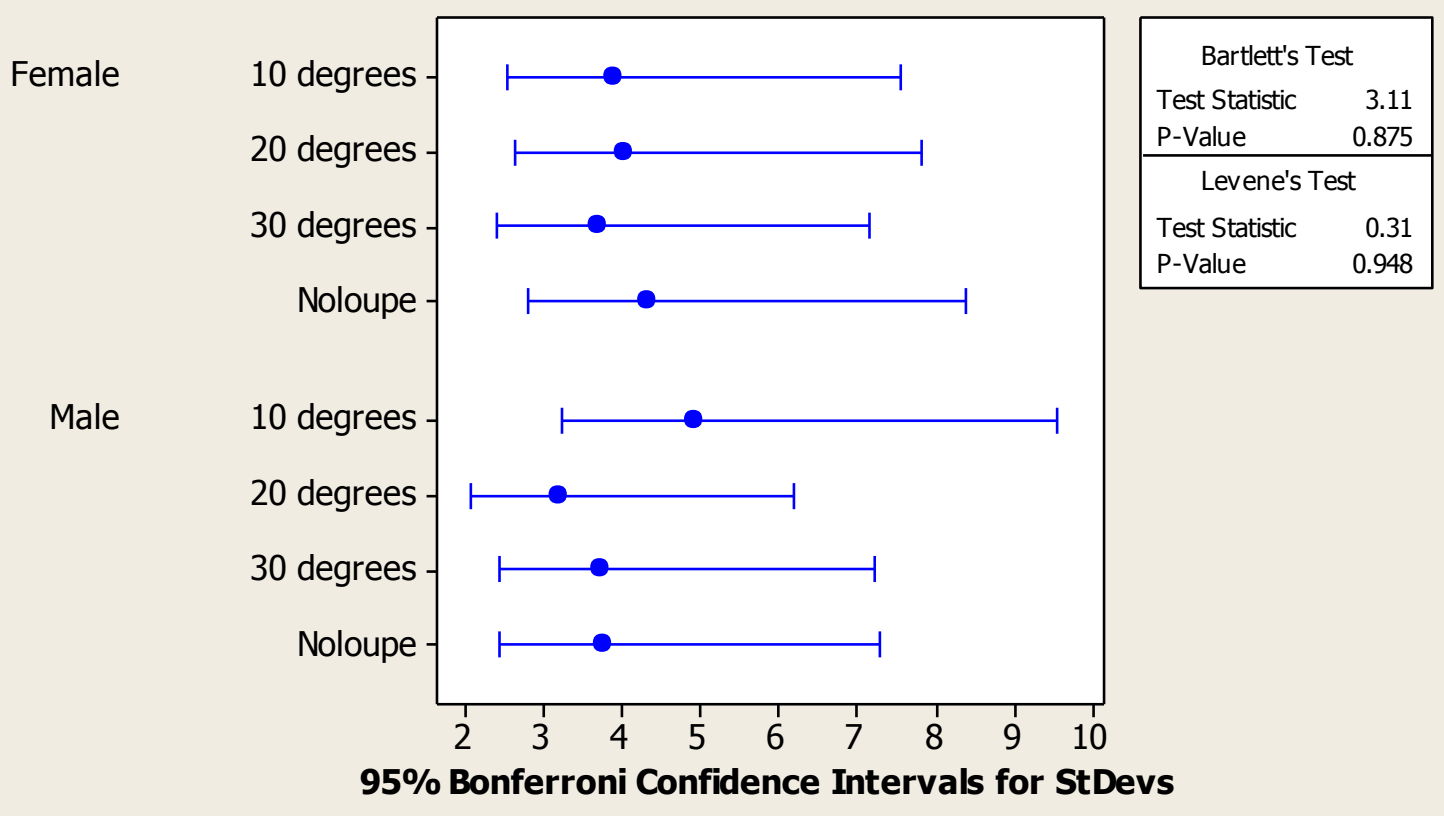




\section{Appendix G: ANOVA Table}

\section{G.1 Rotational joint angle}

General Linear Model: Head bending, Head flexion, ... versus Subject, Gender, .

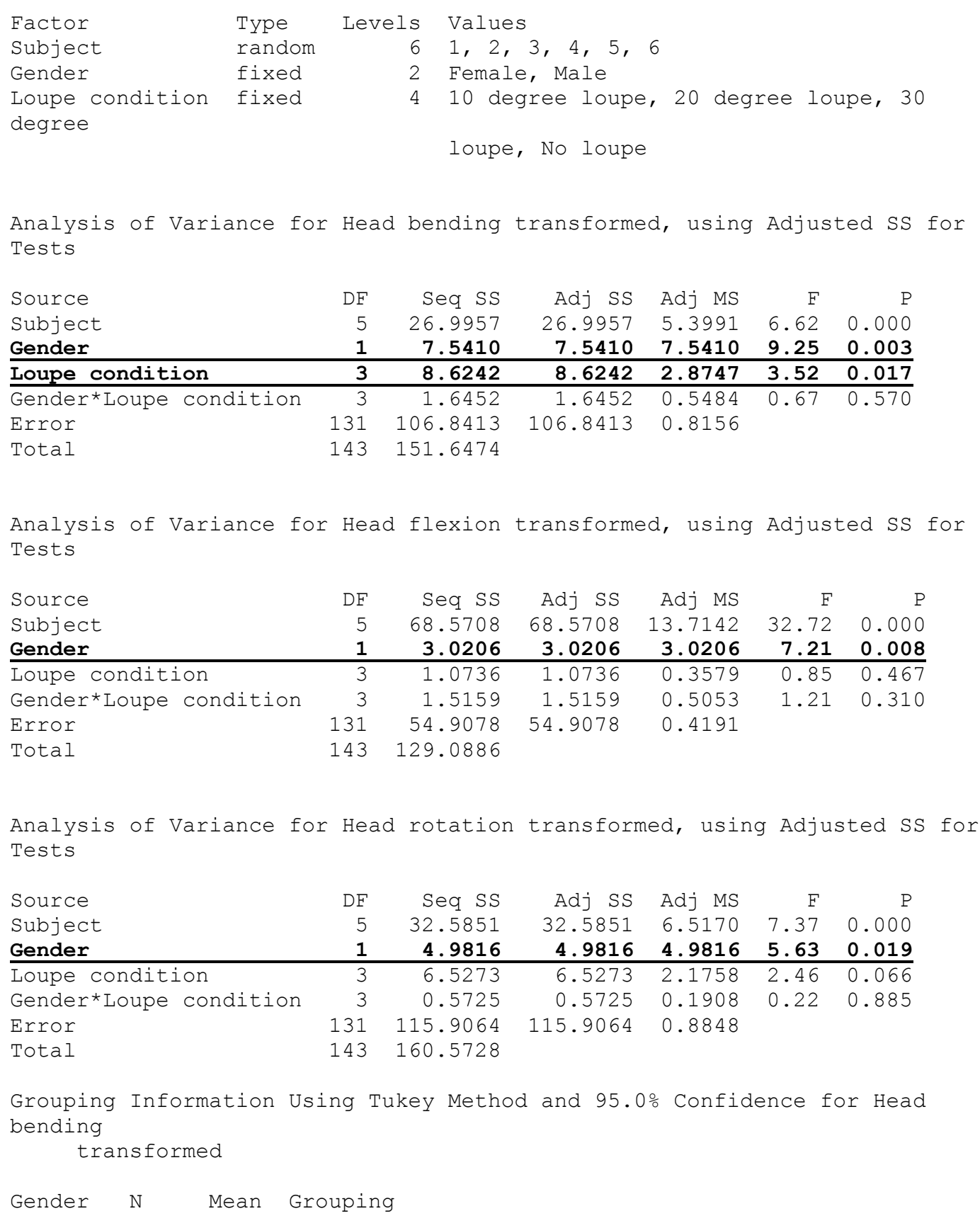




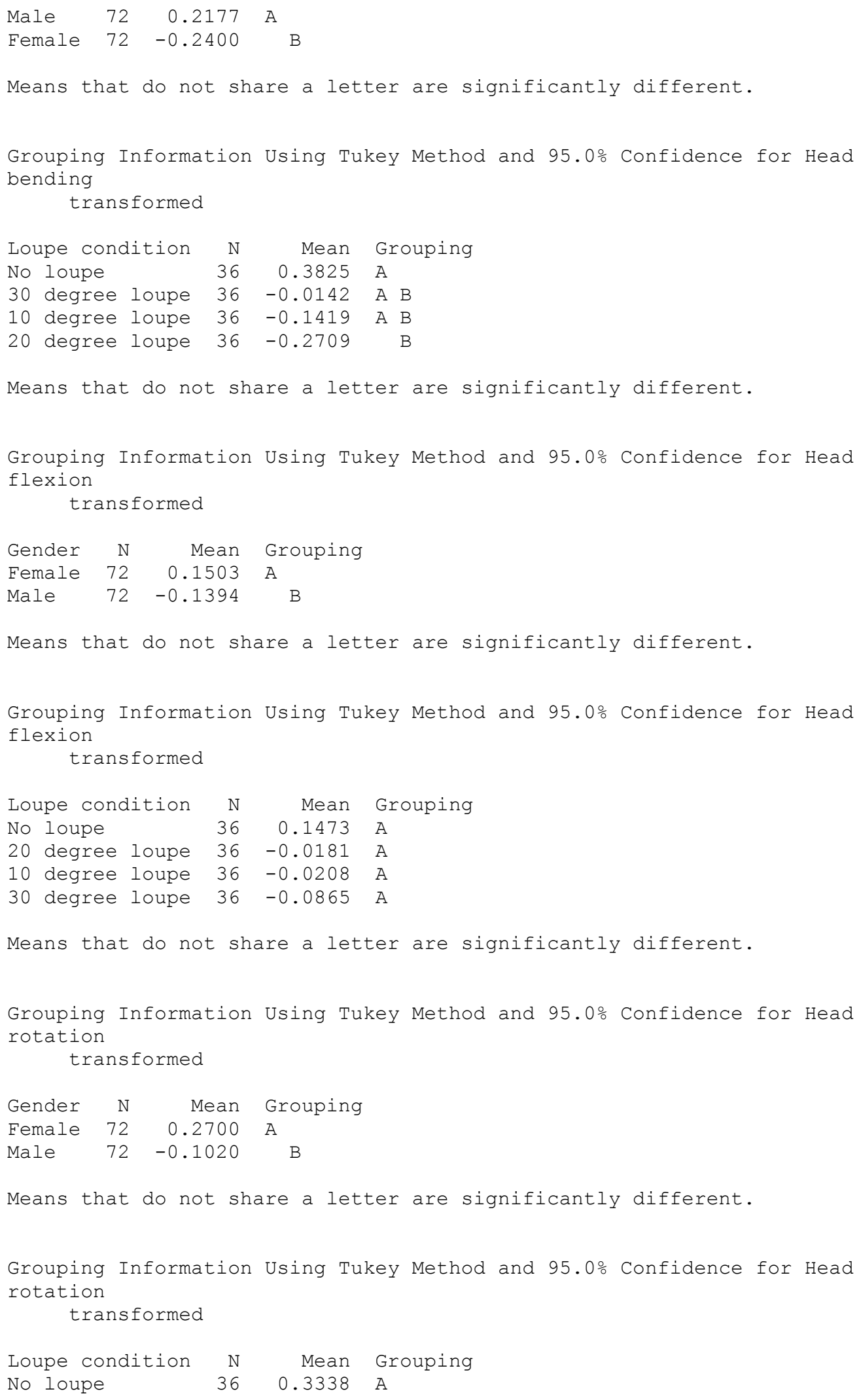




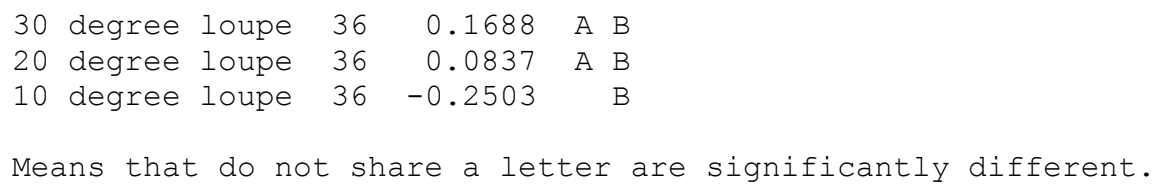

General Linear Model: Neck bending, Neck flexion, ... versus Subject, Gender, .

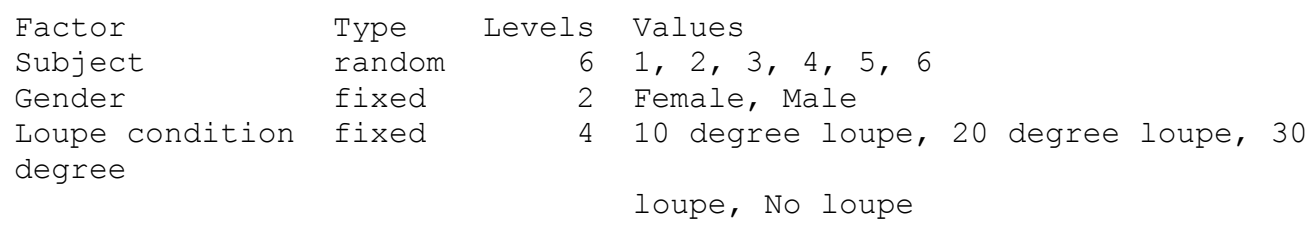




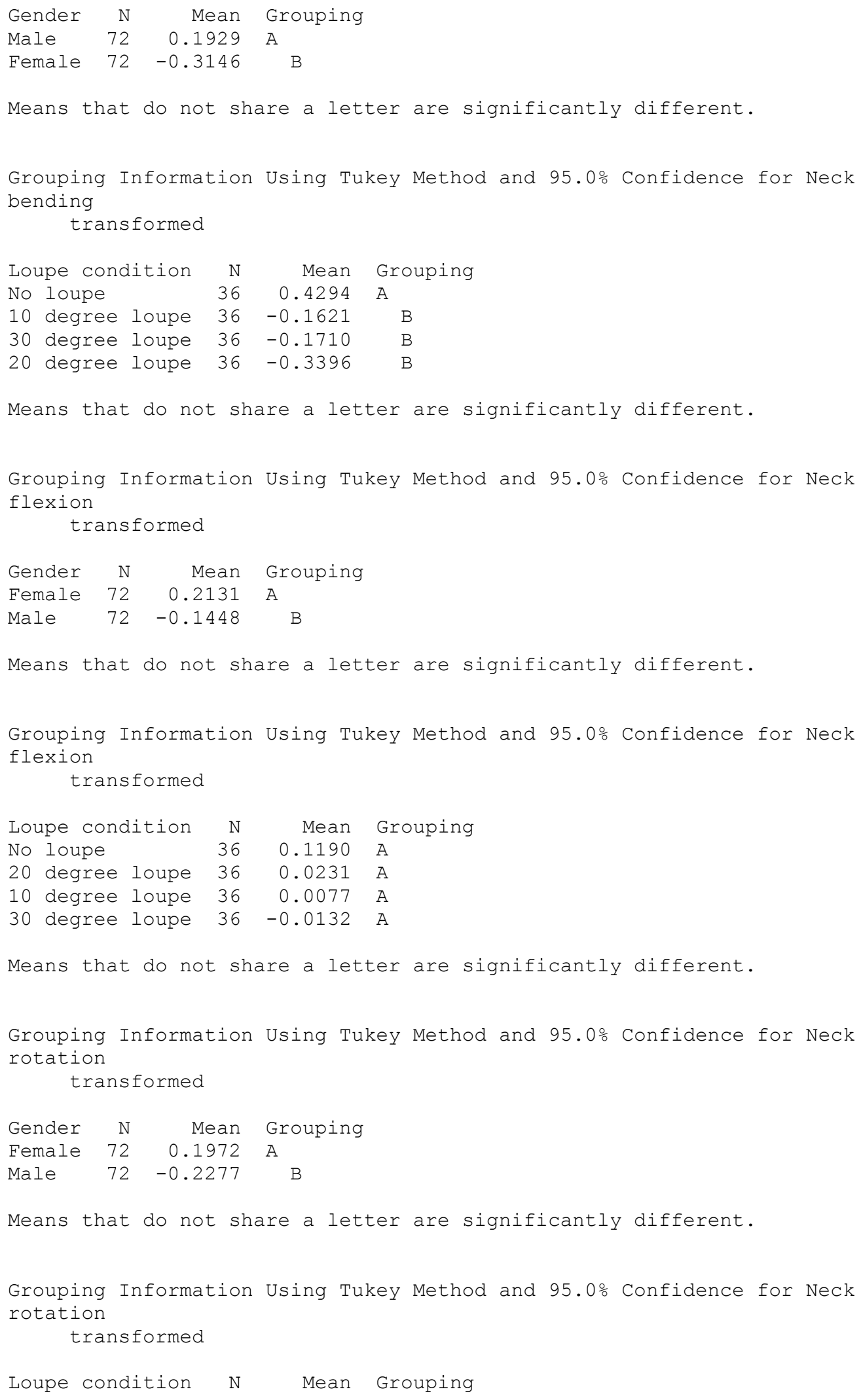




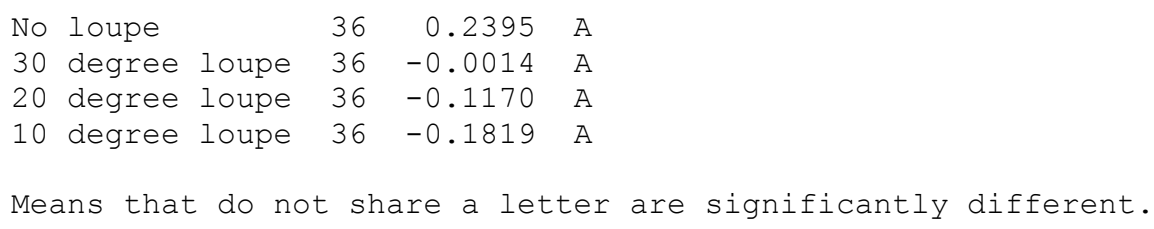

\section{General Linear Model: Head-neck be, Head-neck fl, ... versus Subject, Gender, .}

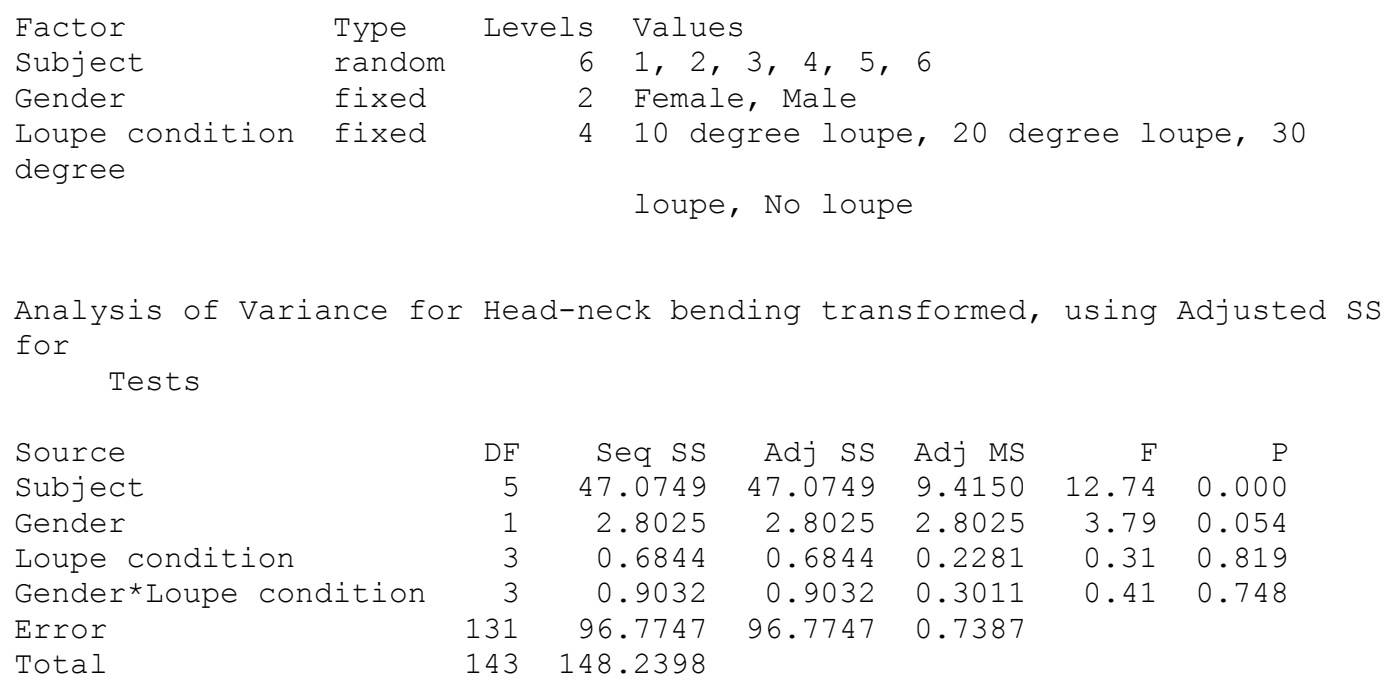




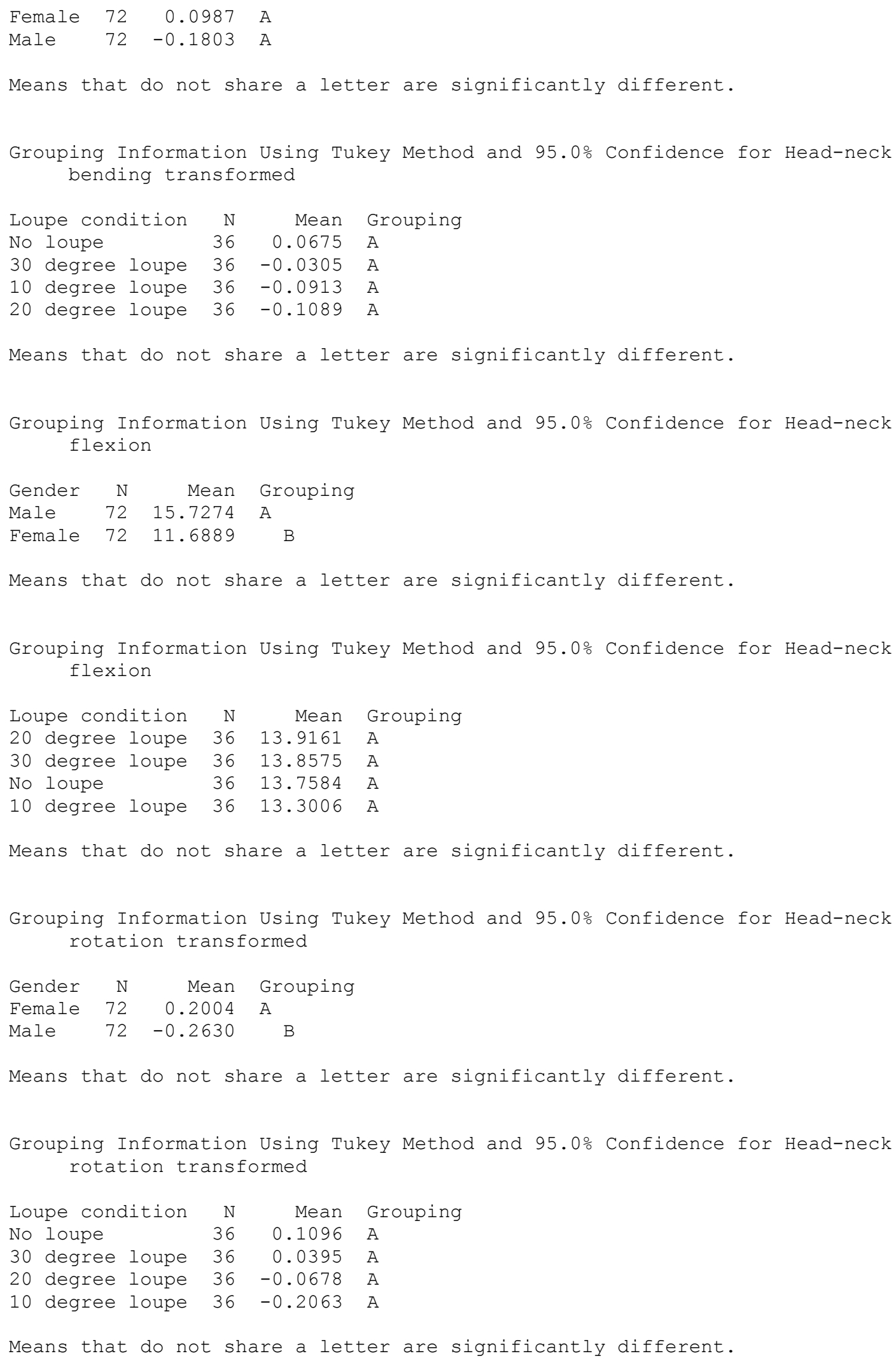




\section{G.2 Segmental translation General Linear Model: Head-trunk_A, Head-trunk_M, ... versus Subject, Loupe_con}

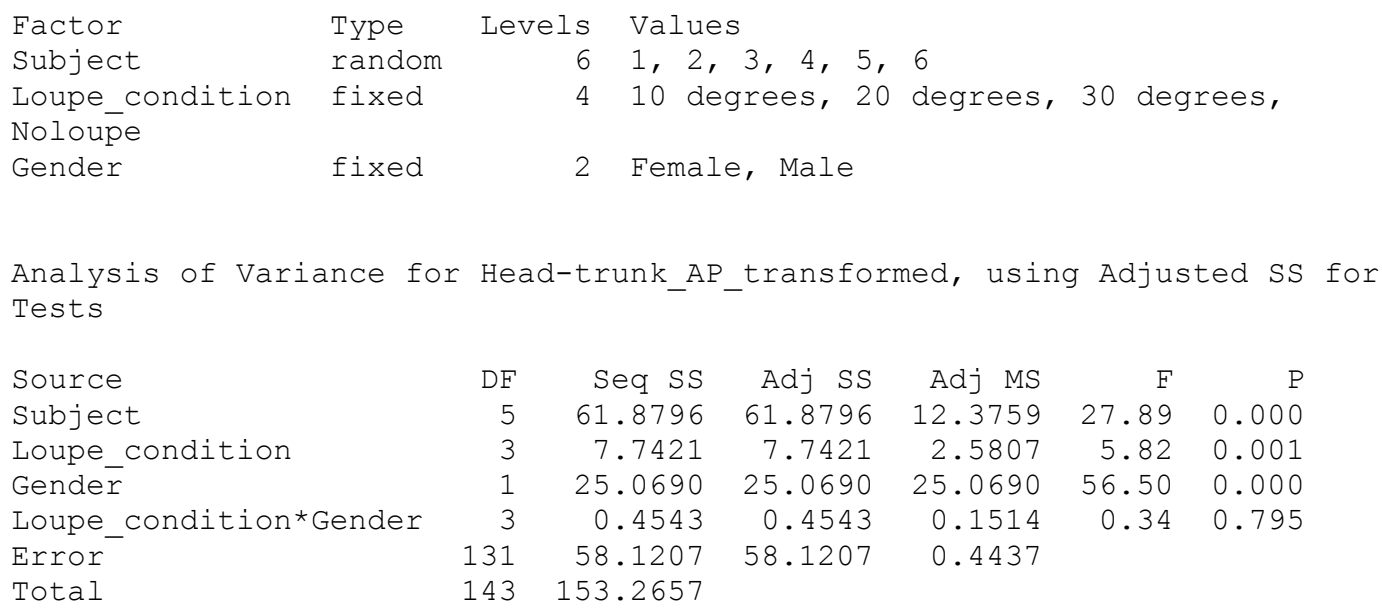

$\begin{array}{rr}131 & 58.1207 \\ 143 & 153.2657\end{array}$

$\begin{array}{rr}131 & 58.1207 \\ 143 & 153.2657\end{array}$

Adj SS

61.8796

7.7421

25.0690

0.4543

58.1207

$\begin{array}{rrr}\text { Adj MS } & F & P \\ 12.3759 & 27.89 & 0.000 \\ 2.5807 & 5.82 & 0.001 \\ 25.0690 & 56.50 & 0.000 \\ 0.1514 & 0.34 & 0.795\end{array}$

0.4437

Analysis of Variance for Head-trunk ML transformed, using Adjusted SS for Tests

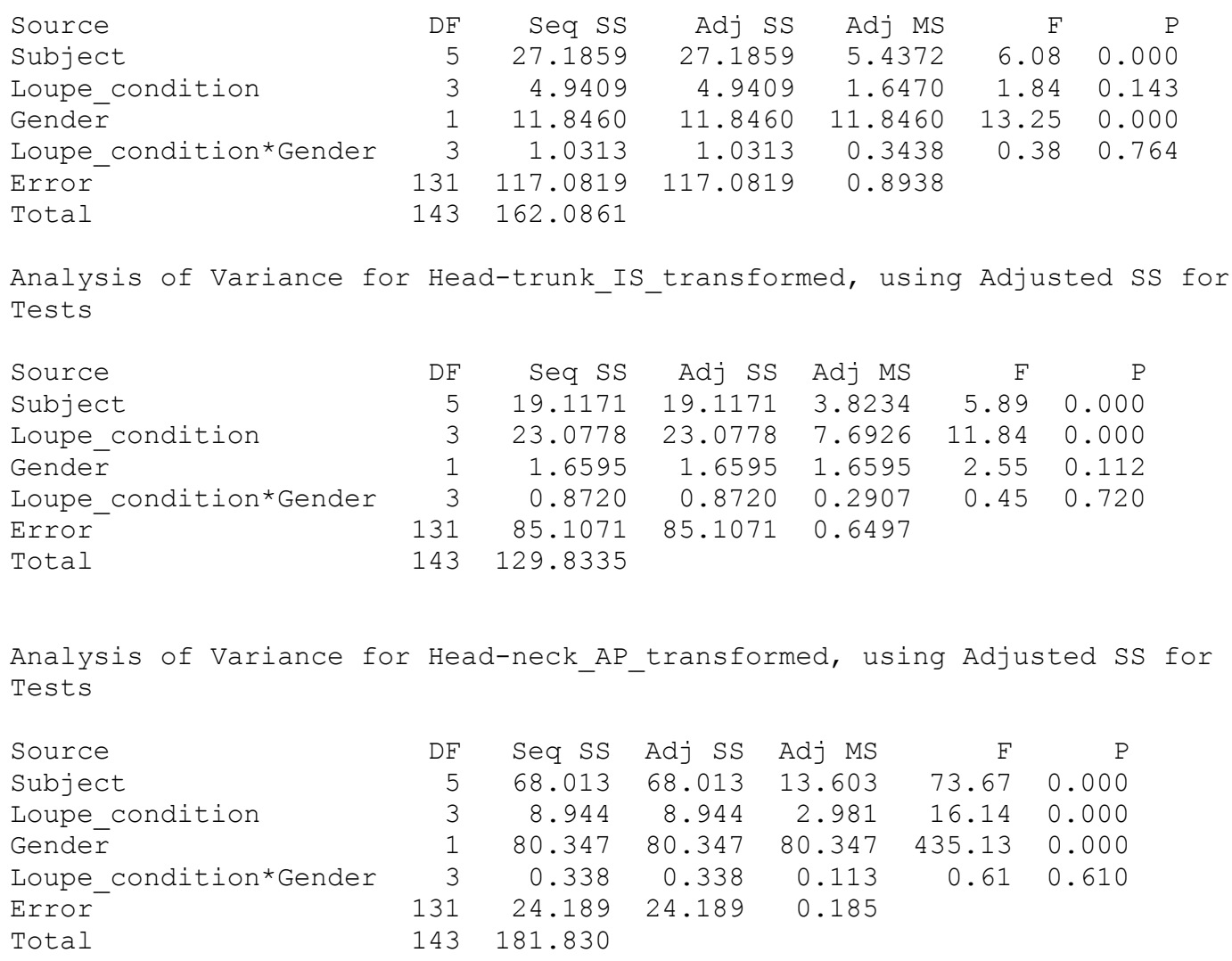




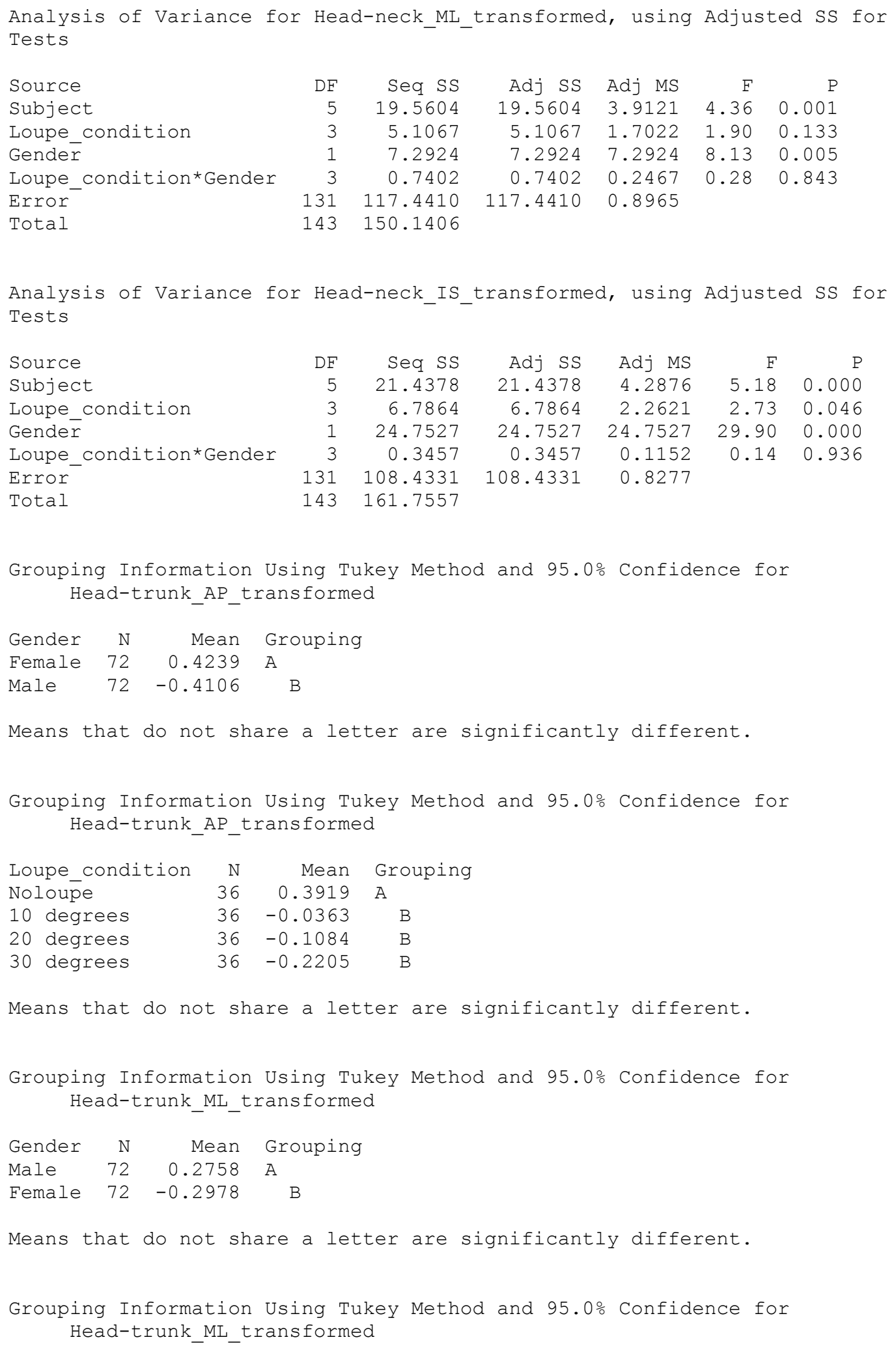




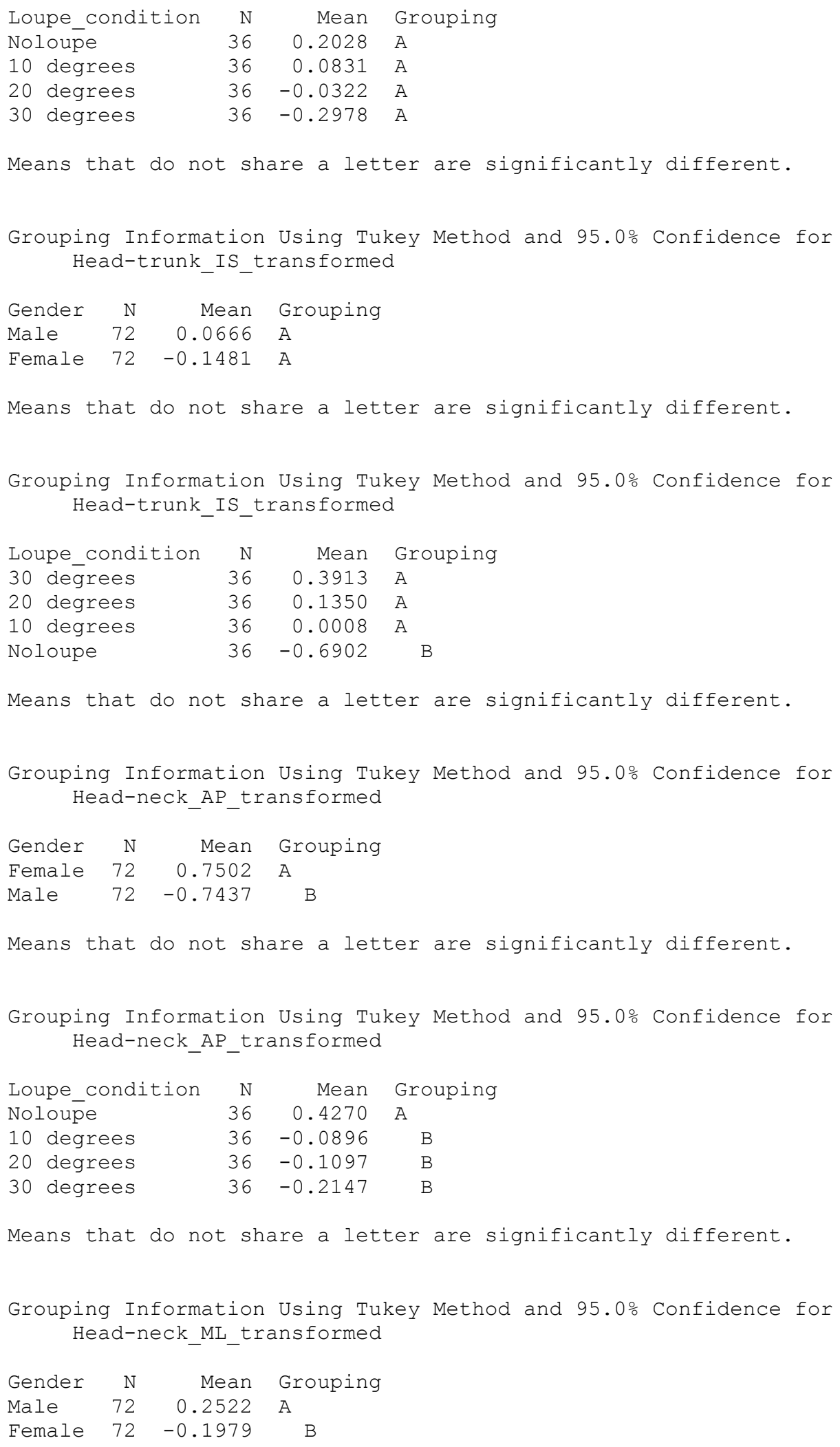




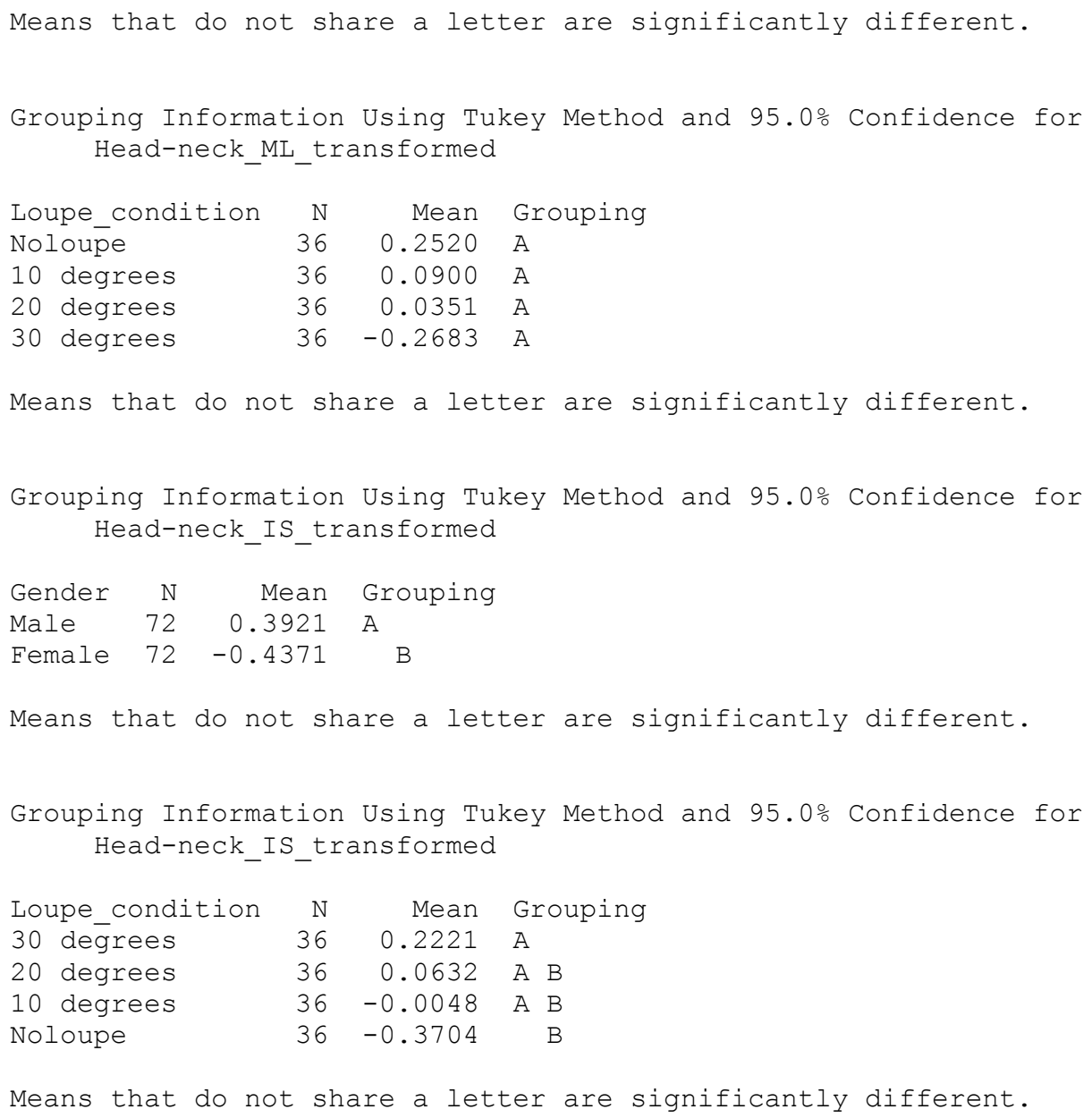




\section{G.3 Muscle activity \\ General Linear Model: RSCM transfo, RCTRP transf, ... versus Subject, Loupe_con}

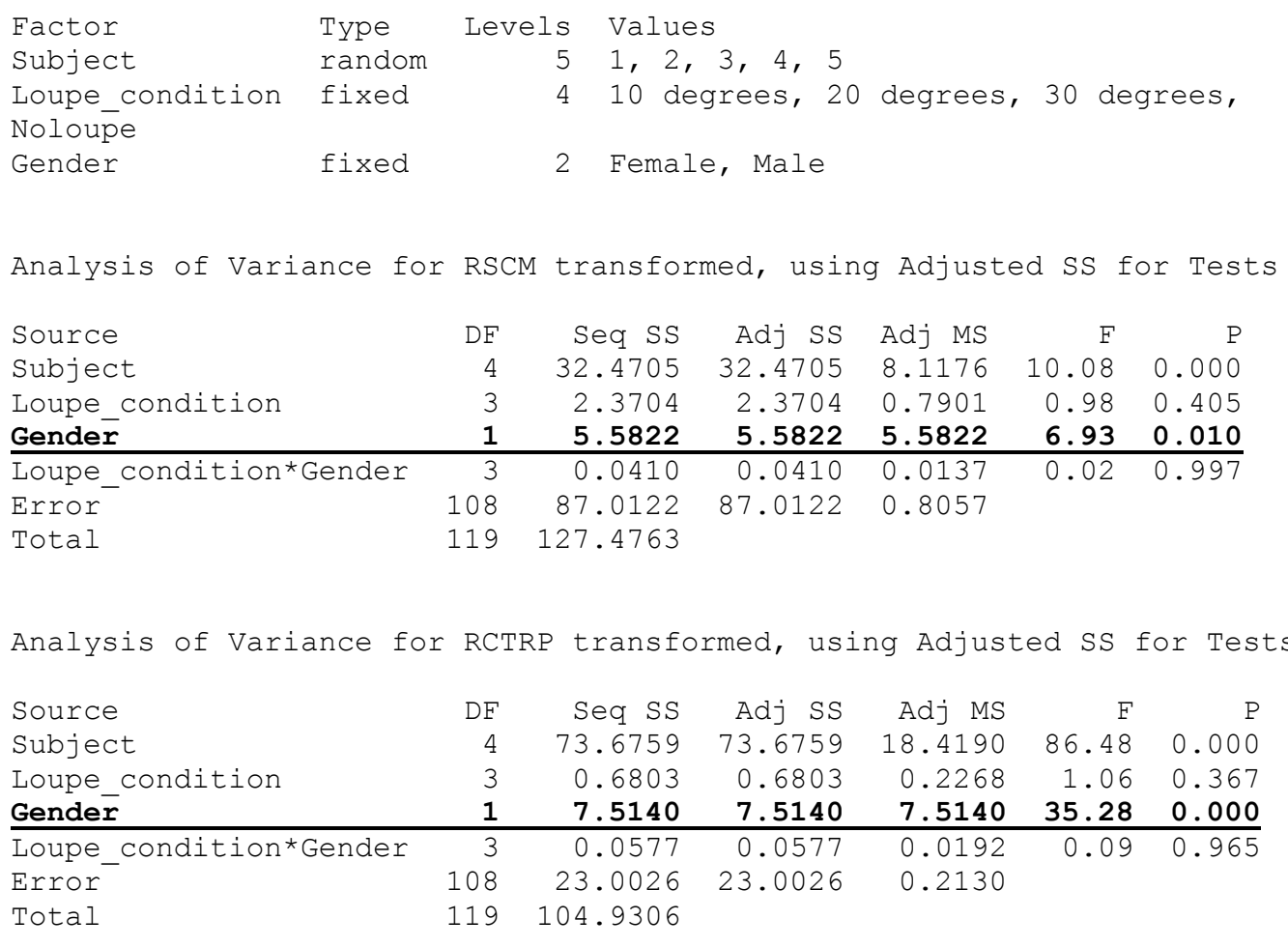

Analysis of Variance for LSCM, using Adjusted SS for Tests

\begin{tabular}{lrrrrrr} 
Source & DF & Seq SS & Adj SS & Adj MS & F & P \\
Subject & 4 & 235.946 & 235.946 & 58.986 & 54.45 & 0.000 \\
Loupe_condition & 3 & 2.075 & 2.075 & 0.692 & 0.64 & 0.592 \\
Gender & 1 & $\mathbf{4 3 . 4 6 4}$ & $\mathbf{4 3 . 4 6 4}$ & $\mathbf{4 3 . 4 6 4}$ & $\mathbf{4 0 . 1 2}$ & $\mathbf{0 . 0 0 0}$ \\
\hline Loupe_condition*Gender & 3 & 3.146 & 3.146 & 1.049 & 0.97 & 0.411 \\
Error & 108 & 116.989 & 116.989 & 1.083 & & \\
Total & 119 & 401.619 & & & & \\
& & & & & & \\
Analysis of Variance for & LCTRP, & using & Adjusted SS for Tests & \\
Source & & & & & & \\
Subject & DF & Seq SS & Adj SS & Adj MS & F & P \\
Loupe_condition & 4 & 849.584 & 849.584 & 212.396 & 24.78 & 0.000 \\
Gender & 3 & 6.564 & 6.564 & 2.188 & 0.26 & 0.857 \\
Loupe_condition*Gender & 1 & 6.653 & 6.653 & 6.653 & 0.78 & 0.380 \\
Error & 3 & 10.546 & 10.546 & 3.515 & 0.41 & 0.746 \\
Total & 108 & 925.531 & 925.531 & 8.570 & &
\end{tabular}

Grouping Information Using Tukey Method and 95.0\% Confidence for RSCM transformed

Gender N Mean Grouping

Female $60 \quad 0.1942$ A 


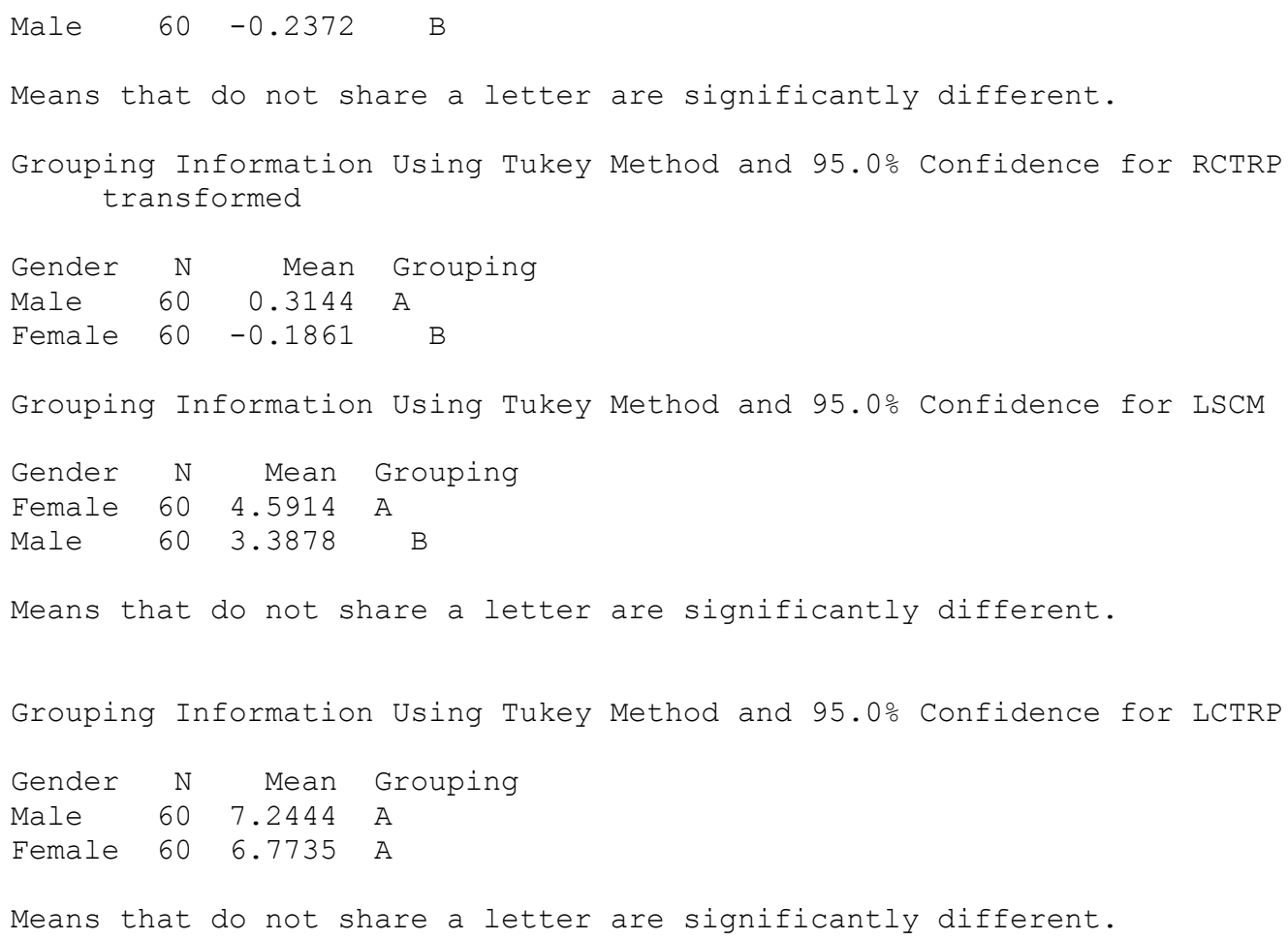

